\title{
Increased Bicycle Helmet Use in Sweden Needs and Possibilities
}

Sixten Nolén

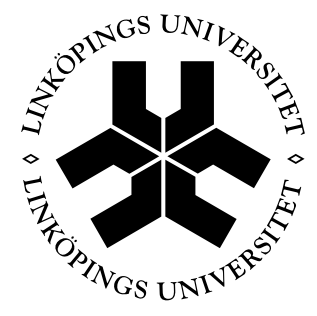

FACULTY OF HEALTH SCIENCES

LINKÖPING UNIVERSITY

Division of Social Medicine and Public Health Science, Department of Health and Society, Linköping University, SE-581 85 Linköping, Sweden

Linköping 2004 
Increased Bicycle Helmet Use in Sweden

Needs and Possibilities

(C) Sixten Nolén, 2004

Cover picture by Christina Ruthger

Published papers were reprinted with the permission of the copyright holder.

Printed in Sweden by UniTryck, Linköping 2004

ISBN 91-7373-832-8

ISSN 0345-0082 


\section{CONTENTS}

ABSTRACT................................................................................................................................. 1

LIST OF PAPERS................................................................................................................

LIST OF FIGURES AND TABLES............................................................................................ 4

1 BACKGROUND ............................................................................................................... 5

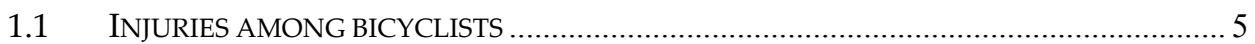

1.2 PREVENTION OF HEAD INJURIES BY USE OF BICYCLE HELMETS................................ 9

1.3 BARRIERS AND FACILITATORS OF HELMET WEARING AMONG CYCLISTS ................ 10

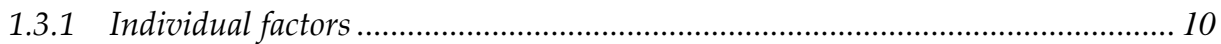

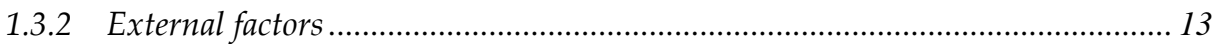

1.4 EFFECTS OF INTERVENTIONS AIMED AT INCREASING THE USE OF BICYCLE HELMETS - REVIEW OF THE LITERATURE ……..................................................... 14

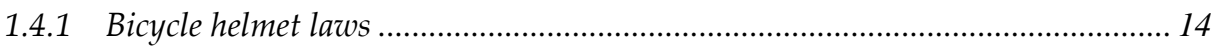

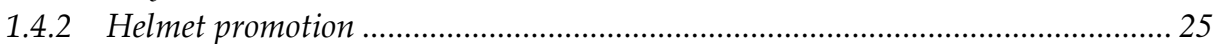

1.5 AN OUTLINE OF A THEORETICAL FRAMEWORK FOR HELMET WEARING BY

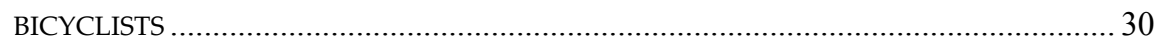

1.6 CONCLUDING REMARKS FROM THE BACKGROUND ............................................... 35

2 AIMS .............................................................................................................................. 36

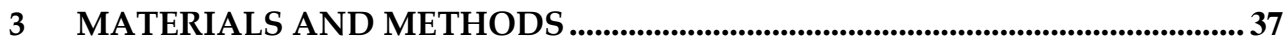

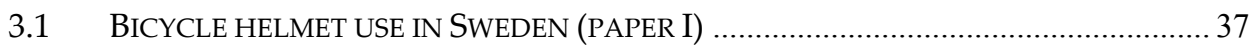

3.2 EVAluAtion OF A LOCAL BiCYClE HELMET LAW IN MOTALA (PAPERS II-IV) ..... 40

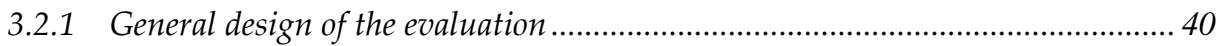

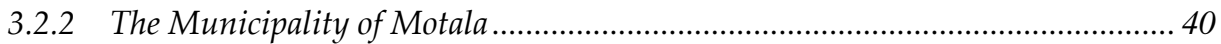

3.2.3 The intervention program - the local bicycle helmet law in Motala..................... 41

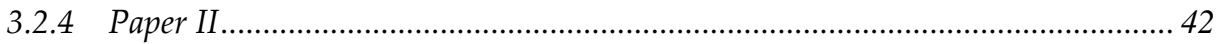

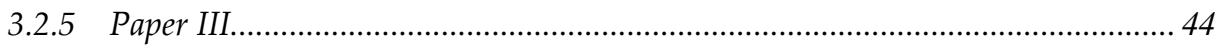

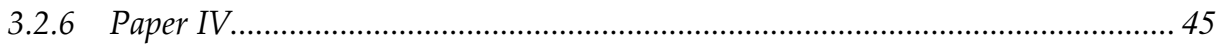

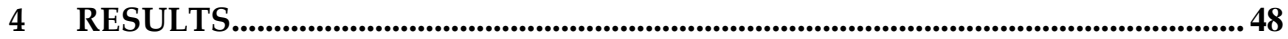

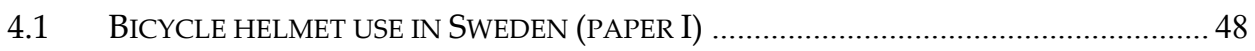

4.2 EVAluation OF THE LOCAL BiCYCle Helmet LAW IN MOTAla (PAPERS II-IV) 49

4.2.1 Structure and process during initiation and implementation of the

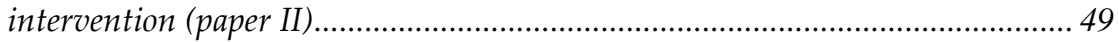

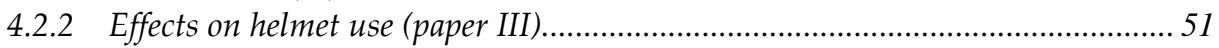

4.2.3 Effects on children's attitudes, beliefs, and self-reported behavior (paper IV) ..... 52 


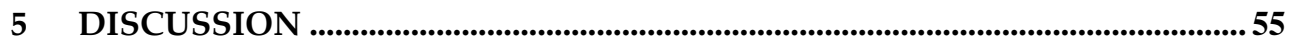

5.1 IS IT NECESSARY TO INCREASE THE USE OF BICYCLE HELMETS IN SWEDEN? ........... 55

5.2 DIFFERENT STRATEGIES FOR INCREASED HELMET USE ....................................... 58

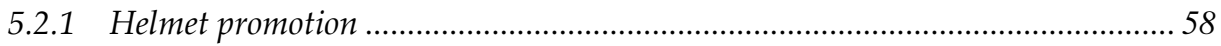

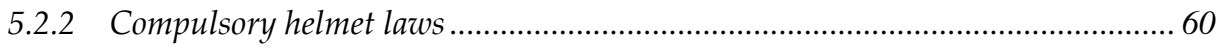

5.3 IS A NON-COMPULSORY LOCAL HELMET LAW AN APPROPRIATE ALTERNATIVE TO A NATIONAL HELMET LAW?

5.4 IS THERE A NEED FOR A NATIONAL HELMET LAW THAT APPLIES TO ALL

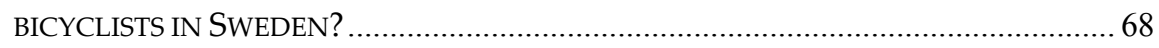

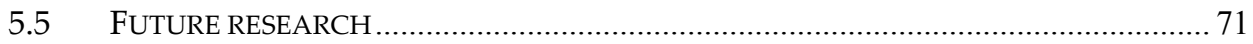

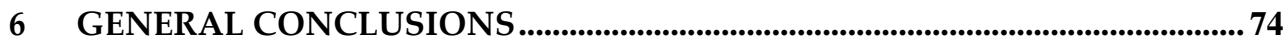

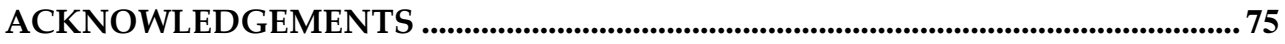

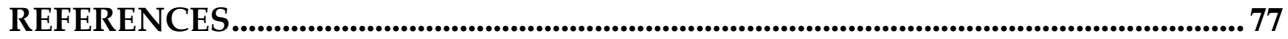

\section{PAPERS I-IV}




\section{ABSTRACT}

Background: From the perspective of what is called "vision zero" in Sweden, fatalities and injuries among bicyclists are unacceptable. Despite that, bicyclists constitutes approximately one third of all road user inpatients in Swedish hospitals, which is about the same proportion seen for drivers and passengers of motor vehicles. There are too many bicycle-related head injuries, but the risk of such traumas could be reduced considerably by the use of helmets. Bicycle helmet wearing can be increased by voluntary means, for instance by long-term community-based helmet promotion programs. However, the best effect has been achieved by combining promotion with a compulsory helmet law for all bicyclists, as has been done in Australia, New Zealand, and North America.

Aim: The general aim of the research underlying this dissertation was to provide further information about the need for increased bicycle helmet use in Sweden, and to determine what measures can lead to more widespread helmet wearing. The four papers included addressed two main questions: (1) What is the need for increased helmet wearing among different categories of bicyclists in Sweden? (2) Is a noncompulsory local bicycle helmet law a realistic alternative to a mandatory helmet law for all bicyclists?

Materials and methods: Observational studies of helmet use by bicyclists in Sweden were conducted once a year (average $n=37,031 /$ year) during the period 1988-2002 (paper I). The general trend in observed helmet wearing in different categories of bicyclists was analyzed by linear regression, and the results were used to predict future trends in helmet wearing. Three studies (papers II-IV) were also performed to evaluate a non-compulsory local bicycle helmet "law" in Motala municipality during the study period 1995 to 1998 (papers II-IV). This law was introduced in 1996 and applies specifically to school children (ages 6-12 years), although the intention is to increase helmet use among all bicyclists. Adoption of the law was accompanied by helmet promotion activities. In one of the studies in the evaluation, written material and in-depth interviews $(n=8)$ were analyzed qualitatively to describe the process and structure of development of the Motala helmet law. The other two studies used a quasi-experimental design to assess the impact of the helmet law: one comprised annual observations of helmet wearing among bicyclists in Motala (average $n=2,458 /$ year) and control areas (average $n=17,818$ /year); and the other included questionnaire data on attitudes, beliefs, and self-reported behavior of school children in Motala $(n=1,277)$ and control areas $(n=2,198)$. The average response rate was $72.8 \%$.

Results and discussion: There was a significant upward trend in helmet use in all categories of bicyclists from 1988 to 2002 . Helmet wearing increased from $20 \%$ to $35 \%$ among children ( $\leq 10$ years) riding bikes in their leisure time, from $5 \%$ to $33 \%$ among 
school children, and from $2 \%$ to $14 \%$ in adults. Total average helmet use rose from $4 \%$ to $17 \%$. However, during the last five years of the study period (1998-2002), there was no upward trend in helmet wearing for any of the categories of bicyclists. If the historic trend in helmet use continues, the average wearing rate will be about $30 \%$ by the year 2010. The Motala helmet law was dogged by several problems, mainly during the initiation phase, and some of them led to poor rooting of the law in the schools and indistinct roles and responsibilities of the municipal actors. Despite that, the law initially led to a significant increase in helmet wearing among the primary target group (school children), from a pre-law level of $65 \%$ to about $76 \%$ six months post-law, whereas thereafter the wearing rate gradually decreased and was at the pre-law level $2 \frac{1}{2}$ years after the law was adopted. Nonetheless, a weak but significant effect on adult bicyclists remained: the pre-law level of about $2 \%$ rose to about $8 \%$ at the end of the study period. Only about $10 \%$ of bicyclists on bike paths in Motala wore helmets $2 \frac{1}{2}$ years post-law. The questionnaire study showed one significant effect on school children in Motala two years post-law, namely, a stronger intention to ride bicycles if a national compulsory helmet law was introduced. There was, however, no significant long-term influence on children's attitudes or beliefs about helmet wearing, which agrees with the results of the observational study.

\section{General conclusions:}

It is indeed necessary to increase bicycle helmet wearing in Sweden. Both the current average rate of helmet use and the rate predicted for the near future are far from the goal of $80 \%$ that was officially proposed by several years ago. Previous research has shown that, to achieve substantial and sustained bicycle helmet use, it is necessary to use helmet promotion in combination with a national helmet law that is compulsory and applies to all bicyclists. The present evaluation of the non-compulsory local helmet law in Motala indicated that this type of initiative is not a powerful alternative to a mandatory national helmet law. Nevertheless, much has been learned from the initiation and implementation of this local action.

Keywords: bicyclist; head injuries; bicycle helmet; wearing rate; observational study; public health; safety promotion; injury prevention; helmet promotion; legislation; Sweden; questionnaire study; attitudes; beliefs. 


\section{LIST OF PAPERS}

The thesis is based on the following papers, which will be referred to in the text by their Roman numerals:

I Nolén, S., Ekman, R., \& Lindqvist, K. (2004). Bicycle helmet use in Sweden during the 1990s and in the future. Accepted for publication in Health Promotion International.

II Nolén, S., \& Lindqvist, K. (2002). A local bicycle helmet "law" in a Swedish municipality - the structure and process of initiation and implementation. Injury Control and Safety Promotion, 9(2), 89-98.

III Nolén, S., \& Lindqvist, K. (2004). A local bicycle helmet "law" in a Swedish municipality - the effects on helmet use. Injury Control and Safety Promotion, 11(2), 39-46.

IV Nolén, S., \& Lindqvist, K. (2004). A local bicycle helmet "law" in a Swedish municipality - the effects on children's attitudes, beliefs and self-reported behaviour. Submitted for publication.

The following report is not included as a paper in the thesis, but it constitutes an important part of the background.

Nolén, S., \& Lindqvist, K. (2003). Effects of measures for increased bicycle helmet use. Review of the research (in Swedish) (VTI Report 487). Linköping: Swedish Road and Transport Research Institute. 


\section{LIST OF FIGURES AND TABLES}

\section{Figures}

Figure 1. Relative trend in number of bicyclists killed and injured in Sweden in 1960-2002

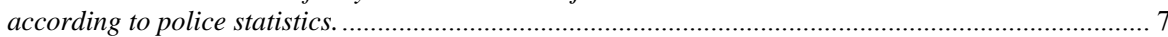

Figure 2. Number of hospitalized bicyclists in Sweden 1988-2001 in relation to the mechanism of injury. .......... 7

Figure 3. Number of fatalities and head injuries leading to hospitalization among bicyclists in Sweden (average for 1999-2001). Proportional distribution for different age groups........................ 8

Figure 4. Illustration of the balance between different reasons for (+) and against (-) the use of bicycle helmets.

Figure 5. Observed bicycle helmet wearing in Victoria, Australia.

Figure 6. Observed bicycle helmet wearing in New South Wales, South Australia, Western

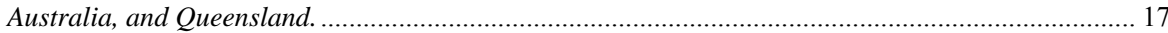

Figure 7. Observed bicycle helmet wearing in New Zealand..................................................................... 18

Figure 8. Observed bicycle helmet wearing in the Canadian provinces of Ontario (Ottawa), British Columbia, and Nova Scotia (Halifax).

Figure 9. Number of bicyclists killed and seriously injured, and the proportion of helmet wearing and cyclists sustaining head injuries in Victoria.

Figure 10. Head injuries among hospitalized bicyclists before and after introduction of helmet laws in New South Wales and South Australia.

Figure 11. Estimation of the effects of helmet laws on cycling exposure in Melbourne, Australia, and in East York, Canada.

Figure 12. Systematic helmet promotion and average helmet wearing among bicyclists in Victoria, Australia.

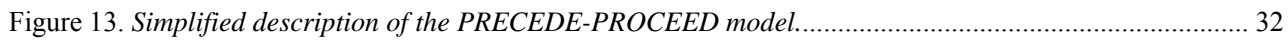

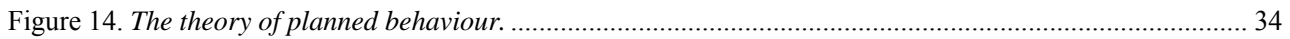

Figure 15. General design of the evaluation of the local bicycle helmet law in Motala...................................... 40

Figure 16. Schematic representation of the supposed effects of the local bicycle helmet law in Motala.

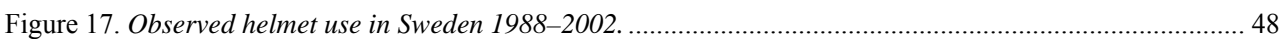

Figure 18. The structure of the work on the bicycle helmet law in Motala....................................................... 50

Figure 19. Trends in bicycle helmet use shown for school children and adults on bike paths............................ 52

Figure 20. Observed average bicycle helmet use in Sweden and helmet promotion activities conducted at a national level during the period 1988-2002.

Figure 21. Tentative description of the plausible effects of a bicycle helmet law on public health.

\section{Tables}

Table 1. Bicycle fatalities in some high-income countries in the year 2000.

Table 2. The risk of being killed or hospitalized due to head injuries among bicyclists in Sweden, based on average data for 1999-2001.

Table 3. Countries that enacted bicycle helmet laws before January 2004.

Table 4. Number and relative change (\%) of bicyclists killed two years after the introduction of helmet laws in Australia.

Table 5. Summary of materials and methods in the studies described in papers I-IV ........................................ 39

Table 6. Sample sizes and response rates in Motala and the control area....................................................... 45

Table 7. Predicted helmet use in Sweden in 2010 based on linear regression of observational data for the period 1988-2002.

Table 8. Questionnaire responses (\%) to selected items given by school children in Motala before and after introduction of the local bicycle helmet law. 


\section{BACKGROUND}

According to the World Health Organization (WHO), road traffic injuries ranked ninth among all public health problems ${ }^{1}$ in the world in 1998, but it has been predicted that they will constitute the third largest problem by 2020 (2, 3 ). Today, road traffic injuries are the main cause of injury related deaths worldwide, and about 3,000 people die every day in road traffic accidents, which represents more than one million fatalities annually. In addition, about 20-50 million people are seriously injured in road traffic accidents each year (4), and this problem is most prominent for men up to the age of about 45 . About $90 \%$ of the road traffic injuries in the world occur in low- and middleincome countries, but the number of casualties in high-income countries constitutes a larger proportion of all injuries compared to other health-related problems (2).

Sweden is a high-income country with good traffic safety compared to many other nations in the world. From a European perspective, the annual number of road fatalities is very low in Sweden, even though about 550 people are killed in traffic each year (5). This is not compatible with what is referred to as vision zero, which is the ultimately goal of traffic safety work in Sweden $(6,7)$ and applies to all road users, including pedal cyclists - the group in focus in this dissertation.

\subsection{Injuries among bicyclists}

Bicyclists constitute about $8 \%$ of all road traffic fatalities in Sweden, which is a relatively low rate compared to some other high-income countries (8-12) (Table 1). However, the absolute number of bicyclists killed each year is related to the size of the population and to the extent of bicycling in traffic. For instance, in the United States, the number of bicyclists killed each year is 15 times higher than in Sweden, but, related to the size of the population, the rate is only half of that in Sweden. Another example is that the number of bicycle fatalities in the Netherlands is four times the number observed in Sweden, and the fatality rate per population is about twice that recorded in Sweden. However, considering the amount of exposure to bicycling, the fatality rate is somewhat lower in the Netherlands than in Sweden (8).

\footnotetext{
${ }^{1}$ The public health problem expressed as DALYs (Disability Adjusted Life Years), which is an estimation of the total number of life years with full health in the population, adjusted for the number of years with functional disorder (1).
} 
Table 1. Bicycle fatalities in some high-income countries in the year 2000.

\begin{tabular}{lrccc}
\hline & \multicolumn{4}{c}{ Bicycle fatalities in 2000 } \\
\cline { 2 - 5 } Country & Number & $\begin{array}{c}\text { All traffic } \\
\text { fatalities }(\%)\end{array}$ & $\begin{array}{c}\text { Fatality rate } \\
100,000 \text { pop. }\end{array}$ & $\begin{array}{c}\text { Fatality rate } \\
10^{9} \text { pkm }\end{array}$ \\
\hline Japan & 1273 & 12 & 1.00 & - \\
United States & 690 & 2 & 0.24 & - \\
Germany & 659 & 9 & 0.80 & - \\
The Netherlands & 198 & 18 & 1.24 & 13.1 \\
Unitid Kingdom & 127 & 4 & 0.21 & 31.8 \\
Denmark & 58 & 12 & 1.09 & - \\
Finland & 53 & 13 & 1.03 & - \\
Sweden & 47 & 8 & 0.53 & 15.7 \\
Canada & 40 & 1 & 0.13 & - \\
Australia & 31 & 2 & 0.16 & - \\
Norway & 13 & 4 & 0.29 & - \\
\hline
\end{tabular}

According to reports made by the Swedish police (5), about 45 bicyclists were killed annually during the years 2000 to 2002, which represents a declining trend since the 1960s, when about four times as many bicyclists were killed (Figure 1). Bicyclists constitute a relatively small proportion of the annual number of road fatalities, but they represent a larger fraction of the road injuries. The police reports indicate that about 2,300 bike riders were injured annually from 2000 to 2002, which is about the same level as in the 1960s (5). However, there is a high rate of underreporting in the official statistics, particularly for unprotected road users such as bicyclists. The police are not informed about most of the people who are injured while riding bicycles (13), and indeed it has been estimated that between $60 \%$ to $90 \%$ of all cases are missing (14).

In the context of hospital care, bicyclists are one of the largest traffic safety problems. Inpatient statistics show that around 3,500 to 4,000 cyclists are injured each year in Sweden, and this group constitutes about one third of all road user inpatients, which is almost the same proportion as observed for car drivers and passengers (15). Local injury surveillance systems show that 75$80 \%$ of all injured bicyclists taken to hospitals are treated as outpatients (16, $17)$, and it has been roughly estimated that at least 20,000 people seek hospital care each year in Sweden for injuries incurred while riding bicycles $(18,19)$. 
Most fatalities among bicyclists in Sweden are caused by collisions with motor vehicles $(20,21)$. However, about $75 \%$ of the cyclists who are hospitalized sustain injuries in "single accidents" (15) that do not involve motor vehicles (Figure 2).

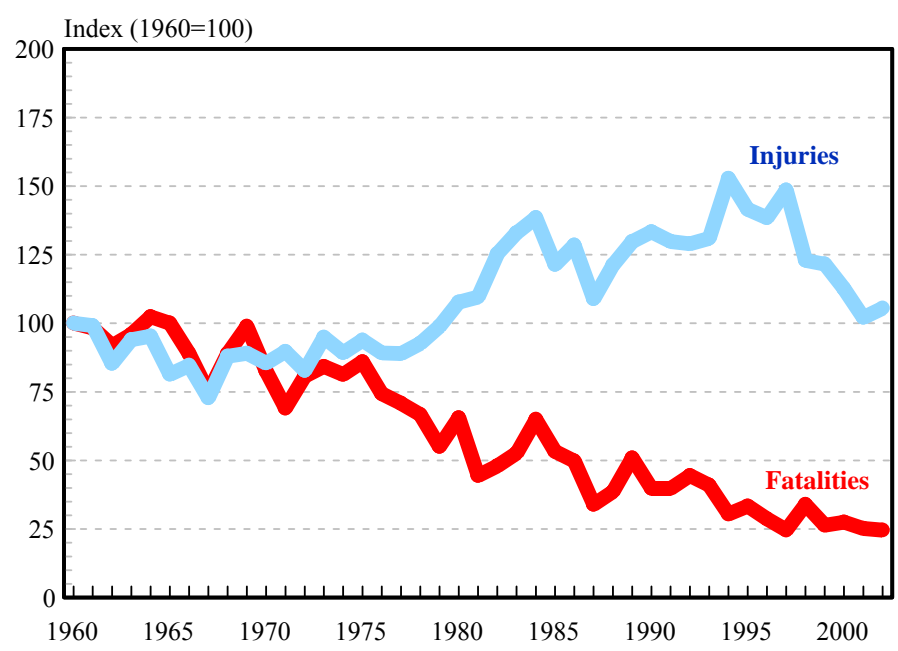

Figure 1. Relative trend in number of bicyclists killed and injured in Sweden in 1960-2002 according to police statistics.

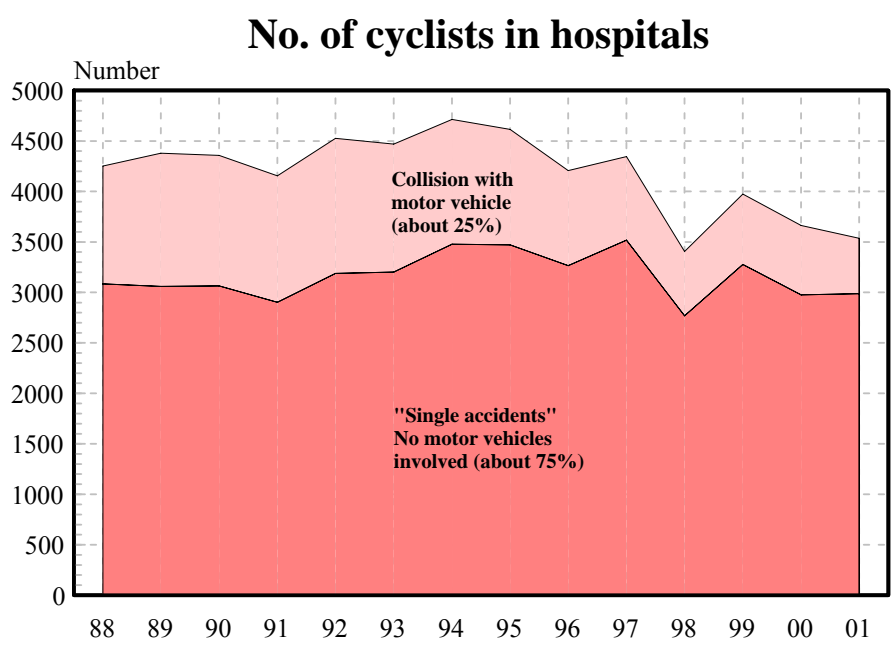

Figure 2. Number of hospitalized bicyclists in Sweden 1988-2001 in relation to the mechanism of injury. 
Many studies have shown that, among bicyclists, the majority of the fatalities and about one third of the casualties have sustained head injuries (22-25), and the rate of such injuries is often even higher among hospitalized bicyclists (26, 27).

The traffic safety problem for bicyclists in Sweden, in absolute numbers, is more pronounced for men and adults than for women and children (Figure 3). About $70-80 \%$ of all bicyclists that are killed are men and more than $90 \%$ are adults. Furthermore, about $60 \%$ of hospitalized bicyclists with head injuries ${ }^{2}$ are men, and about the same proportion are adults $(5,30)$.

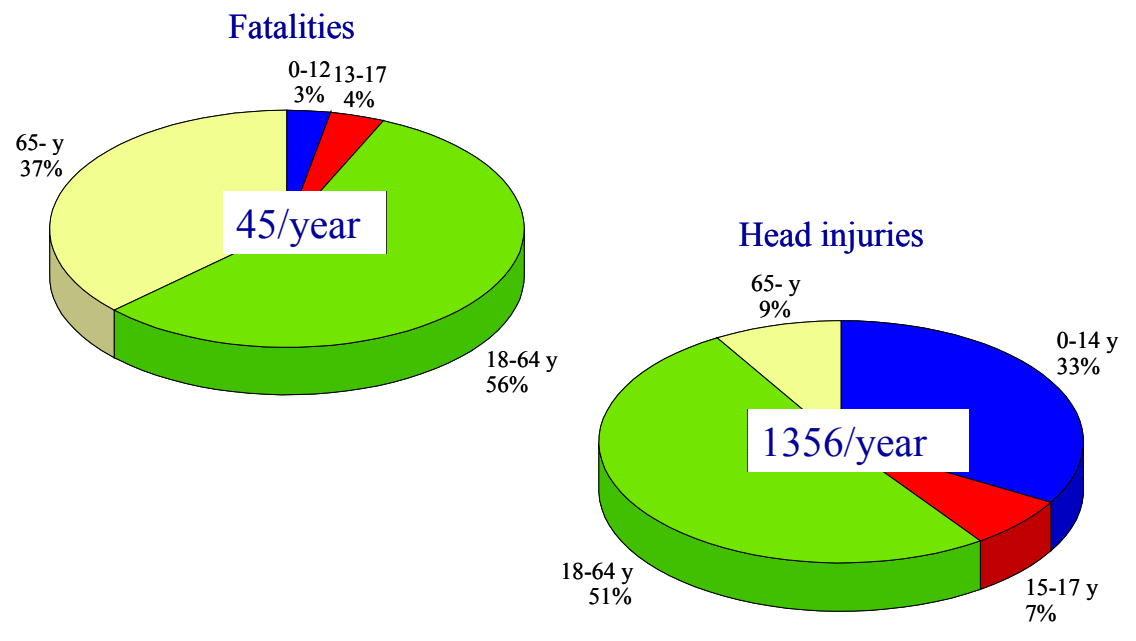

Figure 3. Number of fatalities and head injuries leading to hospitalization among bicyclists in Sweden (average for 1999-2001). Proportional distribution for different age groups ${ }^{3}$.

Considering the traffic safety problem for bicyclists in Sweden in relation to the entire population $(5,30,31)$ of the country in 1999-2001 revealed a greater incidence of fatalities $(5,30,31)$ among adults than children (Table 2). The highest incidence was for older bicyclists, and that level was about 11 times the incidence for younger children. Older cyclists have had a higher incidence of fatalities since the 1960s (32). Nonetheless, the incidence of head injuries

\footnotetext{
${ }^{2}$ Head injuries according to the ICD-10 system and defined as the primary diagnosis, concussion (code S06.0) or fracture in the head or face (code S02). Superficial injuries only as abrasions and lacerations are not included $(28,29)$.

${ }^{3}$ The age categories for children were not completely comparable for fatalities and head injuries, because the data came from different sources.
} 
among hospitalized bicyclists is greater for children than for adults $(14,30)$, as illustrated by data indicating that the incidence in children is about twice that in adults aged 18-64 and about four times the level in adults aged 65 or older. This situation can be partly explained by the fact that, compared to an adult; a child has a heavier head, a thinner cranium, and a larger amount of water in the brain (33).

Table 2. The risk of being killed or hospitalized due to head injuries among bicyclists in Sweden, based on average data for 1999-2001.

\begin{tabular}{|c|c|c|c|c|c|c|c|}
\hline \multicolumn{4}{|c|}{ Fatalities } & \multicolumn{4}{|c|}{ Head injuries } \\
\hline Age & Number ${ }^{1}$ & Incidence $^{2}$ & $\begin{array}{r}\text { Relative } \\
\text { risk }\end{array}$ & Age & Number ${ }^{1}$ & Incidence $^{2}$ & $\begin{array}{r}\text { Relative } \\
\text { risk }\end{array}$ \\
\hline $0-12$ years & 1 & 0.1 & $\overline{1.0}$ & $0-14$ years & 452 & 28.6 & $\overline{3.9}$ \\
\hline $13-17$ years & 2 & 0.3 & 3.2 & $15-17$ years & 94 & 30.5 & 4.1 \\
\hline $18-64$ years & 25 & 0.5 & 4.8 & $18-64$ years & 694 & 12.8 & 1.7 \\
\hline 65 - years & 17 & 1.1 & 10.9 & 65 - years & 116 & 7.4 & 1.0 \\
\hline Total & 45 & 0.5 & & Total & 1356 & 15.3 & \\
\hline
\end{tabular}

\subsection{Prevention of head injuries by use of bicycle helmets}

The purpose of using a bicycle helmet is to reduce the risk of sustaining a head injury if an accident occurs. However, head injuries are defined in different ways. The definition can include trauma to the skull, the brain, or the face, which applies to the Swedish data referred to earlier $(15,22)$, whereas in international studies, it often, but not always, excludes injuries to the face. Furthermore, injuries to different parts of the head (e.g., the skull, brain, and face) have been considered separately in some investigations $(34,35)$.

The degree of a brain injury is often categorized as mild, moderate, or severe. The more serious the injury, the higher is the risk of long-term problems for the individual. Considering children, international studies have shown that prolonged problems occur in $0-30 \%$ with mild brain injuries, in $50-70 \%$ with moderate brain injuries, and in $70-100 \%$ with severe brain injuries (33). The degree of unconsciousness and amnesia at the time of an accident are also indicators of the seriousness of the injury and are often correlated to the risk for long-term sequels $(33,36,37)$. Many cases of trauma to the head in bicyclists 
can, however, be classified as minor brain injuries $(22,33)$, but even such injuries are important to prevent, since they can lead to prolonged negative consequences for the individuals who are hurt $(33,38)$. Furthermore, it is often difficult to predict what type of long-term problems will occur, because different parts of the brain can be affected. In general, two types of conditions can be identified: those entailing impairment of complex cognitive functions (effects on memory or concentration, or a general mental apathy), and disorders related to the personality or emotional or social aspects of the patient $(36,39)$.

There is empirical evidence that bicycle helmets reduce head injuries caused by traffic accidents $(22,23,40-43)$. A meta-analysis of 16 peer reviewed studies has shown that, on average, bicycle helmets decrease the risk of fatalities by $73 \%$, head injuries and brain injuries by $60 \%$, and face injuries by $47 \%$ (34). One of the studies included in the cited meta analysis focused solely on the effects on facial injuries (44), and the investigators found that bicycle helmets reduce injuries to the upper and middle parts of the face, even though they usually do not cover these areas. This injury-reducing effect on the face is probably due to the fact that a helmet usually sticks out a bit from the forehead. The overall conclusion of the mentioned meta-analysis was later confirmed in a Cochrane Review (35) that showed that bicycle helmets decrease the risk of head injuries and both mild and severe brain injuries by $63-88 \%$; these results applied to cyclists of all ages and to both single and collision accidents.

\subsection{Barriers and facilitators of helmet wearing among cyclists}

This section gives examples from the literature that show how factors related to the individual bicyclist and external factors in the environment are associated with the use of helmets. However, many of the published studies have presented descriptive data or correlations, and it is therefore not clear whether the described associations were causal.

\subsubsection{Individual factors}

\subsubsection{Demographic factors}

In many countries, there is often an age difference in helmet wearing among bicyclists. Most often the rate of helmet use is higher among children up to 
about the age of 12 years than it is among adults, and in many countries, teenagers have the lowest wearing rate (45-48).

Studies have also indicated that social background is associated with helmet wearing (26). For example, higher wearing rate has been observed in children whose parents have a higher education compared to those whose parents have a lower education $(49,50)$. Furthermore, bicycle helmet programs for children in Canada have been more effective in high/middle-income areas than in lowincome areas (51-53).

Bicycle accident involvement might induce some cyclists to start using a helmet. That assumption is supported by the results of a study performed in the United States in which parents whose children had been injured in bicycle accidents and subsequently treated at hospitals, were interviewed; according to the parents, $7 \%$ of the children had used helmets before their accidents and $24 \%$ did so afterwards (54). Similar findings have been reported by Fullerton and Becker (55).

Research results have also indicated that helmet wearing is related to the general risk behavior exhibited by bicyclists. For instance, a Finnish study showed that alcohol consumption among teenagers was associated with lower helmet ownership (56), and a Swedish study found lower helmet wearing among drunk bicyclists involved in accidents compared to sober controls. In addition, there is evidence that risk behaviors like smoking and gambling are associated with a low level of bicycle helmet wearing (27). An American study did also found that helmet wearing was eight times higher among children whose parents used safety belts compared to those whose parents did not use safety belts (50).

Another notable finding is that cycling companionship can lead to conforming helmet-wearing behavior. A tendency towards helmet use by either all or none of the bicyclists in a group has been observed in several studies $(26,57,58)$. Moreover, in a study conducted in Canada, helmet wearing was seen in 3\% of children cycling alone, whereas the rate rose to $50 \%$ if they rode bicycles together with other children who wore helmets, and the rate reached $86 \%$ if the children cycling with a helmet-bearing adult (59). 


\subsubsection{Attitudes and beliefs}

Several studies have described the attitudes and beliefs that bicyclists have about wearing helmets $(26,27,60)$, which are often reflected in statements indicating different reasons for using or not using a helmet. Some of the reasons that are often given are as follows:

- In favor of using a helmet

- Increased safety (the most common reason) (61-64).

- A role model for other bicyclists (stated mainly by adults) $(62,65)$.

- Obligation, imposed by parents or school (stated mainly by children) (61, 65-67).

- Obligation, imposed by helmet legislations (61).

- Normative factors such as "positive peer group pressure" (i.e., wearing a helmet because others do or due to expectations of friends and/or relatives) $(63,65)$.

- Against the use of a helmet

- Discomfort (e.g., too hot or cold, uncomfortable, or heavy) (67-69).

- Negative appearance (e.g., ugly, nerdy, ridiculous, or ruins hairstyle) (66, 69-72).

- Practical problems (e.g., inconvenient to carry around or store) $(73,74)$.

- Normative factors such as "negative peer pressure" (e.g., deviant behavior, no one else uses a helmet, and fear of being teased) $(67,70,72-75)$.

- Risk perception (e.g., presume risk is low or acceptable) $(50,64,68,73)$.

- Cost of a helmet (considered expensive) (50,71, 76).

- Lack of awareness and/or knowledge about helmets $(49,50,63,77)$.

- Other factors (e.g., interferes with sense of freedom when cycling, no habit, easy to forget) (78-80).

The different reasons for and against wearing a bicycle helmet are illustrated in Figure 4, in which the reasons for not using helmet weigh heaviest on the depicted balance scales. The different explanations are usually based on descriptive studies, and it is therefore difficult to predict how the balance will change if an argument disappears or is added. However, correlational studies have shown that attitudes and beliefs of bicyclists are associated with the helmet wearing behavior $(27,81,82)$. 


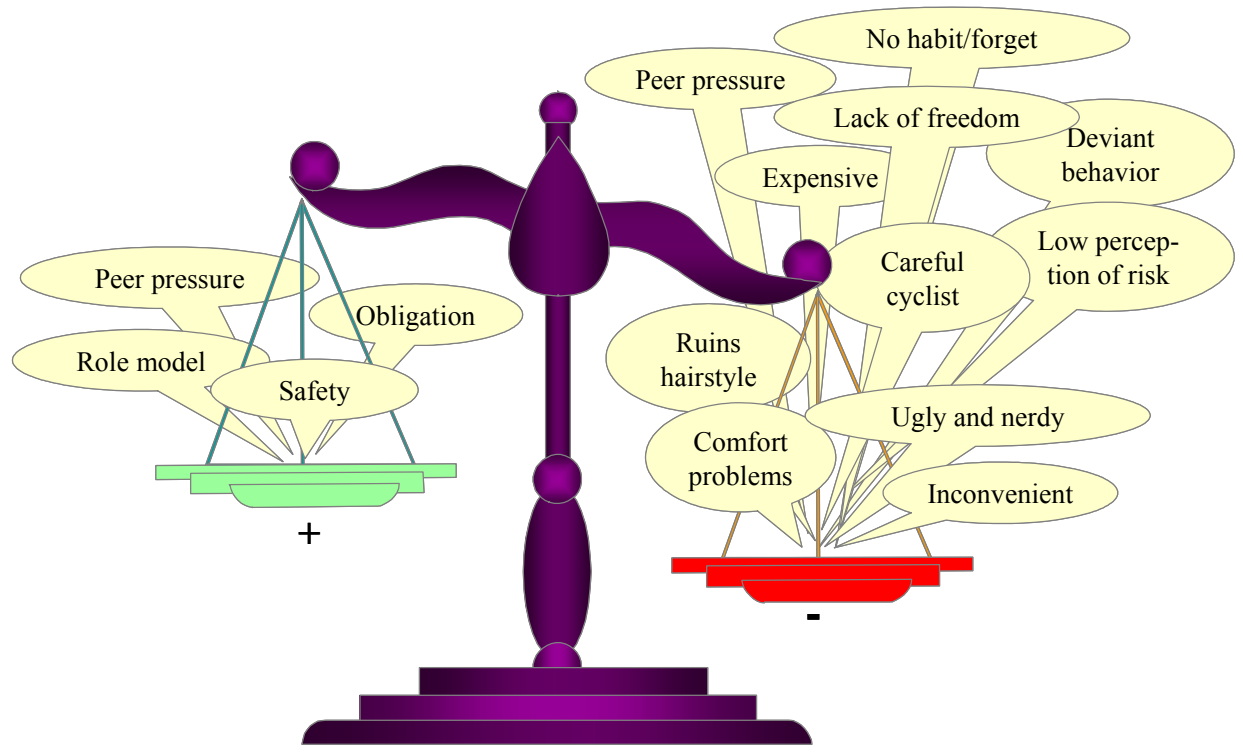

Figure 4. Illustration of the balance between different reasons for (+) and against (-) the use of bicycle helmets.

\subsubsection{External factors}

External factors in the environment can influence helmet wearing indirectly through the factors connected with the individual bicyclist. Examples of external factors are different helmet standardizations that guarantee that the helmets on the market offer sufficient protection. According to Towner et al. (26), there are about ten helmet standardizations in the world, and they all specify roughly the same level of protection for the approved helmets. The design, comfort, usability, and pricing and accessibility of helmets also influence use. The authors of a study conducted in Sweden at the beginning of the 1980s (83) stated the following: "A bicycle helmet that provides good protection is of no value if it is too uncomfortable to use." There were few different brands of bicycle helmets available in Sweden in the 1980s, and most of them were not very comfortable to wear. However, the selection of approved helmets grew quite rapidly at the beginning of the 1990s, partly because standardization was implemented at that time (84). 


\subsection{Effects of interventions aimed at increasing the use of bicycle helmets - review of the literature}

This section gives an overview of previous research concerning the effects of both voluntary helmet promotion and compulsory bicycle helmet laws, with the focus on the latter. For more detailed information, see Nolén and Lindqvist (85). Helmet promotion refers to all types of interventions that do not include legislated compulsion. This often means different kinds of education and information, but it also includes improvement of the design and usability of helmets, as well as rewards or different incentives such as subsidizing or providing free helmets. Bicycle helmet laws are political decisions that make helmet wearing obligatory.

\subsubsection{Bicycle helmet laws}

Nine countries have enacted some type of bicycle helmet legislation before January 2004 (see Table 3) (26, 27, 86, 87). Three of those countries are Australia, New Zeeland, and Finland, where the helmet laws apply to all categories of bicyclists. In Canada, five provinces have helmet laws for all bicyclists and two have laws that apply only to children. Twenty states in the United States have helmet laws, but they apply only to children, but the national goal is to have helmet laws for all bicyclists in all states by the year 2010 (88). Both the United States and Canada also have several local bicycle helmet laws. The other countries that have enacted helmet laws for bicyclists are Iceland, Slovenia, the Czech Republic, and Spain. Also in Sweden the government has decided to make helmet use mandatory for children (aged 0-14 years) riding bicycles (89), but this ordinance is not introduced yet. It is proposed to take effect on January 1, 2005 (see section 5.4).

It is still too early to estimate the long-term effects of the bicycle helmet law in Finland, which does not stipulate any fines or modes of enforcement (90). Nonetheless, preliminary results indicate that there has been only a small effect on observed helmet wearing, from an average pre-law level of $20-25 \%$ to a post-law level of $25-30 \%(48,91)$. However, the first post-law helmet observations were made before any supporting helmet promotion activities were conducted (48). 
Table 3. Countries that enacted bicycle helmet laws before January 2004.

\begin{tabular}{lllc}
\hline Country & Date & Coverage & Fines \\
\hline $\begin{array}{l}\text { Australia } \\
\text { New Zealand }\end{array}$ & $1990-1992$ & All bicyclists & Yes \\
USA & 1994 & All bicyclists & Yes \\
20 states & $1992-2002$ & Children & Yes \\
About 130 "local laws" & $1990-2004$ & Mostly children & Yes \\
Canada & & & \\
Five provinces & $1995-2002$ & All bicyclists or childrer & Yes \\
About 5 "local laws" & & All bicyclists or childrer & Yes \\
Iceland & 1997 & Children $\leq 15$ years & $*$ \\
Slovenia & 1998 & Children $\leq 14$ years & $*$ \\
Spain & 1999 & $*$ & $*$ \\
Czech Republic & 2001 & Children $\leq 14$ years & $*$ \\
Finland & 2003 & All bicyclists & No \\
\hline
\end{tabular}

* Information not avaliable

The results in this section primarily concern the bicycle helmet laws in Australia, New Zealand, the United States, and Canada. Very little or no information has yet been published on the effects of the helmet laws in the other five countries.

Before adopting helmet laws, authorities in Australia and New Zealand tried to increase voluntary use of bicycle helmets by conducting systematic promotion, including actions such as helmet subsidies and information campaigns at both the local and national level (92-94). Furthermore, helmet wearing was made mandatory for children at many schools $(95,96)$. The actual introduction of helmet laws in these countries, and partly in Canada, was also coordinated with intensified helmet promotion (97-101).

The bicycle helmet laws in Australia, New Zealand and Canada have a sanction system that imposes fines or warnings on people who do not wear helmets while riding bicycles. The warnings are given chiefly to children, although in some cases parents have to pay fines incurred by their offspring. At the time the helmet laws were introduced in Australia and New Zealand, the fines were 20-41 AUD (1 AUD = 4.34 SEK, January 1991) and 35 NZD (1 NZD $=4.67$ SEK, January 1994), respectively, and in rare cases fines of up to 100 AUD and 500 NZD could be imposed $(99,102)$. In 2003, the fines in Canada were 21-100 CAD (1 CAD = 5.52 SEK, January 2003) (103). In the United States, there is generally a fine of 25-100 USD (1 USD = 8.68 SEK, January 2003) for violating a helmet law, and parents are liable for payment of their children's fines (104). 


\subsubsection{Effects of laws on helmet use}

\section{Australia}

Australia was the first country in the world to adopt bicycle helmet laws. The laws were introduced gradually in different territories, first in Victoria (on July 1, 1990), which served as a model for the other territories in Australia (97).

Observational studies have been performed to monitor helmet wearing rates among bicyclists in several of the Australian territories. Considering Victoria as an example, the results indicate that average helmet wearing increased from $5 \%$ in 1983 to $31 \%$ in 1990 , but rose to $75 \%$ directly after the helmet law had taken effect, and had risen to $84 \%$ four years later $(45,105-107)$. The post-law increase in helmet wearing applies to bicycling commuters of all age (Figure 5), and there was a similar impact on both children and adults during recreational cycling $(45,105,106)$.
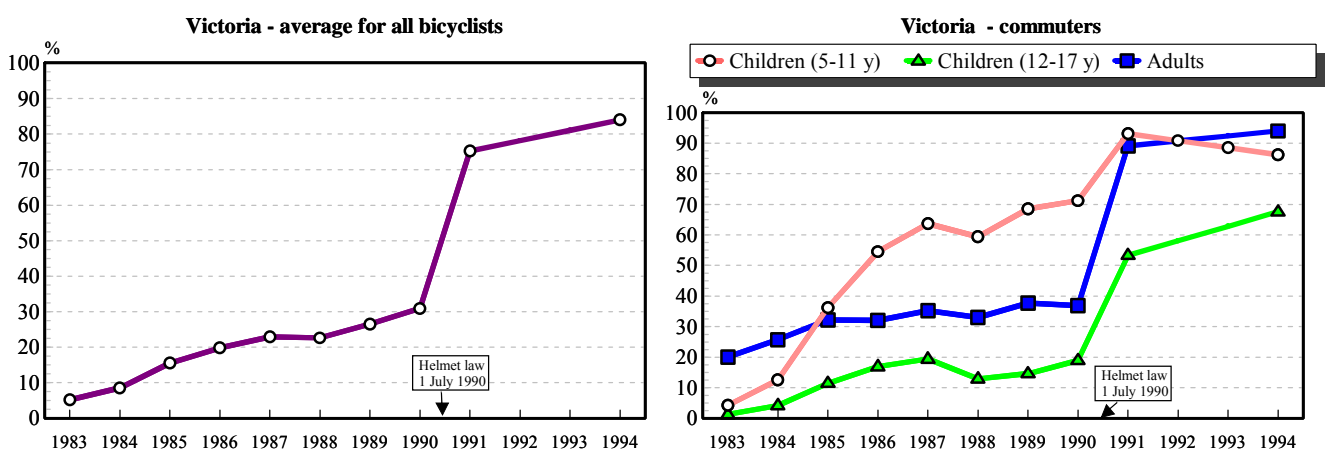

Figure 5. Observed bicycle helmet wearing in Victoria, Australia.

Data on observed helmet wearing in the Australian territories of New South Wales, South Australia, Western Australia, and Queensland have also indicated a large increase in use of bicycle helmets among children, teenagers, and adults (Figure 6) $(46,108-111)$. In New South Wales and Queensland, the helmet laws had a gradual effect. The law in New South Wales initially applied only to adults, and six months later it was extended to include children, and this strategy led to markedly increased helmet wearing in both categories of bicyclists, although the rise occurred earlier in adults (112-115). The helmet law in Queensland had no system of sanctions during the first 18 months. Nevertheless, there was a definite increase in helmet wearing the first few 
months in all age groups, but that effect was temporary, and, after about one and a half years, helmet wearing returned to the pre-law level. Thereafter, it was decided to add a sanctions system that allowed fines, which immediately led to a level of helmet use that was higher and more stable than before enactment of the law (111).
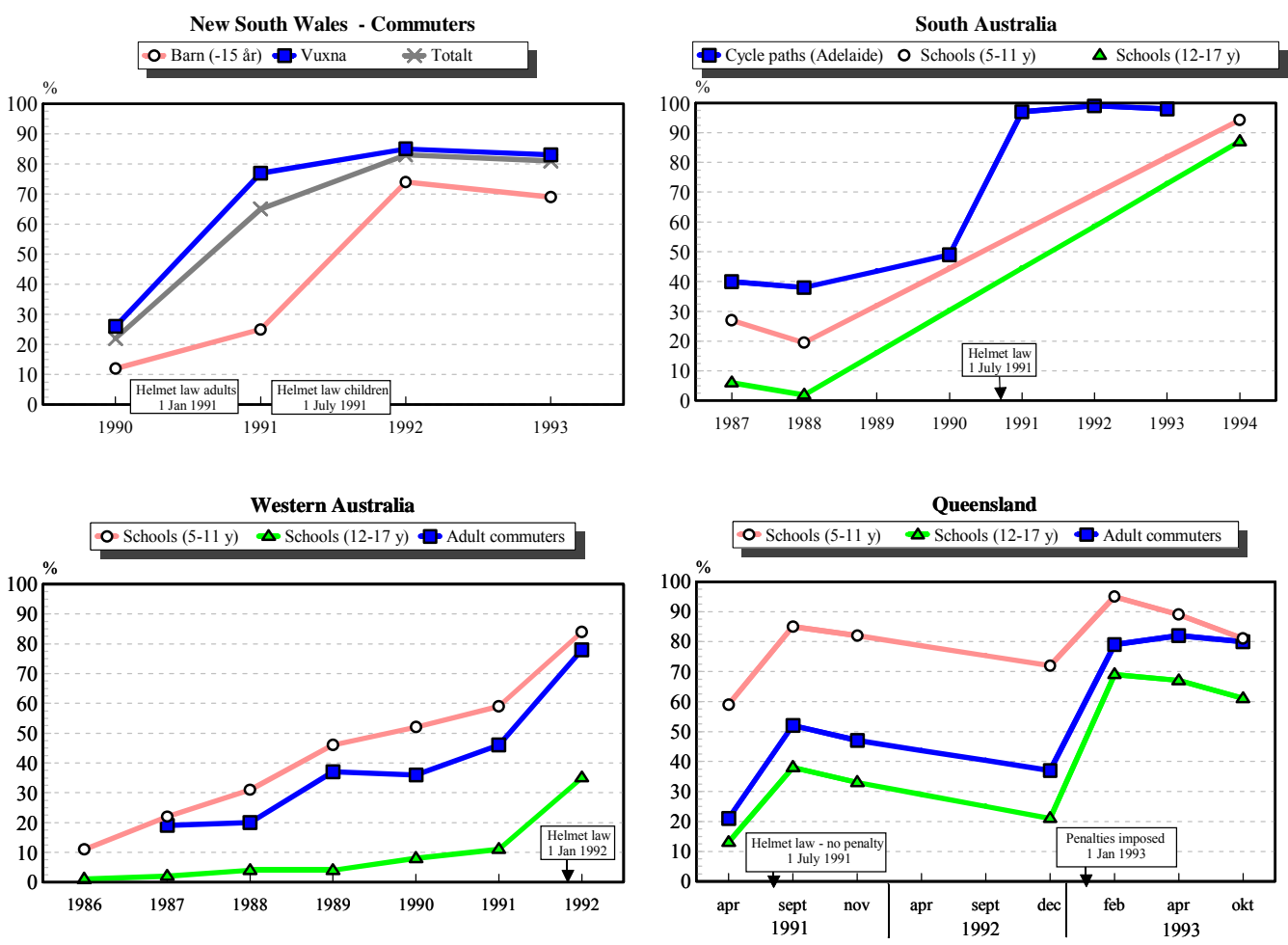

Figure 6. Observed bicycle helmet wearing in New South Wales, South Australia, Western Australia, and Queensland.

The lowest level of compliance with the helmet laws appeared to be among older children (12-17 years), although helmet wearing did increase even in this age category. However, helmet use often differed less between age groups after adoption of the helmet law compared to before introduction of the ordinance. Furthermore, post-law observational studies in Victoria indicated that some bicyclists, especially teenagers, did not wear a helmet but instead let it hang on the bicycle $(45,106)$. 


\section{New Zealand}

In the early 1980s, almost no bicyclists in New Zealand wore helmets, but the rate of voluntary use gradually increased after a helmet promotion program was started in $1986(92,116)$. The year before the helmet law was introduced, voluntary wearing was $86 \%$ among children, $63 \%$ among teenagers, and $46 \%$ among adults (99). Despite these very high voluntary wearing rates, adoption of the helmet law immediately led to $90-95 \%$ wearing among all bicyclists, and since then the rate has remained at a high level (Figure 7) (116-118).

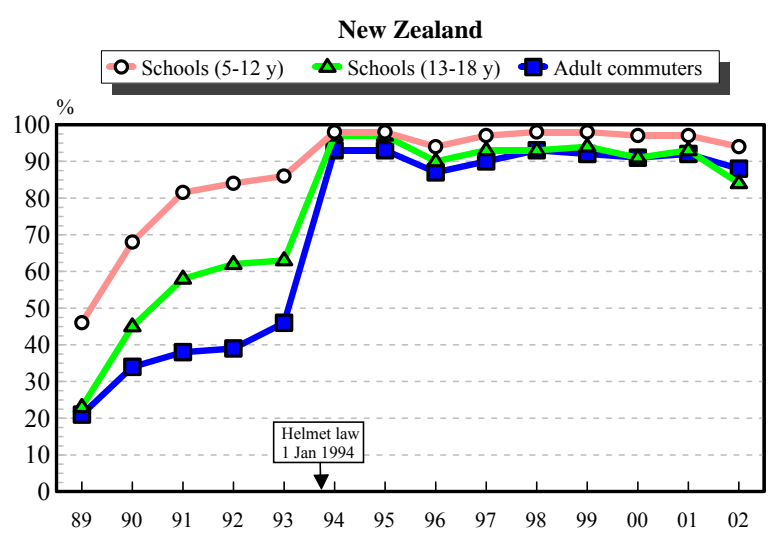

Figure 7. Observed bicycle helmet wearing in New Zealand.

\section{Canada}

Observational studies of bicycle helmet wearing before and after introduction of helmet laws in Canada have been conducted in Nova Scotia, Ontario, and British Columbia $(47,100,101)$, and the results indicate definite increases in all three of these provinces after the laws took effect (Figure 8). The average postlaw rates of helmet use were $60 \%$ in Ontario (city of Ottawa), about $70 \%$ in British Colombia, and about $85 \%$ in Nova Scotia (city of Halifax), and these high rates were still seen several years later, which indicates that the law had a stable effect. In Ontario, the helmet law applied only to children up to 17 years, and the increase in helmet wearing was also more profound in that age group than among bicyclists in general. 

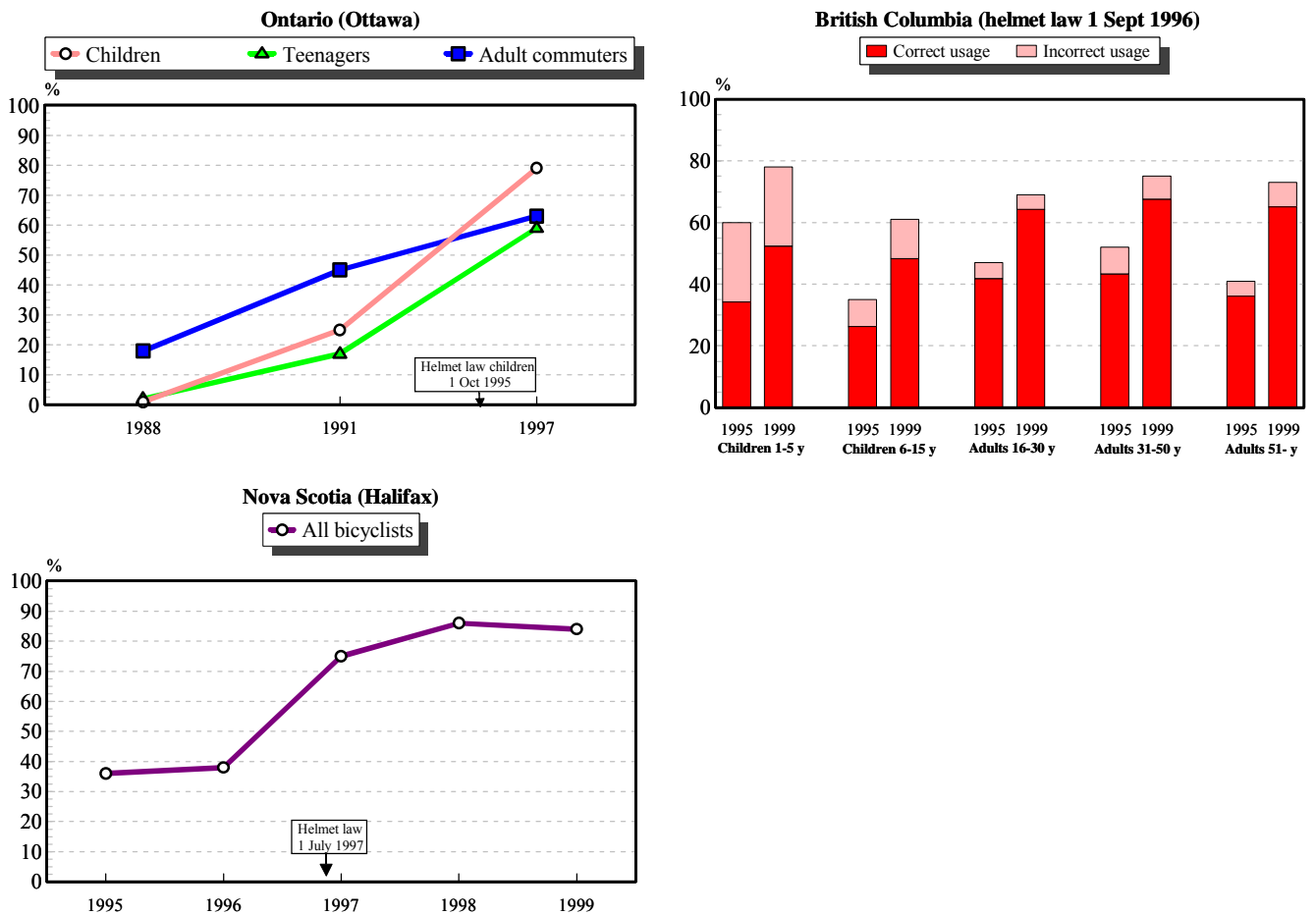

Figure 8. Observed bicycle helmet wearing in the Canadian provinces of Ontario (Ottawa), British Columbia, and Nova Scotia (Halifax).

\section{United States}

Relatively few evaluations of the bicycle helmet laws have been conducted in the United States, despite the fact that a substantial number of such laws have been passed in that country. Moreover, few observational studies have comprised several years. The assessments that have been performed have often been based on observational or self-reported data collected once before and once after the bicycle helmet law. Control areas have been included in some of the studies.

Four studies $(119,120)$ evaluated statewide bicycle helmet laws for children up to 15 years, and the results consistently showed post-law increases in helmet wearing. Helmet use rose 29 percentage points in Georgia, and 24-36 percentage points in Oregon one year after the laws took effect $(119,120)$. In Florida, average helmet wearing among children was $79 \%$ in counties that had adopted a law two years earlier, but was only 33\% in three counties without a helmet law (121). Another local example from Florida is Hillsborough County, 
where voluntary helmet wearing among children increased from $4 \%$ to $15 \%$ during a period of 3-4 years, whereas the wearing rate rose to $60-70 \%$ after the law took effect (122). In one study carried out in 1998 (123), self-reported helmet use among children was compared between states that did and did not have bicycle helmet laws. The results indicate that self-reported helmet wearing in this age group would increase from about $50 \%$ to $70 \%$ if all states passed a bicycle helmet law.

Three evaluations of local bicycle helmet laws in the United States compared the impact of bicycle helmet laws and helmet promotion, alone or in combination (124-126), and the results indicated that helmet wearing rates could be increased more effectively by combining these two interventions than by using them separately. That conclusion is also supported by a study from a small town in Georgia (127), where almost no children used bicycle helmets even though a helmet law had been introduced four years earlier. However, the authorities in that town had not started any helmet promotion activities or tried to enforce the helmet law after it took effect. On the initiative of the local police, such strategies were subsequently launched, and observed helmet wearing among children increased to $45 \%$ about five months later and was $54 \%$ after two years.

The first local bicycle helmet law in the United States was introduced in 1990 in Howard County, Maryland, in combination with a helmet promotion campaign. An evaluation (124) showed that observed helmet wearing among children up to 15 years of age increased from $4 \%$ pre-law to $47 \%$ seven months post-law. Two control towns were included in the study: in one there was only a helmet promotion campaign, and in the other there were no promotion activities at all. There were no significant changes in helmet wearing in either of the control towns during the study period. The positive effect of the helmet law and helmet promotion in Howard County was also found in a study based on self-reported helmet wearing (128).

Most of the bicycle helmet laws in the United States apply only to children. However, one study (129) compared three local helmet laws that pertained to different age categories: children up to 11 years, children up to 13 years, and bicyclists of all ages. The results clearly showed that the highest overall level of observed helmet wearing was achieved by a law encompassing all bicyclists - not just children. In other words, even helmet wearing among children alone was increased by a helmet law that included all people riding bicycles. 


\subsubsection{Effects of helmet laws on injuries to bicyclists}

\section{Australia}

The number of bicyclists killed and injured in Australia decreased after the introduction of helmet laws. The rate of bicycle-related fatalities was lower two years post-law compared to two years pre-law, and there was an overall average decrease of $45 \%$ in fatalities in the entire country (Table 4$)((130)$.

Table 4. Number and relative change (\%) of bicyclists killed two years after the introduction of helmet laws in Australia.

\begin{tabular}{rrrrrrrr}
\hline & \multicolumn{7}{c}{ State } \\
\cline { 2 - 6 } Period & NSW & VIC & QLD & SA & WA & Others & Total \\
\hline Two years before & 39 & 54 & 39 & 15 & 17 & 10 & 174 \\
Two years after & 16 & 32 & 30 & 9 & 6 & 3 & 96 \\
Relative change \% & $-59 \%$ & $-41 \%$ & $-23 \%$ & $-40 \%$ & $-65 \%$ & $-70 \%$ & $-45 \%$ \\
\hline
\end{tabular}

Notwithstanding, the reduction in injuries and fatalities among bicyclists might have been due to factors other than the helmet laws. For instance, other traffic safety measures were implemented, and there was a recession in the economy that coincided with the helmet law, which, among other things, reduced the sale of alcohol (131). Bicycle helmet laws have also been criticized for decreasing the level of exposure in traffic, which might influence the number of injured cyclists (see section 1.4.1.3). Therefore, when attempting to estimate the impact of a bicycle helmet law, it is important to analyze changes in injuries to the head and other parts of the body separately. Only the rate of head injuries should be affected by increased bicycle helmet wearing, thus the ratio of number of head injuries to other types of injuries among bicyclists is often used to measure the injury-preventing impact of a helmet law.

In Victoria, the number of bicyclists hospitalized with head injuries sustained in a collision with a motor vehicle was reduced by $70 \%$ two years after introduction of the bicycle helmet law, and the corresponding reduction for other types of injuries among cyclists was $28 \%$ (Figure 9) $(102,107,132,133)$. A similar pattern has been reported for head injuries sustained in single accidents (134). A negative correlation can be seen between the trend in helmet wearing and the proportion of head injuries among bicyclists in Victoria during a period of about ten years. The proportion of head injuries two years after the helmet law was also significantly smaller than could have been expected from 
the trend in injuries before the law $(102,107,132)$. The positive effect on head injuries also remains four years after the helmet law, if the results are adjusted for potential confounders, such as changes in injury surveillance systems and other traffic safety measures (135).
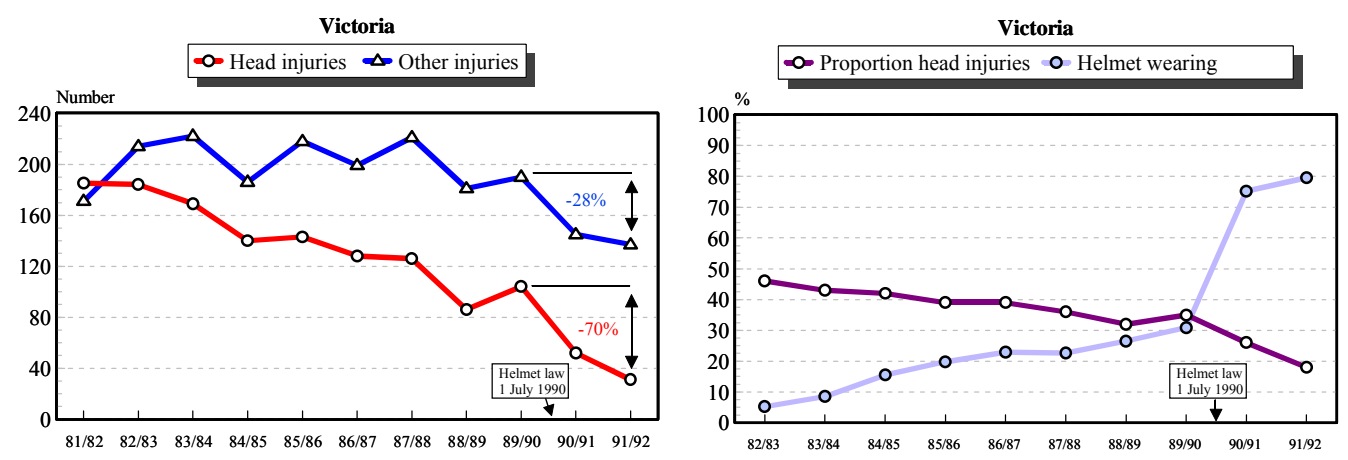

Figure 9. Number of bicyclists killed and seriously injured, and the proportion of helmet wearing and cyclists sustaining head injuries in Victoria.

Inception of the helmet laws in New South Wales, South Australia, Western Australia, and Queensland have been followed by a reduction in the rate of head injuries among bicyclists (Figure 10) $(108,110,111,130)$. Data on the decrease in head injuries in South Australia have also been adjusted for potential confounders (e.g., the change in cyclists exposure in traffic and other traffic safety reforms), which revealed that more extensive wearing of bicycle helmets reduced the number of head injuries by about $25 \%$ two years after the helmet law compared with two years before (108). In Queensland, police injury data show that the number of bicyclists killed and seriously injured per quarter was reduced by $13 \%$ during the no-penalty period of the law but was decreased by $29 \%$ after penalties were introduced. Data from Brisbane in Queensland also show a decrease in bicyclists hospitalized with head injuries, and the reduction in serious head injuries per quarter was twice as high after adding sanctions than during the no-penalty period. Adjusting for changes in non-head injuries indicates that the reduction in serious head injuries was $26 \%$ during the no-penalty period but was $55 \%$ when penalties were applied (111). 

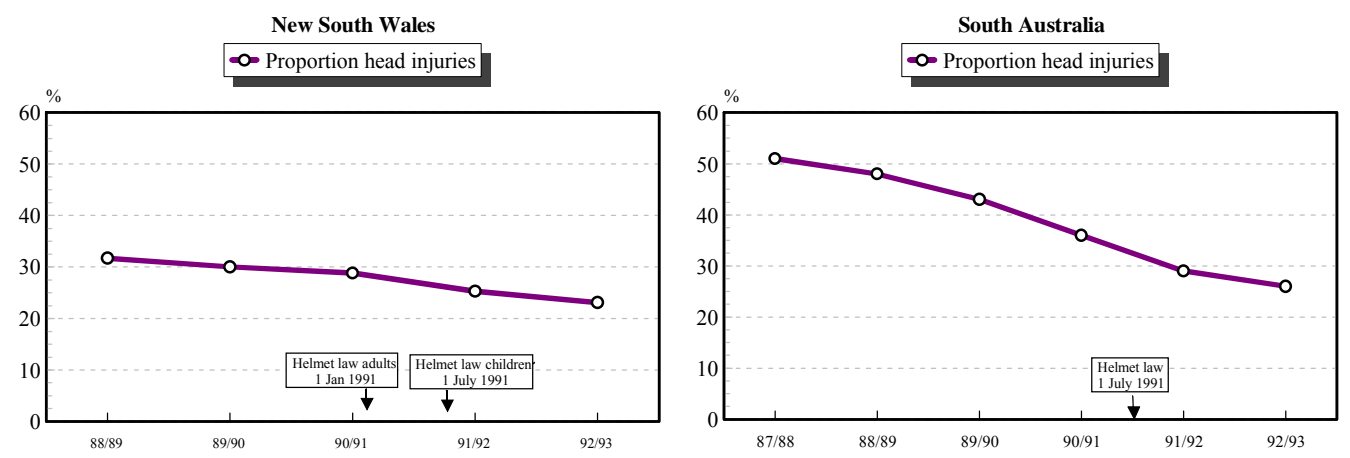

Figure 10. Head injuries among hospitalized bicyclists before and after introduction of helmet laws in New South Wales and South Australia.

\section{New Zealand}

The effects of the helmet law in New Zealand on levels of injuries among bicyclists have been assessed in two studies (116). Both of these focused on head injuries in hospitalized bicyclists, and they also controlled for risk exposures by adjusting for arm and leg fractures among bike riders. The study periods were somewhat different in the two studies, but in both cases the results show that head injuries were reduced by $20-30 \%$. According to one of the studies, the number of head injuries per quarter was reduced by $19 \%$ after introduction of the helmet law (116). The other study showed that the risk of head injuries in single accidents was reduced $24-32 \%$ two years after adoption of the helmet law compared to two years before, and the corresponding decrease in head injuries in collision accidents was 20\% (118).

\section{Canada}

In Nova Scotia, the proportion of bicyclists hospitalized with head injuries was reduced by $50 \%$ two years after the bicycle helmet law took effect (101). Another study (136) compared the four provinces that passed bicycle helmet laws in Canada in 1994-1998 with the other provinces that did not have helmet laws and found that adoption of a law led to a significant reduction in the incidence of head injuries among children (5-19 years) riding bicycles. More exactly, the reduction was $45 \%$ in provinces with a helmet law but only $27 \%$ in non-law provinces. There were no changes in the rate of non-head injuries among bicyclists in any of the provinces during the study period. The study also controlled for potentially confounding demographical factors between provinces with and without a helmet law, and the only factor that proved to be significant in the analysis was whether or not a helmet law had been passed. 


\section{United States}

Two studies have analyzed bicycle-related head injuries among hospitalized children in Broward County, Florida, and in Buffalo, New York (137, 138). Both of these studies were based on few observations, hence the analysis focused on comparisons of injuries incurred by helmet wearers and non-wearers in general. Nevertheless, the results show that the use of helmets did increase after helmet laws were passed, and the proportion of serious head injuries was significantly smaller among children that used helmets compared to those who did not.

\subsubsection{Effects of helmet laws on cycling exposure}

In Melbourne, Australia, one study (139) was designed to evaluate the effects of the Victorian helmet legislation on cycling exposure. This analysis was based on observational data about the time children, teenagers, and adults spent riding bicycles (Figure 11) (139). The results show that total cycling exposure, irrespective of the cyclist's age, increased about $12 \%$ two years after the law compared to two and a half years before. However, opposite tendencies were seen when considering the different age categories separately. Among older children (12-17 years), bicycling was markedly reduced (by 46\%) two years after the law compared to immediately before the law took effect. Moreover, a reduction of $11 \%$ occurred among younger children (5-11 years) during the same period, but that downward trend had already started before the law was introduced. In contrast, bicycling among adults had increased $100 \%$ two years after the law compared to two and a half years before. However, it is difficult to know whether that finding was due to an initial effect of the law, since there are no data on the rate of bicycling by adults during the immediate pre-law period, although it should be mentioned that a tendency toward increasing cycling among adults was noted between the first and second year after induction of the law. In the mentioned study there were also an additional analysis about any changes in the number of people observed riding bicycles, and they found a reduction in all age categories during the first year after the helmet law, although this decrease was most pronounced among teenagers. Two years after inception of the helmet law, the reduction was no longer apparent among younger children or adults but remained among teenagers (139).

In some of the other territories in Australia, researchers have estimated the effects of the helmet laws on bicycling. These studies were based on changes in 
the numbers of bicyclists noted in the regular (annual) observational studies of helmet use and in some cases also on self-reported data. The results were similar in New South Wales and Victoria, for example showing reduced cycling among teenagers but not adults (110, 115). In South Australia and Western Australia, there was no indication of decreased bicycling among adults, and the results for children and teenagers are uncertain due to contradictory data $(46,108,140)$.

A study carried out in Ontario, Canada (141) revealed no reduction in the number of children (age 5-14 years) seen riding bicycles, instead there was a tendency towards increased cycling after introduction of the helmet law in October 1995 (Figure 11) (141). There are no studies found about the effects of helmet laws on bicycling in New Zealand or the United States.
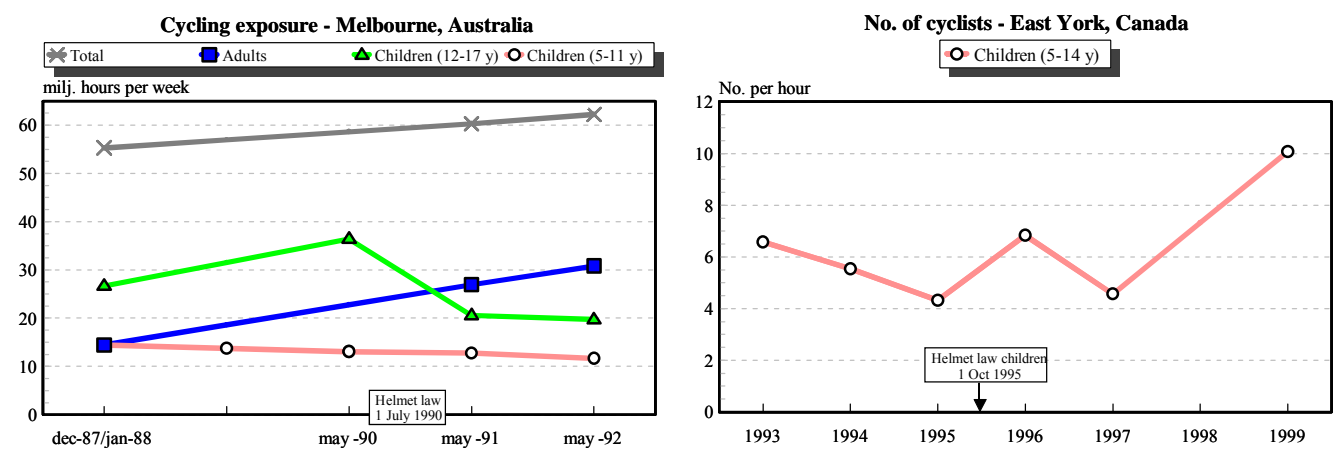

Figure 11. Estimation of the effects of helmet laws on cycling exposure in Melbourne, Australia, and in East York, Canada.

Considering the findings above, it seems reasonable to conclude that introduction of helmet laws, at least in Australia, has led to decreased bicycling among teenagers for up to two years, but has had no persistent negative effect on cycling among younger children and adults.

\subsubsection{Helmet promotion}

The effects of bicycle helmet promotion on voluntary helmet wearing are outlined on four levels, taking into consideration whether the studies targeted individuals, groups, communities, or states/provinces/countries. Similar intervention levels have been used in a previous review of evidence-based injury prevention (142). In the context of interventions aimed at promoting the use of 
bicycle helmets, the terms "physician-based," "school-based," and "community-based" are often used to describe the first three levels (41). However, here the four intervention levels considered are simply referred to as the individual, group, community, and state/national levels.

\subsubsection{Promotion on an individual level}

According to a questionnaire study about $80 \%$ of pediatrics in the United States gives their patients information about bicycle helmets (143), hence it is not surprising that the studies that concerned the level of individuals were conducted in North America. All were randomized control studies focused on the effects of helmet promotion on pediatric patients or their parents. The results show that sporadic information from doctors about bicycle helmets does not lead to increased helmet wearing $(144,145)$, whereas more regular information given over a longer period of time could have positive effects (146). One study also indicated that short-term therapy aimed at changing the general risk behavior of injured patents did increase bicycle helmet wearing in those individuals (147).

In addition to being provided information about bicycle helmets, patients are sometimes given the opportunity to buy helmets at a reduced price or are even given free helmets. One study revealed tendencies towards higher selfreported helmet wearing among patients who had paid for their helmets compared to those who had gotten one for free, but the difference between these groups was not significant (148).

\subsubsection{Promotion on a group level}

Most of the studies of group-based interventions that were found in the literature concerned school children up to the age of 15 . About half of the studies had a robust design" with matched or randomized control groups, whereas a majority of them were short-term evaluations covering a period of only a few weeks or months after the intervention.

Most of the studies of interventions on a group level indicated positive effects on helmet wearing, with post-intervention wearing between $11 \%$ and $58 \%$, depending on whether the rates were observed or self reported (53, 149-155). Indeed, wearing rates of up to $90 \%$ have been noted, but those results were valid solely under special circumstances (156-158). If the assessment is limited to studies that have a robust design and report data on observed helmet wear- 
ing, the interventions increased helmet wearing from a baseline of $0-8 \%$ to a level of $22-33 \%$ (159-161).

Group-based interventions targeting children often consist of information and education about bicycle helmets combined with helmet subsidies or free helmets, or some type of reward/incentive system. Most studies that have been conducted have evaluated the overall impact of an intervention, which makes it difficult to estimate the effects of separate components. Nonetheless, some studies have considered different factors individually $(149,156)$, and the findings indicate that positive results can be achieved by distributing free helmets at information meetings and by giving helmet information to both children and their parents. The impact of helmet subsidy systems has been evaluated in two studies $(160,162)$, but only one of them revealed significant positive effects on helmet wearing. However, in another study (161), it was found that a reward system for helmet wearing did have a relatively strong positive influence when it was combined with helmet information. However, it has also been pointed out that there is a risk that the positive effects of temporary reward systems will disappear if the reward system is suddenly terminated (153). One study did also show the importance of theory-based interventions when they observed that a helmet program using the "theory of planned behavior" (see section 1.5) succeeded in increasing helmet wearing among children from $0 \%$ to $25 \%$ in five months (163).

Some group-level research performed in Sweden has focused on adult bicyclists. One study has indicated that "commitment contracts" or "helmet contracts" combined with free bicycle helmets at workplaces increased observed helmet wearing about three times to about $30 \%$ one year after the intervention (164). The impact of helmet contracts with employees tends to diminish after about one year, but it can apparently be reactivated by introducing a helmet subsidy system at the same workplaces (165). Other studies have shown that information meetings combined with helmet subsidies at workplaces and universities increased the use of bicycle helmets by up to about $15 \%(166,167)$.

\subsubsection{Promotion on a community level}

Studies with a robust design (e.g., using matched or randomized control groups) have more often focused on individual- and group-based interventions than on interventions conducted at a community level. Only three of the studies found in the literature included control groups (51, 57, 168). Furthermore, most of the studies examined various multistrategy helmet programs 
that had been conducted over several years and frequently included different information and education activities combined with helmet subsidy systems, and in some cases also systems for rewarding helmet wearers. The targets of the bicycle helmet programs have primarily been children or teenagers, although some Swedish programs have also included adults.

Many evaluations dealt with the overall effect of a helmet program, thus it is difficult to estimate the effects of separate helmet-promoting activities. However, one exception is a study of a helmet promotion program run for one year in a Canadian community, which showed that the intervention led to increased bicycle helmet wearing among school children from a baseline of $1 \%$ to about $13 \%$. Sadly enough, shortly after the helmet program, a nine-year-old boy was killed while riding a bicycle without a helmet, after which the use of helmets immediately increased to about $50 \%$ among school children.

The "Seattle Children's Bicycle Helmet Campaign" in the United States was one of the first major community-level helmet programs to be conducted. The campaign was started in 1986 and targeted school children 5-15 years of age, with a focus on younger school children. The helmet program in Seattle took into consideration the results of earlier studies showing that there are three important barriers to helmet wearing by children: many parents are not aware of the need for wearing a helmet; there is peer pressure against helmet use; the cost of buying a helmet is prohibitive (50). The Seattle helmet program tries to reduce the mentioned barriers by using information and education materials and by implementing helmet subsidy schemes (169). An evaluation of the program has shown that helmet wearing among school children increased from $6 \%$ to $57 \%$ during the first six years of the campaign, and the proportion of head injuries among cyclists was reduced by $60 \%$ during the same period (57, 170, 171).

All the studies of community-based interventions indicated that the measures taken had had positive effects on the use of bicycle helmets by children, and had also led to a reduction in the number of head injuries (52, 168, 170-173). The level of helmet wearing that was achieved after the interventions varied from $13 \%$ to $30 \%$ for short-term programs lasting up to one year (174-176) and from $30 \%$ to $57 \%$ for long-term programs lasting at least two years (51, 168, 172). Studies that included control groups indicated that the level of helmet wearing achieved ranged from $16 \%$ to $33 \%(51,57,168)$. 
Helmet programs can be improved not only by prolonging the period of performance, but also by using a theory-based strategy. An example of this is a four-year helmet program aimed at influencing children ages 5-12 years in Montérégie, Canada, which was based on the PRECEDE-PROCEED model (see section 1.5) (177). Evaluation of this program showed that use of helmets by children had increased from about $1 \%$ to $33 \%$ in five years $(51,178)$.

Some community-based interventions in Sweden have also targeted adult bicyclists, and they covered both general traffic safety programs (including activities such as bicycle helmet promotion) and evaluations of separate helmet programs. Studies have shown that these interventions had positive effects, resulting in observed helmet wearing in the range $14-26 \%$ within a few years (179-183). Attempts have also been made to motivate adult bicyclists in a Swedish community to become official "helmet role models," which meant that adults who signed an agreement to wear a helmet when riding a bicycle were given a free helmet. It was found that after about one month, $50-70 \%$ of the helmet role models said they often used a bicycle helmet, whereas only $30 \%$ answered in the same way after two years $(184,185)$.

\subsubsection{Promotion on a state/national level}

Only a few evaluations have concerned helmet-promoting efforts made on the level of a state or country. One of those studies examined an Israeli mass media campaign aimed at increasing the use of bicycle helmets, and it was found that, on average, the rate of observed helmet wearing by all categories of bicyclists increased from $8 \%$ to $15 \%$ within a few months (186). Likewise, studies performed in Victoria, Australia, before introduction of the bicycle helmet law showed that systematic helmet promotion that included regular information campaigns and helmet subsidies increased average helmet wearing from $5 \%$ to $31 \%$ over a period of seven years (Figure 12$)(93,94)$. Several of the information campaigns in Victoria were also preceded by pilot surveys that were used to coordinate the message of the campaigns with the target groups $(74,187)$. Similar effects have been noted in New Zealand: after approximately four years of systematic helmet promotion (i.e., before introduction of the helmet law), voluntary use of helmets rose to fairly high levels of about $85 \%$ among children, $63 \%$ among teenagers, and $46 \%$ among adults (116). 


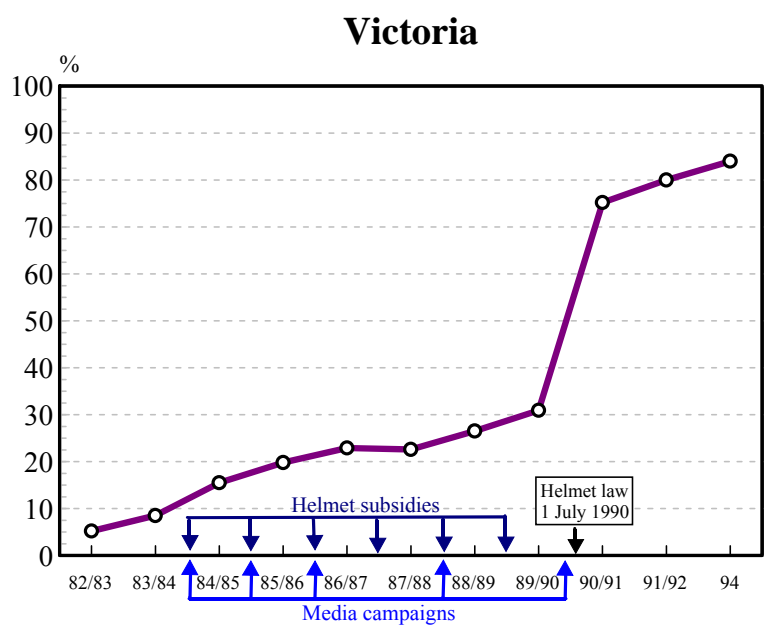

Figure 12. Systematic helmet promotion and average helmet wearing among bicyclists in Victoria, Australia.

National bicycle helmet promotion activities have also been performed in Sweden, particularly in the 1990s. During that decade, among other things, four annual helmet campaigns targeting adults were conducted at the national level (188-191). However, those campaigns were supported by promotional actions taken at the local and regional levels.

\subsection{An outline of a theoretical framework for hel- met wearing by bicyclists}

The aim of this section is to put bicycle helmet use in a theoretical perspective and to provide a general understanding of how different factors may influence the choice of whether or not to wear a helmet. Hopefully, the information given here will facilitate the discussion of the empirical results of the research underlying this thesis.

There are many theoretical models that describe human behavior, some of which focus on internal cognitive factors in the individual, like attitudes and beliefs (192), and others consider the influence of external societal or environmental factors (193). Two models are discussed briefly in this section, one deals with cognitive aspects of the individual, and the other concerns the effects of internal and external factors on public health. The latter model is called PRECEDE-PROCEED (Figure 13), and it is often used as a framework for 
health promotion in community settings (177) and is also frequently mentioned in studies of bicycle helmet interventions (194). An example of successful application of this model is the design of a long-term helmet program for children in Quebec, Canada $(51,178)$.

The PRECEDE-PROCEED model can be used during the initiation and planning of an intervention, as well as during the implementation and evaluation stages. As the name implies, the model consists of two main parts: PRECEDE (Predisposing, Reinforcing, and Enabling Constructs in Educational Diagnosis and Evaluation), which includes different steps in the initiation and planning process; and PROCEED (Policy, Regulatory, and Organizational Constructs in Educational and Environmental Development), which comprises various phases of the implementation and evaluation. The PRECEDE and PROCEED have different "directions" in that the former starts with a description of the particular health problem and ends with designing the intervention, whereas the latter begins with implementation and concludes with an evaluation of the objectives of the intervention. If this model is to be used as a framework for a bicycle helmet intervention, the starting point would be that head injuries represent a health problem among bicyclists, and that problem can be reduced by increasing the use of bicycle helmets. However, to achieve that objective, it is necessary to identify the factors that influence the decision to use a helmet. Such knowledge represents an input to the design of the intervention, which could, for example, be a helmet program. If implementation of the helmet program progresses without difficulties, and the previous causal analysis is correct, then the results of the evaluation should indicate increased helmet use and a reduced number of head injuries.

An important phase in PRECEDE is the mapping of factors that supposedly influence the behavior of interest (177), for instance bicycle helmet use. According to the model, there are three categories of such factors:

- Predisposing factors, which include aspects such as the knowledge, attitudes, beliefs, and values of an individual, and influence the motivation to use or not use a bicycle helmet.

- Reinforcing factors, which embrace rewards or incentives for the behavior. This also includes the way that a person perceives social support provided by other people. Reinforcing factors may influence the probability that a cyclist continues to use or not use a helmet. 
- Enabling factors, which comprise a person's skills and the way that he or she perceives resources favoring or barriers against helmet use. Enabling factors can facilitate or impede the use of helmets.

A behavior is seldom influenced by only one of the mentioned categories of factors, but is instead usually cooperatively affected by all three (177). According to the PRECEDE-PROCEED model, the process of influencing a behavior is often started by increasing the motivation (predisposing factors) for a certain behavior, for instance bicycle helmet use. Motivation can be augmented by applying measures such as information, education, regulations. If people are to change their behavior, it is also important that they have sufficient abilities or resources (enabling factors), for example they already own a helmet or can afford one. Whether a new behavior will be maintained over time depends on, among other things, the way the actor perceives the reactions of other people to the behavior of interest (reinforcing factors).

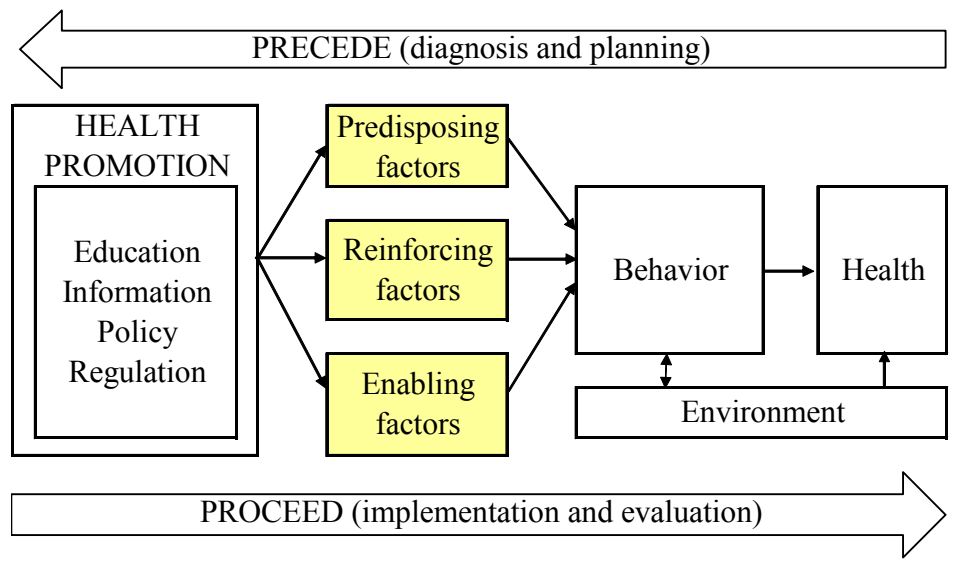

Figure 13. Simplified description of the PRECEDE-PROCEED model. Adapted from Green and Kreuter (177).

The predisposing, reinforcing, and enabling factors are mainly about people's attitudes and beliefs. Our understanding of how attitudes and beliefs are formed and how they influence behavior can also be extended by using what is known as a Social Cognition Model (192), an example of which is the theory of planned behaviour (TPB) (Figure 14) (195-197). TPB and the earlier theory of reasoned action (198) have often been used to predict and comprehend behaviors related to traffic safety, such as violations committed by car drivers, and 
the use of safety belts and child protection systems in motor vehicles (199). The models have also been employed to predict children's intentions to use bicycle helmets.

According to TPB, most humans think rationally and try to weigh the pros and cons when they deliberately choose to behave in a certain way. The process of decision making can be automatic and unconscious, but it can also be revealed through interviews and questionnaires. In TPB, a behavior is best predicted from a behavioral intention, even if certain behaviors can also be foreseen by considering a person's perceived control of the behavior (199). Correlations between intention and the behavior might be weakened if a long period of time elapses before the behavior is executed. Research has shown that correlations between intentions and behaviors vary depending on the type of behavior studied, but reliable associations have nonetheless been found for a considerable number of behaviors $(199,200)$.

Behavioral intentions, such as intending to use a helmet the next time you ride a bicycle, are formed by three overall perceptions: attitude towards the behavior, for example whether you are positive or negative to the use of a bicycle helmet; subjective norm, for instance how you experience the way that other "important" people perceive your behavior; and perceived control, for example whether you think it should be easy or difficult to use a helmet. The relative importance of the three overall perceptions is determined by the type of behavior and the situational context. There are rather substantial similarities between the overall perceptions in TPB and some parts of the PRECEDEPROCEED model: attitudes resemble the predisposing factors; subjective norm is like the reinforcing factors; and perceived control is similar to the enabling factors.

According to TPB the three overall perceptions are formed by different types of beliefs about the behavior in question:

- Behavioral beliefs and outcome evaluations. You can have certain beliefs, both positive and negative, about the consequences of, for instance, using a bicycle helmet. The consequences can also be more or less important to you.

- Normative beliefs and motivation to comply. You can have certain beliefs about what "important" people will think of you if you use a helmet, and you can also be more or less inclined to comply with different people's opinions. 
- Control beliefs and perceived power to facilitate/inhibit. You can have certain beliefs about how different factors would make it difficult or easy for you to use a helmet, and these factors could be perceived as more or less important to you.

To increase the wearing of bicycle helmets, according to TPB, it is essential to influence the most relevant beliefs that precede the intention to use a helmet. However, it is important to know, through previous research or pilot studies, what beliefs will have a significant impact on helmet use by the target group, otherwise the correlations with the intention and the behavior could be weak (201). According to the TPB model, the effects that are exerted on behavior by external factors like demographic variables, personality traits, and societal factors are not direct but are instead mediated by the factors included in the model.

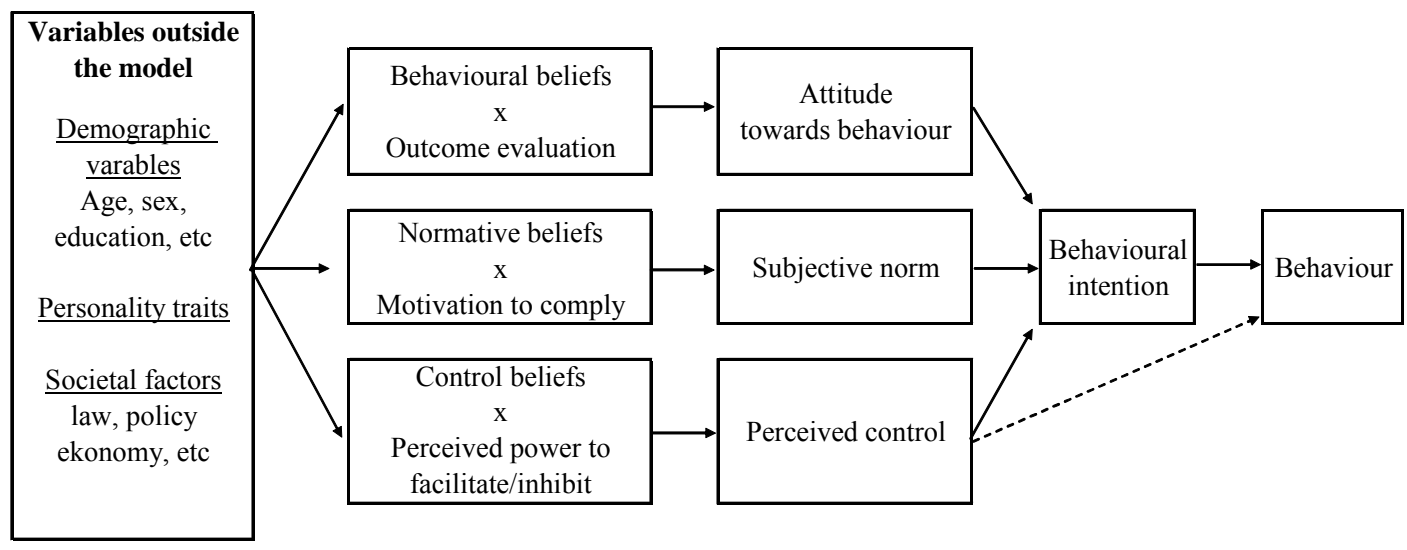

Figure 14. The theory of planned behaviour. Figure adapted from Connor and Sparks (202).

TPB and the earlier theory of reasoned action have been used to predict intentions to use bicycle helmets among children and teenagers. For example, Otis et al. (81) found that about $50 \%$ of the variance in children's helmet use could be explained by both the attitude and the subjective norm associated with helmet wearing, although the former factor was most important. Furthermore, Quine et al. (203) and Lajunen and Räsänen (204) have reported that TPB could predict teenagers' intentions to use bicycle helmets, and, in both those studies, the subjective norm was the most important predictor. The findings of 
a pilot study conducted in Sweden have also indicated that the TPB model has a potential to predict intentions helmet wearing among adult bicyclists (78).

\subsection{Concluding remarks from the background}

The information presented in the background section indicates that too many bicyclists sustain head injuries. However, the risk of head injury could be reduced considerably by the use of bicycle helmets. Research performed thus far has shown that it is possible to increase helmet wearing among bicyclists by voluntary means. The best effects have been attained with community-based long-term helmet programs that are multifaceted, for instance comprising information and education activities combined with helmet subsidies or reward/incentive systems. However, the greatest impact on wearing of bicycle helmets has definitely been achieved by combining helmet promotion with a compulsory helmet law for all categories of bicyclists, as has been done in Australia, New Zealand, and North America. This thesis is about the needs and possibilities of increased bicycle helmet use in Sweden. If there is such a need, an alternative intervention to a compulsory bicycle helmet law might be to combine community-based helmet promotion with a non-mandatory local bicycle helmet ordinance (see section 3.2.3)? This is one of the questions that are addressed in this thesis. 


\section{$2 \quad$ AIMS}

The general aim of the work underlying this thesis was to provide further information about the need for increased bicycle helmet use in Sweden, and to determine what measures are suitable to attain more widespread helmet wearing. Four studies (described in papers I-IV) were conducted that addressed two main questions:

A. What is the need for increased helmet wearing among different categories of cyclists in Sweden?

- Paper I:

The objective was to describe how the use of bicycle helmets in a country in northern Europe has changed over the period 1988-2002, and, based on the results, to predict the future trends in voluntary helmet wearing up to the year 2010 .

B. Is a non-compulsory local bicycle helmet law a realistic alternative to a compulsory helmet law for all bicyclists?

- Paper II:

The objective was to describe the structure and process of designing, initiating, and implementing a non-compulsory local bicycle helmet law in a small European town, and, more specifically, to focusing on the activities performed, the participating actors, and the opinions of the most closely involved actors.

- Paper III:

The aim was to evaluate the effects of a non-compulsory local bicycle helmet law on observed helmet use among children and adults.

- Paper IV:

The purpose of this study was to assess the long-term impact of a noncompulsory local bicycle helmet law on attitudes, beliefs, and self-reported behavior among school children 6-12 years of age. 


\section{MATERIALS AND METHODS}

The papers included in this thesis describe four separate studies of different samples of subjects, and an overview of the materials and methods that were used is presented in Table 5 .

\subsection{Bicycle helmet use in Sweden (paper I)}

This paper reports how the use of helmets by different categories of bicyclists in Sweden changed from 1988 to 2002, and it also presents estimates of future trends in voluntary helmet wearing up to the year 2010.

\section{Design and data collection}

A series of observational studies of helmet use by bicyclists in Sweden was conducted during the period 1988-2002. The same method was used to make observations once a year (in September), at the same sites $(n=157)$, in the same cities $(n=21)$, and for the same length of time at the same time of day (two hours in either the morning or the afternoon). Helmet use and gender were recorded for the following categories of cyclists:

- Children $(\leq 10$ years of age) riding bicycles in residential areas in their leisure time (average $n=2,191 /$ year). The observers moved around to cover as many courtyards, playgrounds, bicycle paths, and similar places as possible.

- Children (6-15 years) riding bicycles to school (average $n=5,471 /$ year). The observers stayed in the same place during the entire monitoring session.

- Adults ( $\geq 16$ years) riding bicycles to workplaces and on public bike paths (average $n=29,368 /$ year). The observers stayed in the same place during the whole monitoring session.

Average helmet use by all observed bicyclists, irrespective of age category, was calculated as a weighted average of helmet wearing by both children and adults, based on previously reported exposure data for children and adults cycling in traffic (205).

Temporary dropout was noted at an average of 3.4 observational sites per year during the study period (1988-2002). In the analysis, mean values were substi- 
tuted for dropouts at the missing sites. The means represented total average change in helmet use (in percentage points) between two years of measurement. On average, the analysis comprised a total of 37,031 observed bicyclists per year, of which $605(1.6 \%)$ were accounted for by adjusting dropouts.

\section{Analysis of data}

The general trend in helmet use during the entire study period was analyzed by linear regression analysis of each category of bicyclists. Differences in helmet use according to gender and size of city were analyzed by a Pearson chisquare test for two independent samples. The trend in wearing of bicycle helmets up to the year 2010 was predicted based on the results of linear regression analysis of the observational data for the period 1988-2002. A 95\% prediction interval is given for the estimated proportion of helmet users in 2010. In all statistical analysis, a p-value less than 0.05 was considered to be significant. 


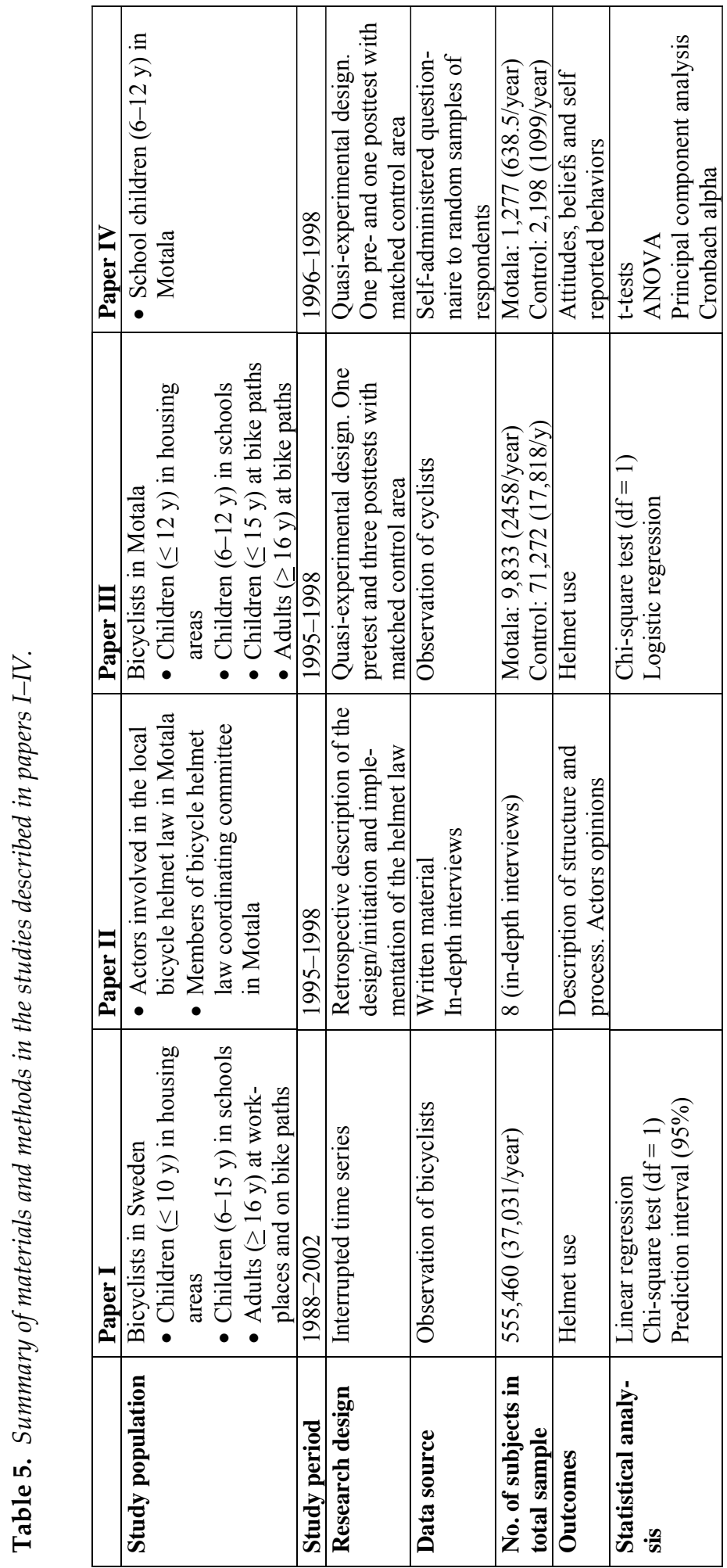




\subsection{Evaluation of a local bicycle helmet law in Mo- tala (papers II-IV)}

\subsubsection{General design of the evaluation}

The evaluation of the local bicycle helmet law in Motala comprised three studies. The first study (paper II) entailed qualitative evaluation of the structure and process of the Motala helmet law during the initiation and implementation of the initiative. The other two studies involved quantitative assessments of the helmet law, one based on observations of bicycle helmet wearing among children and adults (paper III), and the other using a questionnaire to record the attitudes, beliefs, and self-reported behavior of school children (paper IV). Both of the quantitative studies had a quasi-experimental design, with data collection in the municipality of Motala and in matched control areas, both before and after the intervention (Figure 15).

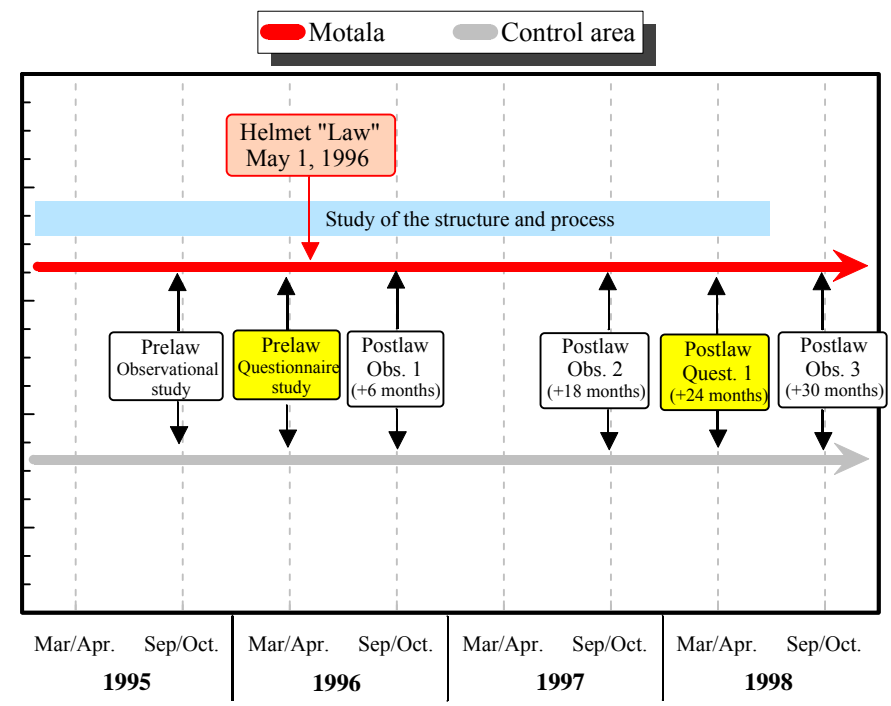

Figure 15. General design of the evaluation of the local bicycle helmet law in Motala.

\subsubsection{The Municipality of Motala}

Motala is a municipality in the western part of Östergötland County in Sweden. It has a population of about 43,000 , and $80 \%$ of the inhabitants live in the central residential area $(206,207)$. In 1990, Motala was designated a Safe 
Community by the World Health Organization (WHO), which implies that the municipality, in cooperation with local stakeholders such as agencies in the public health sector and various private organizations, is actively engaged in preventing injuries within the community (208). Today, there are more than 80 WHO Safe Communities around the world (209).

Injury prevention work within Motala Safe Community is organized according to the Five-Stage Community Organization Model for Health Promotion (210). This work was initiated in 1983, and the experiences of the first ten years of what is known as the Motala Injury Prevention Program have been reported by Lindqvist et al. (211). The idea to adopt a local bicycle helmet law in Motala originated from the activities of Motala Safe Community (paper II).

\subsubsection{The intervention program - the local bicycle helmet law in Motala}

Motala has had a local bicycle helmet "law" since May 1, 1996. The ordinance is still in force, but this ordinance is not compulsory or legally binding, because individual municipalities in Sweden are not allowed to enact their own laws. The Motala helmet law applies specifically to children (ages 6-12 years) while they are riding bicycles, but the explicit objective is to increase helmet use among all bicyclists in the municipality. The law was formulated by the Motala Municipal Council as follows:

"A local helmet "law" is to be introduced in the Municipality for pupils (age 6-12) with effect from 1 May 1996. The "law" is both a recommendation to those concerned that they should wear a helmet while cycling to and from school and in their leisure time, and it also implies some form of voluntary agreement between the schools and the pupils/parents concerning the use of helmets" (212).

The Motala helmet law initiative can also be described as a community-based, multistrategy, helmet-promoting program that has entailed not only introduction of the law itself, but also carrying out a large number of promotional activities (paper II). However, the intention of the Motala law is to increase voluntary use of bicycle helmets to a greater extent than can be accomplished by a traditional information campaign. The core of the initiative is to combine helmet promotion with the potential of a helmet law, but on a voluntary basis. The Motala law is based on an official political decision made by the Municipal Council, thus it should put pressure on the actors involved to make efforts 
to promote the use of helmets. In addition, calling this non-mandatory helmet initiative a "law" should send a signal to bicyclists in the municipality that helmet wearing is considered to be normal behavior. Hopefully, this strategy would also have a more extensive impact on normative beliefs about helmet wearing, such as reinforcing and predisposing factors in the PRECEDEPROCEED model and subjective norms in TPB.

Original assumptions about the potential impact of the helmet law are outlined in Figure 16. The helmet law is expected to have a direct effect on school children, since they represent the primary target group, but it should also have an indirect impact on all categories of cyclists through the helmet-promoting activities and the media publicity that could be anticipated. Furthermore, the members of different target groups probably influence each other, for instance, parents can urge their children to wear helmets, or adults can wear helmets to set an example for children. The Motala helmet law is intended to influence all bicyclists, but it is assumed that the greatest impact will be on school children, since this group is affected by both the helmet law per se and the promotional activities.

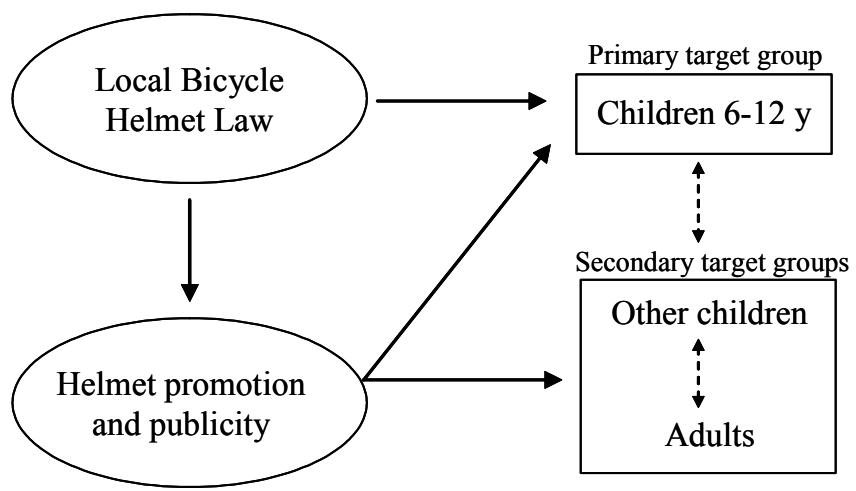

Figure 16. Schematic representation of the supposed effects of the local bicycle helmet law in Motala. Solid arrows depict the direct and indirect impacts of the law itself as well as helmet promotion and publicity; dashed arrows represent influences between target groups.

\subsubsection{Paper II}

This study describes how the work on the Motala helmet law was structured, what activities were carried out, and what actors were involved. It also reports the opinions of the most closely involved actors regarding issues related to the 
Motala bicycle helmet law. The study period (January 1995 to June 1998) comprised two staged of the work, the "design and initiation" and the "implementation" (210).

\section{Design and data collection}

The study is a retrospective description of the design, initiation, and implementation of the helmet law based on qualitative data from written material and in-depth, open-ended interviews with closely involved actors $(n=8)(213)$. The written material consisted of letters and printed communications, minutes of meetings, memos, newspaper articles and helmet promotion materials (e.g., fact sheets and brochures). Most of the material was provided by the Traffic Engineer and the Traffic Safety Information Officer in Motala and by the Municipal Registry or the Secretary of the Bicycle Helmet Law Coordinating Committee. The people interviewed were members of the Coordinating Committee. Each interview lasted 1-2 hours and was tape-recorded. An interview guide was used that included 12 open-ended questions supplemented with key words for follow-up questions.

\section{Analysis of data}

The written material was classified according to the structure and the process of the work on the Motala helmet law: structure refers to aspects such as how the work was organized and what actors were involved; process implies the type of activities that were performed, allocation of responsibilities, and the ways in which different actors participated. The actors were the people who took part in any decision or discussion concerning strategies, problems, or measures associated with the helmet law, and this group also included individuals who signed supporting documents related to the law. Description of the actors was focused on people involved in planning, implementation, or support, thus members of the target groups were not automatically classified as actors.

The interviews were analyzed qualitatively. In short, the interviews were transcribed and then a list was made of all the opinions that were expressed, and the opinions were subsequently classified into more or less comprehensive categories. This analysis was inspired by a phenomenographic approach that primarily considered variation in the experiences and opinions expressed by the respondents (214). 


\subsubsection{Paper III}

The study presented in paper III evaluates how helmet use by children and adults was affected by adoption of the local bicycle helmet law.

\section{Design and data collection}

According to a quasi-experimental design, helmet use by bicyclists was observed once before and three times after introduction of the helmet law, both in Motala (average $\mathrm{n}=2,458$ /year) and in control areas (average $\mathrm{n}=$ 17,818 /year). Pre-law observations were made seven months before the law took effect, and post-law observations were conducted approximately six, 18, and 30 months after introduction of the law. The observations focused on three categories of helmet users: children ( $\leq 12$ years) riding bicycles during leisure time in residential areas, children (6-12 years) bicycling to school, and all people riding bicycles on public bike paths. The third category was further divided into children (0-15 years) and adults (16 years or older). The observations were made at the same sites and times each year, using the method described in paper I.

Two different types of control areas were used depending on what category of bicyclist that was analyzed. Control data for children riding bicycles to schools were collected in three municipalities (Hässleholm, Katrineholm, and Västervik) that matched Motala with respect to population and the incidence of fatalities and injuries among bicyclists. The control data for the other two categories of bicyclists were gathered in the small and midsize towns included in the series of annual helmet observations (paper I) (182).

\section{Analysis of data}

Chi-square tests for two independent samples were used to separately evaluate the changes in bicycle helmet wearing from the pre-law to the post-law period in Motala and in the control areas. Logistic regression was used to analyze differences between Motala and the control area with regard to changes in bicycle helmet wearing. The criterion for assuming that the helmet law did have an impact on helmet wearing was a significant interaction $(\mathrm{p}<0.05)$ between the independent variables "intervention" (test/control) and "time of measurement" (1995-1998). 


\subsubsection{Paper IV}

The study presented in paper IV was performed to evaluate the effects of the local bicycle helmet law on attitudes, beliefs and self-reported behavior among children.

\section{Design and data collection}

A quasi-experimental design was used, and a questionnaire was sent to random samples of school children aged 6-12 years in both Motala and the control area 1-2 months before and two years after introduction of the helmet law. The control area comprised two municipalities (Hässleholm and Katrineholm) that matched Motala with respect to population and incidence of fatalities and injuries among cyclists.

The same procedure was used to select the subjects on both test occasions in Motala and the control area. At both test occasions separate random cluster samples were randomly selected from school classes and were subsequently stratified according to the age of children in the population and the size of the school attended. The total number of children chosen constituted about $20 \%$ of all children in the population. The total sample included 1,277 subjects in Motala and 2,198 in the control area. The average response rate was $76.5 \%$ in Motala and $79.3 \%$ in the control area (Table 6).

Table 6. Sample sizes and response rates in Motala and the control area.

\begin{tabular}{llrrrrr}
\hline & & \multicolumn{3}{c}{ Sample size and response rate } \\
\cline { 3 - 4 } \cline { 5 - 6 } \cline { 5 - 6 } Target group & & \multicolumn{2}{c}{1996} & & \multicolumn{2}{c}{1998} \\
pre-law (1-2 months) & & \multicolumn{2}{c}{ post-law (2 years) } \\
\cline { 3 - 6 } School children & Motala & 632 & 75.5 & & 645 & 77.5 \\
& Control & 1,156 & 83.7 & & 1,042 & 74.4 \\
& Totals & 1,788 & 78.3 & & 1,687 & 72.8 \\
\hline
\end{tabular}

Contact persons at each school administered the questionnaires. The subjects themselves answered the questionnaires individually, except that parents read the questions to younger children aged 6-9 years. The questionnaires consisted of multiple choice questions' comprising 49 items in total.

\section{Analysis of data}

To reduce the number of dependent variables in the questionnaire, principal component analysis (PCA) was used to evaluate the responses to different 
categories of items. Items with factor loadings $\geq 0.50$ were combined into indexes that formed new dependent variables. Eight separate PCAs were performed on the responses from children, which led to 10 composite dependent variables and explained $55-93 \%$ of the variance in the included items. The reliability of the composite dependent variables was tested using Cronbach alpha (215). Eight of the dependent variables consisted of only one item. A total of 18 dependent variables were included in the analysis. The variables were assigned to five comprehensive categories, inspired by the PRECEDE-PROCEED model (177) and the theory of planned behavior (TPB) $(195,197)$. For more details, see section 1.5.

Data were analyzed by t-tests for two independent samples to determine whether answers had changed after the helmet law compared to baseline, evaluating Motala and the control area separately. A two-way, betweengroups ANOVA was used to test for differences between changes in Motala and changes in the control area, which would indicate an effect of the Motala helmet law. The ANOVA was also used to test for average overall differences between Motala and the control area, regardless of which test occasion was considered. The criterion for statistical significance was set at $\mathrm{p}<0.01$, because a relatively large number of tests were conducted.

\section{Additional data and analysis}

Questionnaire data were also gathered from the parents and teachers of the included school children. This was done using the same design and collection method as applied to the children, which is not described in paper IV due to the limited length of that article. The parent group comprised one parent or legal guardian for each of the selected school children, hence the sample size was the same as for the children. The teachers consisted of the total population of teachers of children aged 6-12 years in the intervention area (pretest $n=162$, posttest $n=155$ ) and in the control area (pretest $n=292$, posttest $n=316$ ). The average response rates for the parents and teachers were, respectively, $72.7 \%$ and $68.1 \%$ in the intervention area and $76.6 \%$ and $66.6 \%$ in the control area. The data from parents and teachers were analyzed using the same procedure as applied to data from school children, except that responses given by teachers were not subjected to significance tests because they were based on population data. However, changes in the teachers' responses were compared by calculating standardized effect size, which is the difference between two means divided by the pooled standard deviation. As a rough rule of thumb 
(216), effect sizes could be classified as small (0.2), medium (0.5), or large (0.8), and an effect size $\geq 0.2$ was considered to be of interest. 


\section{$4 \quad$ RESULTS}

\subsection{Bicycle helmet use in Sweden (paper I)}

Considering the entire study period (1988-2002), there was a general upward trend in helmet use for all categories of bicyclists $(\mathrm{p}<0.01, \mathrm{p}<0.001)$. Helmet wearing increased from about $20 \%$ to $35 \%$ among children ( $\leq 10$ years) riding bikes in their leisure time, from approximately $5 \%$ to $33 \%$ among school children, and from around $2 \%$ to $14 \%$ in adults. Total average helmet use rose from about $4 \%$ to $17 \%$. However, during the last five years of the study period (1998-2002), there was no upward trend in helmet wearing for any of the categories of bicyclists (Figure 17). Among adult bicyclists, the rate of helmet use was about the same for men and women, whereas among younger children ( $\leq 10$ years) cycling in their leisure time, the rate was slightly higher for girls $(\mathrm{p}<0.001)$ than for boys $(\mathrm{p}<0.05)$. Also for adults, average total helmet use was higher in larger than in smaller cities $(\mathrm{p}<0.001)$.

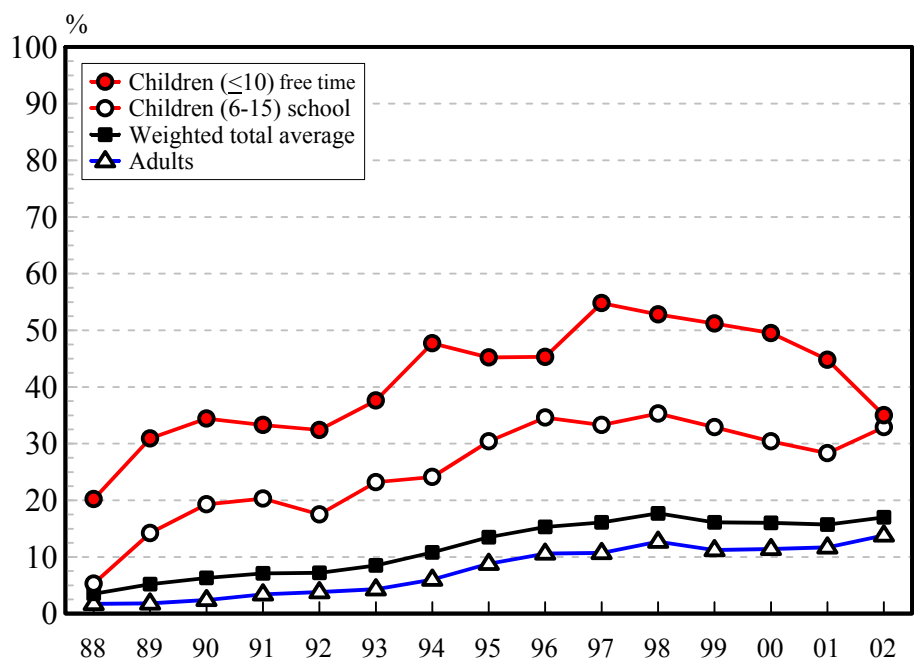

Figure 17. Observed helmet use in Sweden 1988-2002.

If the historic trend in helmet use continues, it can be estimated that an average of about $30 \%$ of bicyclists will wear helmets voluntarily by the year 2010 (Table 7). 
Table 7. Predicted helmet use in Sweden in 2010 based on linear regression of observational data for the period 1988-2002.

\begin{tabular}{lcc}
\hline Cyclist category & Predicted helmet use (\%) & P.I. (\%) \\
\hline Children (<10): free time & 64 & $42-86$ \\
Children (6-15): school & 51 & $36-65$ \\
Adults & 22 & $18-26$ \\
Weighted total average & 27 & $22-32$ \\
\hline
\end{tabular}

P.I. $=95 \%$ prediction interval

\subsection{Evaluation of the local bicycle helmet law in Motala (papers II-IV)}

\subsubsection{Structure and process during initiation and im- plementation of the intervention (paper II)}

During the study period, Motala was governed by a Municipal Council that was supported by different Executive Committees and Municipal Operators. There were also three groups concerned with traffic safety issues (Figure 18), one of which, the Bicycle Helmet Law Coordinating Committee, performed most of the work on the bicycle helmet law. This committee had eight members: one municipal politician, three municipal officials, two national officials, and two external researchers.

During the study period, a total of 134 people representing 19 different organizations were involved in the work on the Motala bicycle helmet law. Of these, $53 \%$ were municipal politicians, $16 \%$ were municipal officials, and $31 \%$ were external officials. The activities of the actors varied from affecting municipal resolutions related to the helmet law, to discussions about different helmet law issues. The routine operative work on the law was done by six to eight people. 


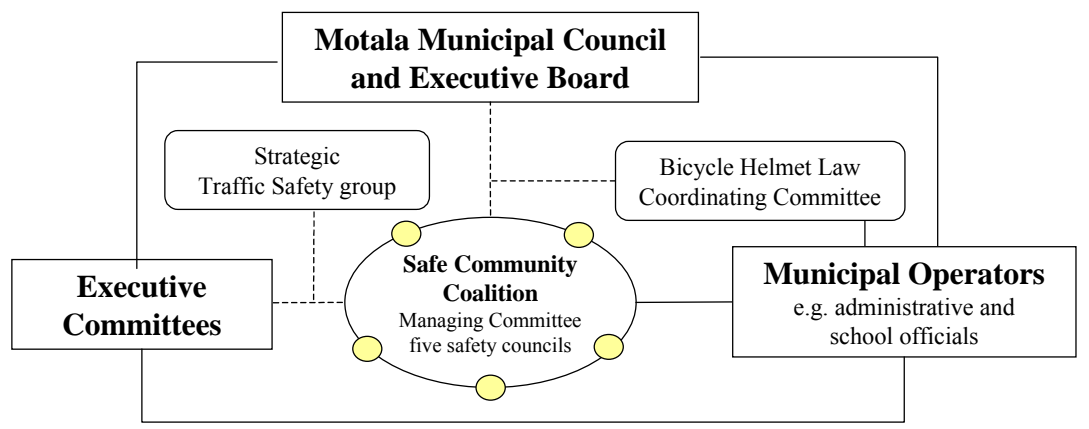

Figure 18. The structure of the work on the bicycle helmet law in Motala. Solid and dashed lines respectively indicate official and unofficial connections.

During the design and initiation phase, work on the helmet law was done chiefly by a single Municipal Commissioner, who gained political support for the law. The law was passed in June 1995, and it came into effect in May 1996. The decision to introduce the law was supported by the Swedish Helmet Initiative (217).

The different actions taken during the design and initiation phase and the implementation phase were assigned to the following six categories: basic organization and planning of the work; political decisions and discussions; information about the law; helmet law promotion activities; basic helmet promotion activities; media publicity. These activities have been described in more detail by Nolén and Lindqvist (218).

The analysis of both the written material and the interviews with closely involved actors revealed that several problems dogged the work on the helmet law, especially during the design and initiation phase. The main difficulties were that the helmet law was not properly rooted in the schools and that there were shortcomings in clarification of the roles and responsibilities of various municipal groups in bicycle helmet issues. Several of the problems were probably due to a "political scandal" and loss of certain key members of the Coordinating Committee during the initiation phase. Moreover, the difficulties were probably the cause of a lack of helmet-promoting activities during the first six post-law months. For instance, no intensified helmet promotion was done in connection with introduction of the law, and the "helmet contracts" established between children, schools, and parents did not work as planned. However, about $70 \%$ of all media publicity on the helmet law occurred during the first six months after the ordinance was introduced, and during this period 
the politicians required the schools to report what actions they had taken to ensure that the law was obeyed.

Most of the interviewed actors felt that the helmet law had boosted the interest in traffic safety issues, as well as the cooperation between individuals and organizations within the municipality. There was also extensive helmet promotion during the study period, which probably would not have been the case if the local helmet law had not been adopted. Therefore, the results presented in paper II indicate that local bicycle helmet laws of this type should have the potential to make a long-lasting impact on helmet use, provided that some of the problems encountered can be avoided and some of the promotional activities are intensified.

\subsubsection{Effects on helmet use (paper III)}

During the first six months post law, helmet wearing in Motala increased among school children (6-12 years) and adults riding bicycles on bike paths: from $65 \%$ to $75.7 \%(\mathrm{p}<0.001)$ and from $1.8 \%$ to $4.5 \%(\mathrm{p}<0.001)$, respectively. During this period there was also a non-significant tendency towards increased helmet use among children on bike paths in general and when bicycling during their leisure time in residential areas. However, for most categories of bike riders, helmet wearing decreased gradually after six months. After two and a half years, the wearing rate was at about a pre-law level for school children and was even lower for children cycling during leisure time or on bike paths. Only among adults riding on bike paths did helmet wearing continue to increase to $7.6 \%$ at the end of the study period $(p<0.001)$.

Including data from the control area in the logistic regression analysis indicated that, during the first six months, the local helmet law in Motala had a positive effect on school children (the primary target group) and a delayed but more long-term positive impact on adult bicyclists (Figure 19). There was also a positive effect on helmet use among all cyclists on bike paths the first six months after the law $(\mathrm{p}<0.01)$. Nonetheless, the law did not have a positive influence on children riding bicycles on bike paths or in their leisure time in residential areas. 

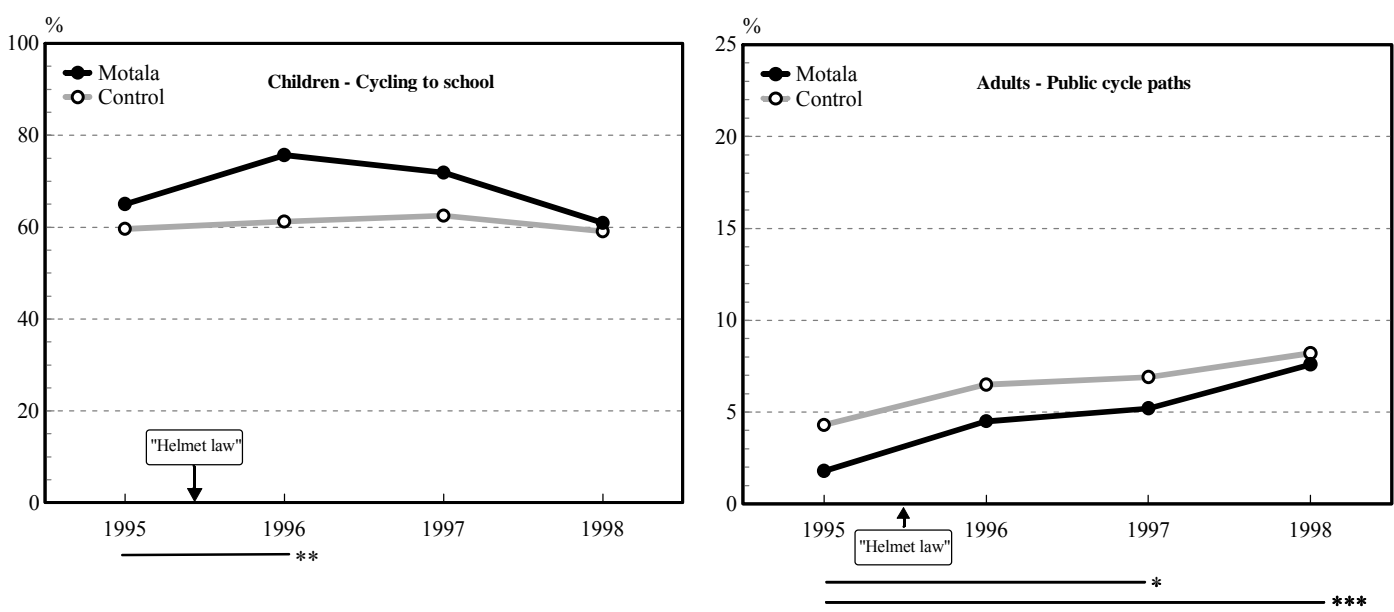

Figure 19. Trends in bicycle helmet use shown for school children and adults on bike paths. ${ }^{*} p<0.05,{ }^{* *} p<0.01,{ }^{* * *} p<0.001$ according to logistic regression of the interaction between the intervention factor and the time factor).

\subsubsection{Effects on children's attitudes, beliefs, and self- reported behavior (paper IV)}

Both before and after the intervention in Motala, most of the children experienced exposure to bicycle helmet information and were positive to helmet use and compulsory helmet laws. Most of them also owned a helmet and said they always wore one when riding a bicycle (Table 8). There were three significant changes in the responses of the children in Motala after the intervention: they agreed less with statements indicating that bicycle helmets are relevant only for children $(p<0.01)$ and are more important for children $(p<0.01)$, and they indicated that they would be much more inclined to ride a bicycle if a national compulsory helmet law was passed $(\mathrm{p}<0.001)$. However, when these changes were adjusted for changes in the control groups, the helmet law in Motala had only one positive long-term effect, namely, the stronger intention to ride a bicycle if a national compulsory helmet law is introduced $(p<0.001)$. This is well illustrated by the following: at the pretest, most of the children in Motala said that their bicycling would not be affected by introduction of a national helmet law, whereas at the posttest their intention had changed dramatically, and a large majority said they would ride a bicycle more often if a national helmet law were adopted. 
On average, over both test occasions, the responses of the children in Motala were often "better" compared to the control groups. In general, children in Motala reported more favorable attitudes and beliefs about helmet use, and they perceived a stronger social norm for helmet wearing. Furthermore, they said they were more inclined to wear bicycle helmets, and there was a higher rate of self-reported helmet use in this group. Since there were no differences in demographic variables between Motala and the control area, the overall differences in responses were probably caused by helmet promotion actions taken in Motala before the pretest. However, the results suggest that helmetsupporting activities related to the Motala law that were carried out between the pretest and the posttest did not have any major long-lasting effects on the variables related to the PRECEDE-PROCEED model (see section 1.5) for children, that is, helmet-associated attitudes, beliefs, and self-reported behavior.

Table 8. Questionnaire responses (\%) to selected items given by school children in Motala before and after introduction of the local bicycle helmet law.

\begin{tabular}{|c|c|c|c|c|c|}
\hline \multirow[b]{2}{*}{ Variables } & \multicolumn{2}{|c|}{ Before } & \multicolumn{2}{|c|}{ After } & \multirow[b]{2}{*}{$\mathrm{p}$} \\
\hline & $\%$ & $\overline{\mathrm{n}}$ & $\%$ & $\overline{\mathrm{n}}$ & \\
\hline \multicolumn{6}{|l|}{ Predisposing factors } \\
\hline Exposed to helmet info. previous six months & 71.4 & 475 & 75.0 & 491 & \\
\hline Positive to own helmet use & 94.5 & 476 & 96.1 & 491 & \\
\hline Positive to helmet use by other children & 99.2 & 474 & 99.4 & 492 & \\
\hline Positive to helmet use by adults & 94.2 & 469 & 97.4 & 488 & \\
\hline Positive to helmet laws for children & 83.4 & 475 & 86.0 & 491 & \\
\hline Positive to helmet laws for adults & 76.6 & 474 & 80.0 & 490 & \\
\hline Helmet use is relevant only for children & 15.8 & 461 & 7.4 & 484 & $<.01$ \\
\hline Helmet use is more important for children & 52.1 & 470 & 43.8 & 483 & $<.01$ \\
\hline \multicolumn{6}{|l|}{ Reinforcing factors } \\
\hline Think most peers use helmets & 78.0 & 473 & 79.3 & 489 & \\
\hline \multicolumn{6}{|l|}{ Enabling factors } \\
\hline Own a helmet & 97.7 & 476 & 98.4 & 499 & \\
\hline \multicolumn{6}{|l|}{ Intention } \\
\hline Will wear helmet next time riding a bicycle & 82.8 & 476 & 83.2 & 495 & \\
\hline Will bike more often if helmet use mandatory & 8.7 & 473 & 90.4 & 481 & $<.001$ \\
\hline \multicolumn{6}{|l|}{ Self reported behavior } \\
\hline Always wear helmet when biking in general & 72.0 & 465 & 71.5 & 495 & \\
\hline Always wear helmet when biking to school & 75.7 & 272 & 74.8 & 286 & \\
\hline
\end{tabular}

${ }^{1}$ Significant difference between means before and after the intervention (t-test)

\section{Additional findings}

The results of the additional analysis of parents and teachers (see section 3.2.6) showed that there were several positive changes compared to baseline in Motala after the helmet law was introduced. These changes among parents included perceiving the following: more exposure to helmet information 
$(p<0.001)$, more positive beliefs about the comfort of helmets $(p<0.01)$, less of a social norm against helmet use $(\mathrm{p}<0.01)$, more extensive helmet use among other adult bicyclists $(\mathrm{p}<0.01)$, and helmets were perceived less expensive $(p<0.01)$. Among the teachers in Motala, there were three major positive changes compared to baseline (effect size $\geq 0.2$ ): they perceived that there had been an increase in helmet use among children and among other adults, and they said they used helmets more often themselves. However, when the changes for parents and teachers were adjusted for changes in the control groups, the helmet law in Motala had few positive long-term effects on selfreported behavior or on factors supposed to precede their behavior. Those positive effects were as follows:

- Parents experienced an increased exposure to helmet information

- Parents perceived helmets as less expensive

- Teachers were more positive to helmet use by children

As was the case for children, the overall responses of parents and teachers in Motala (on average over both test occasions) were often "better" than the responses in the control groups. In general, both parents and teachers in Motala perceived a stronger social norm favoring helmet use, and they had a higher rate of self-reported helmet use and helmet ownership. Furthermore, compared to the controls, on average the teachers in Motala felt they had been exposed to more helmet information, they were more positive to the idea of wearing a helmet themselves, and they indicated a stronger intention to use a helmet in the future. 


\section{DISCUSSION}

The focus in this thesis is about the needs and possibilities of increased bicycle helmet use in Sweden. Most of the following discussion is, however, considered to be valid also for other countries that have a similar traffic safety problem for bicyclists and where the voluntary helmet wearing is low.

\subsection{Is it necessary to increase the use of bicycle helmets in Sweden?}

The ultimate aim of bicycle helmets is to save lives and prevent head injuries. In Sweden, there has, however, been a downward trend in bicycle-related fatalities for many years. In light of that positive trend, perhaps it will be possible to solve the traffic safety problem among bicyclists without increasing the use of helmets? The answer to that question is probably no. The number of bicyclists killed each year is still too high to satisfy the previously mentioned vision zero $(6,7)$, and there is no similar positive trend in the number of injuries among bicyclists, and head injuries still represent a major traffic safety problem in this group of road users.

The decreasing trend in bicycle-related fatalities in recent years has occurred mainly in urban areas (219), where most cycling exposure takes place (220). The decreasing trend in fatalities and in the number of bicyclists hospitalized after a collision with a motor vehicle is probably explained by a safer traffic environment for bicyclists. For instance, from 1998 to 2002, roads with a speed limit of $30 \mathrm{~km} / \mathrm{h}$ has increased, and cycling exposure increased on bike paths as compared to roads used by all kinds of vehicles (221). However, during the same period, there has been no apparent downward trend in the number of bicyclists hospitalized due to single accidents (i.e., no motor vehicle involved). Single accidents are also responsible for the majority of bicycle-associated head injuries that require hospital care (22). It is important to continue to improve the traffic environment for people riding bicycles, but obviously, it will not be possible to avoid most of the head injuries that occur in this category of road users without increasing the rate of helmet wearing.

The objective of increasing helmet wearing among bicyclists has been given high priority by authorities and politicians responsible for traffic safety in Sweden $(7,222,223)$. A national traffic safety program for 1995-2000 stated 
that the official goal was to achieve an average helmet wearing of about $80 \%$ among bicyclists (224), but, the use of helmets is still relatively low. A majority of people who ride bicycles in Sweden do not wear helmets (paper I). Nonetheless, there has been a trend towards increasing helmet use from 1988 to 2002 among both children and adults, and the average wearing rate rose threefold during the 1990s. Despite that, over the last five years, the average rate of helmet wearing has been around $15-20 \%$, which is much below the official goal of $80 \%$. The observational results reported in paper I can not be automatically generalized to a national level or to all parts of the year. To achieve such generalization would require observational data from a large number of randomly chosen places and times, which was not possible due to limited resources. However, in 1995-1999, the Swedish Road Administration (SRA) conducted supplementary observational studies at about 1,700 randomly selected sites, and the results were very similar to the findings described in paper I, with respect to changes in helmet use and to the absolute level of use (225). Both the SRA study and the observational study in paper I were carried out in urban areas and during the latter part of the bicycle season, therefore it can be assumed that the data in paper I do adequately represent average helmet wearing in Sweden in urban areas during that particular time of the year. The use of helmets does, however, vary between different cities in Sweden. In general, the wearing rate is higher on public bike paths in large cities, although there are also differences in those rates between the large cities themselves, for instance 5\% helmet wearing has been observed in Malmö, 30\% in Göteborg, and 50\% in Stockholm (182, 226-228).

Self-reported information from questionnaires about bicycle helmet wearing is also collected on a regular basis in Sweden. An advantage of questionnaire data is that the use of helmets can quite easily be related to demographic variables such as age and gender, whereas a potential disadvantage is the risk that bicyclists will overestimate the rate of helmet wearing. There are large discrepancies between observational and self-reported data, particularly regarding the use of helmets by children in Sweden. For example, according to selfreported data from parents, about $80-90 \%$ of children up to the age of 12 years always or almost always wear a helmet when riding a bicycle (229), whereas the corresponding observational data indicate an average wearing rate of only $52 \%$ for that age group (paper I). A plausible explanation for the differences in wearing rates is that parents overestimate how often their children use a helmet. However, it may also be true that most younger children only occasionally wear a bicycle helmet, but such individual irregularity is difficult to 
measure in observational studies. At the end of the 1990s, the average selfreported helmet wearing by adult bicyclists was about five percentage points higher than the observed use of helmets (230).

The present research addressed the issue of whether there is a real need to increase bicycle helmet wearing in Sweden, and the answer to that question is definitely yes. The need is motivated from the perspective of traffic safety and also in light of the official goal of bicycle helmet wearing that was proposed by the former Swedish National Traffic Safety Program. Helmet wearing should be boosted among both children and adults, although the need is more prominent for adults. A majority of bicycle-related fatalities and head injuries in Sweden occur in adults, and, notably, there is a lower rate of helmet wearing in that age group compared to children. In contrast, children constitute a larger proportion of the injured bicyclists in some other countries, which might explain why many helmet programs in those nations have focused only on children. This is particularly evident in the United States, where, for instance, all statewide bicycle helmet laws apply solely to children. Despite that, injury statistics show that adults constitute a majority of the annual bicycleassociated deaths in the United States $(231,232)$, which indicates that the bicycle helmet programs and laws should target all people riding bicycles, not just children.

The need for increased helmet wearing among adult cyclists in Sweden, and probably other countries as well, is motivated from a societal perspective. The traffic safety potential of increased wearing of bicycle helmets is greatest for adults, if it is illustrated in absolute terms, for example in numbers of fatalities and injuries. However, considering individual bicyclists, the need for increased helmet use is largest among older people and children, because they are at substantially greater risk of being killed or sustaining head injuries compared to other age groups. When a conflict arises between a societal and an individual perspective in the context of injury prevention, it is sometimes referred to as a "prevention paradox". If a minority of the members of a population is at high risk of injuries and the majority is at moderate risk, then preventive actions targeting high-risk groups will have a large effect on those individuals but a small effect on the population as a whole. On the other hand, if preventive actions are focused on moderate risk groups, the impact will be greater on a population basis (233). According to vision zero it is also important to argue for injury prevention strategies based on a societal perspective. 


\subsection{Different strategies for increased helmet use}

In principle, one of the following strategies can be used to increase helmet wearing among bicyclists:

1. Perform helmet promotion to influence voluntary use of helmets.

2. Introduce a helmet law that makes helmet wearing mandatory.

3. Combine helmet promotion with a helmet law.

According to the literature review presented in section 1.4, the first strategy can markedly increase helmet wearing. However, the success of helmet promotion alone has varied a great deal and has seldom led to more than 50-60\% helmet use among children/young people and approximately $30 \%$ for adults. In contrast, the third strategy of combining a law and promotion often results in substantial and sustained increases in helmet use. As illustrated in section 1.4.1, that approach has led to average helmet wearing of about $80-90 \%$ in Australia and New Zeeland and 50-80\% in North America.

The research findings described in section 1.4 were obtained primarily in studies that were regarded as relevant for evaluating bicycle helmet interventions, but also former reviews have been used as a valuable foundation $(41,71,234$ 238). Formal, systematic reviews frequently select studies on the basis of strict inclusion criteria, which often specify the quality of the study design and therefore limit the number of studies that can be included in the final analysis (239). Cochrane reviews are one type of systematic reviews that are commonly used in the field of injury prevention (240). The inclusion criteria used in section 1.4 were based on perceived relevance and not strictly on the type of study design, which means that the conclusions might have been biased because the review could include studies of low quality. Conversely, the risk of using very rigorous inclusion criteria is that new interventions with potential effects could be missed. Notwithstanding, the general conclusions arrived at in section 1.4 agree well with the findings of other reviews conducted in recent years $(27,241-244)$, one of which was also a systematic review (26).

\subsubsection{Helmet promotion}

Helmet promotion seems to have the best effect on voluntary helmet use when it is conducted as community-based programs over several years, and when the local and regional activities are supported by helmet promotion on a national level. The helmet programs should use a multi-strategy approach, for 
instance including information and education combined with helmet subsidies and reward/incentive systems, such as offering a free helmet to people who sign a helmet contract that commits them to wearing a helmet when riding a bicycle $(164,165,184,185)$.

Several of the countries and states that have introduced bicycle helmet laws also had clearly increasing pre-law trends in helmet wearing. This has been most evident in Victoria in Australia and New Zealand, where systematic helmet promotion was successful quite some time before the helmet laws were passed $(93,94,116)$. However, from a scientific perspective, it is difficult to prove any causal relationships between helmet promotion activities and increased wearing rate on a national or state level. In such situations, it is seldom possible to perform randomized controlled experiments. Nonetheless, it is reasonable to assume that a definite trend towards increased helmet wearing reflects the combined influence of all helmet promotion activities during the period in question. This assumption also seems to apply to the increased wearing of bicycle helmets seen in Sweden during the 1990s (paper I).

The most intensive period of helmet promotion in Sweden so far was 1994 to 1998 (paper I). Every spring from 1995 to 1998, media campaigns about bicycle helmets were carried out that were mainly aimed at adults (188-190). The national actions were also coordinated with helmet promotion at the regional and local levels. Furthermore a Swedish Bicycle Helmet Group was formed at the beginning of the 1990s, after a global call by the World Health Organization (217). The aim of this group was to act as a national forum in which authorities and organizations could exchange information on helmet issues. During the 1990s, the group disseminated booklets about helmet wearing and also arranged two national bicycle helmet conferences $(245,246)$. There is not necessarily any causal relationship between helmet promotion activities and changes in helmet wearing, although it does seem that the increasing trend in average helmet use in Sweden from 1988 to 1998 corresponds fairly well with helmet activities conducted at the national level during that period (paper I). In addition, the downward trend seen after 1998 coincides with the lack of major information campaigns (Figure 20). 


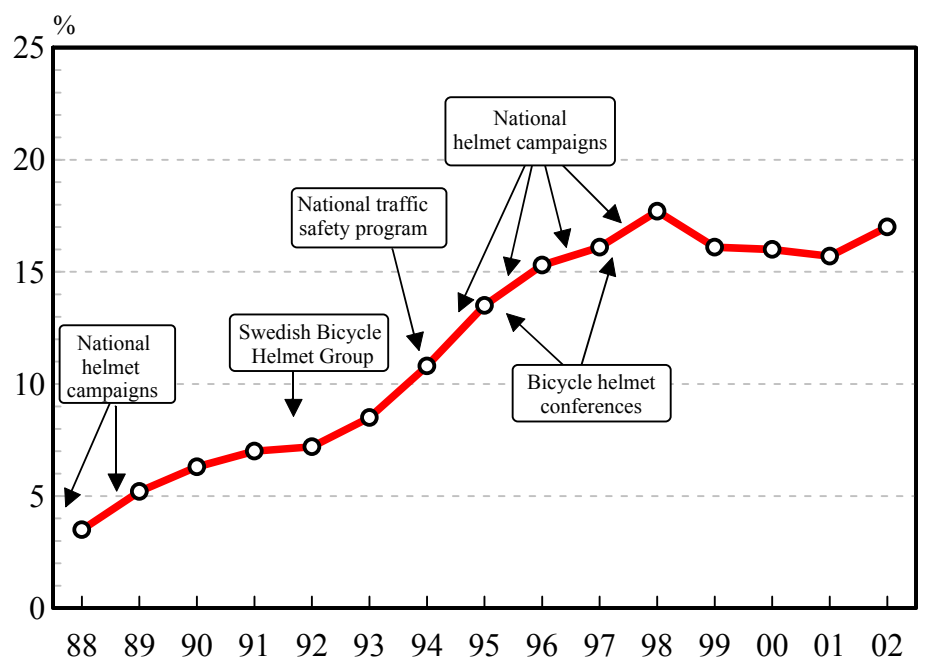

Figure 20. Observed average bicycle helmet use in Sweden and helmet promotion activities conducted at a national level during the period 1988-2002.

\subsubsection{Compulsory helmet laws}

Helmet laws are often evaluated by comparing pre-law and post-law data, and, in some but not all cases, control areas are included. Hence, it is obviously possible that helmet use or injuries among bicyclists can be influenced by confounding factors, e.g. factors other than the helmet law per se. Nonetheless, the changes in helmet use that have been reported after passing helmet laws have usually been very definite, and they have often appeared directly after the laws took effect, thus it is reasonable to presume that they were caused by the laws. Experiences of legislation concerning safety belts or motorcycle helmets also show definite positive effects on levels of usage and injuries (247). The influence of bicycle helmet laws on wearing rate also seems to be sustained over a period of several years, which is well illustrated by observations made in New Zealand (116-118). Unfortunately, post-law observational studies covering more than four years of helmet use have not been performed in Australia. However, if there had been a significant decrease in helmet use after a longer period of time, it probably would have been noticed even without systematic observational studies, and it might also have prompted initiation of new series of observational studies. 
The literature review (see section 1.4) showed that laws mandating the use of bicycle helmets can be more effective than helmet promotion alone. It is possible to reach sustainable average wearing rates of about $80 \%$ if legislation applies to all bicyclists and is combined with helmet promotion. It is also important that a helmet law is accompanied by a system of sanctions and some type of enforcement (85). But why is bicycle helmet wearing affected to a greater extent by combined legislation-promotion than by promotion alone? One explanation according to both the PRECEDE-PROCEED model and TPB is that a bicycle helmet law exerts extra influence on the reinforcing and predisposing factors in the former model and on the subjective norm in the latter. All these factors are related to normative beliefs concerning what other people think about a particular behavior. A bicycle helmet law is also a "signal" from society that helmet wearing is the norm, and that it should affect the way we perceive other people's attitudes towards bicycle helmets. Among bicyclists who have considered wearing a helmet but have not yet made up their minds, a helmet law could also be an additional argument that tips the scales in favor of helmet wearing. Furthermore, helmet legislation that includes a system of sanctions is probably regarded as a barrier against violating the law, e.g. not using a helmet. It should therefore be an enabling factor according to the PRECEDE-PROCEED model, and it should also influence perceived control in the TPB model.

Helmet laws have, however, certain potential drawbacks. Ever since the first helmet law was introduced in Australia, there has been an international debate between those who support and those who oppose such laws. The most widespread argument against introducing a helmet law is the risk that it can have a negative impact on bicycling, which in the long run could be detrimental to public health due to decreased physical activity. Several opponents of helmet laws have argued that that has indeed been the case in Australia, and that that effect outweighs any possible reductions in head injuries (248-254). There are no reports in the literature indicating that the potentially negative effects of helmet laws on bicycling have been debated in New Zealand or the United States. However, that subject has been examined in studies conducted in Australia and Canada (46, 108, 110, 115, 139-141), but the results do not consistently agree with the ideas stated by the opponents of helmet laws. However, international findings indicate that there is a risk of reduced cycling among teenagers, but not among younger children and adults. 
Some of the opponents of bicycle helmet laws are also critical to activities aimed at promoting voluntary use of helmets, because they assume that helmet wearing per se gives a false sense of security and leads to risk compensation (255-258). Risk compensation may be a general phenomenon in the area of traffic safety, although injury prevention measures usually have a positive net effect $(259,260)$. It is difficult to focus experimental studies on a supposed causal relationship between bicycle helmet use and risk compensation, thus it is not surprising that no such studies have been found in the literature. However, one correlation-based study has indicated that helmet wearers take fewer risks in traffic compared to non-wearers (261). It has also been reported that other types of risk behavior, like smoking and gambling, are associated with a low rate of bicycle helmet wearing (27). Furthermore, Thompson et al. (262) have estimated that it would be necessary for bicycle helmet wearers to increase their risk behavior in traffic about fourfold in order to cancel out the injury-preventing effects of helmets, but they think it is unlikely that such a change would actually occur.

\subsection{Is a non-compulsory local helmet law an ap- propriate alternative to a national helmet law?}

Compared to a real national law, an advantage of a local non-compulsory helmet law is that it can more easily gain the acceptance of politicians and bicyclists, and it also avoids the need for administration of enforcement and imposing fines. The initiation of the helmet law in Motala proceeded without much political opposition (218). Formally, the Motala helmet law applies only to children ages 6-12 years, although the goal is to increase helmet wearing among all bicyclists in the municipality. The reason the law does not officially include all people riding bicycles is probably that that would have made it very difficult to achieve political acceptance. The primary intention was, however, to gradually extend the helmet law to formally embrace teenagers and adults as well (paper II).

A disadvantage of a non-compulsory helmet law is that it could be toothless and therefore not taken seriously. If that is the case, such initiative might not be more effective than an ordinary helmet promotion campaign. Nevertheless, even if the Motala law is not legally binding it has resulted in substantial media publicity and many helmet promotion activities, which probably would not have occurred if the helmet law had not been introduced (paper II). Another possible drawback with a "voluntary" law is that it could lead to a nega- 
tive debate about the initiative, and it might also make bicyclists less inclined to wear helmets than they were before the law took effect. However, there is no evidence of such negative side effects in Motala. The publicity of the nonmandatory helmet law comprised either neutral information or positive criticism (paper II), and there is no indication that the law has led to more negative attitudes or beliefs among people riding bicycles in Motala (paper IV).

The helmet initiative in Motala is formally referred to as a local bicycle helmet law, and it might be asked whether it is correct to use such a designation. The word "law" means "to decide" or "to stipulate," and we usually distinguish between descriptive laws (e.g., natural laws) and normative laws (e.g., legal laws) (263). A law is traditionally a constitutional decision made by the parliament. Legally binding decisions can also be made by municipalities, but they can apply only to certain matters and are called regulations (263). However, the local bicycle helmet law can not be referred to as a regulation, because it is not legally binding. The word "recommendation" is also included in the municipal decision to introduce the Motala helmet law, which may be a more correct term in this context, because it can signify a non-mandatory, normative resolution (263). Nevertheless, the helmet law initiative represents a formal decision made by the municipal council, and it would therefore be misleading to call it an ordinary helmet campaign. Traditional helmet promotion alone had also been tested for quite some time in Motala before considering inception of a law (218), but it had not been sufficiently successful, according to the chairman of Motala Safe Community, who took the initiative for the local helmet law (paper II).

The Motala helmet law initiative can also be looked upon as a municipal "policy." A policy can be described as an "official guideline" (264) that, in contrast to a specific project or a program, does not usually have a deadline or a budget (265). Furthermore, a policy does not comprise single decisions or actions, but is instead comprehensive in that it includes the official intentions and the actions that are taken, as well as the actions that are deliberately not taken (264, 266). If the helmet law in Motala were to be called a policy, it would have to cover the entire process from initiation to implementation. According to Vedung (267), there are three basic policy instruments that can be used for interventions: regulations, economic means, and information. The category called regulations includes true laws that require people to act in the way that is stipulated, and they often (but not always) have a system of sanctions (267). The initiation and implementation of the bicycle helmet law in Motala incor- 
porated at least two of the mentioned policy instruments-information (helmet promotion activities) and economic means (helmet subsidies). Whether or not the regulation instrument is used in the Motala initiative depends on which target group you refer to. No regulations have been applied to individual bicyclists in Motala, but the traffic safety actors in the municipal organization should feel obligated to implement the "helmet policy."

Even if it may be incorrect to call the Motala helmet initiative a law, such a designation has probably had several advantages. This initiative is unique in Sweden, and it led to a considerable amount of publicity, both locally and nationally, during the first six months after the law was introduced (paper II). Most of the publicity focused on the issue of adopting a local helmet law, and would probably have been less extensive if the initiative had been called a local helmet campaign or policy (218). The opinions about referring to the initiative as a law varied among the most closely involved actors, although a majority of them did eventually accept the word "law" (paper II).

During the first six months after the helmet law was introduced, there was a positive effect on helmet wearing among children riding bicycles to school, and also a delayed but weak long-term effect on adults (paper III). There was no positive influence, and perhaps even a negative influence, on children's recreational cycling (e.g., on bike paths or in residential areas). However, the data on children in residential areas are difficult to interpret, because there were large pre-law differences in helmet use between Motala and the control area, which indicates poor comparability for this category of cyclists. The estimated helmet use by children during recreational cycling in Motala is also more sensitive to occasional variations, because it is based on a lower number of observations than for the other categories of bike riders. In addition, these categories of observations are more sensitive to errors in estimation of the children's age than is the case for children riding to primary schools and adults riding on bike paths (268). It is possible, but not likely, that the law in Motala has had a negative effect on children's recreational cycling. For instance, if negative effects had been due to an adverse reaction to the helmet law (e.g., owing to lack of acceptance), wearing of helmets ought to have decreased directly after the law was introduced, since publicity in the media was most intensive at that time. However, there was instead an increasing tendency in helmet use during that period (paper III). Furthermore, there was no tendency to express negative attitudes or beliefs about helmets or helmet laws among the affected children or their parents (paper IV). 
It is an advantage if a helmet program can be based on a theoretical model of the factors underlying a person's choice of using a bicycle helmet, e.g. the PRECEDE-PROCEED model or the theory of planned behaviour (TPB) (163, $178,203)$. One successful example of a long-term, theory-based helmet program applied to children on a community level is the one conducted in Montérégie, Canada (51). During the initiation phase of that program, results were available from a questionnaire study guided by the theory of reasoned action (198), which described children's beliefs about wearing helmets (81). Unfortunately, there were no similar data available on relevant beliefs about helmet use among cyclists in Motala during the initiation of the helmet law. Such data would have made it easier to adjust the content of the supportive promotion activities to meet the needs of different target groups. According to $\mathrm{TPB}$, it is important to have access to these salient beliefs in order to establish strong relationships with intentions and behavior (195-197). Furthermore, it seems to be particularly important that helmet programs are related to reinforcing factors or people's subjective norms, e.g. beliefs about what other people think about your helmet wearing. Negative normative beliefs, such as perceiving negative peer pressure against helmet wearing, are often the reasons why many bicyclists, especially teenagers, do not use a helmet $(67,70,72-75$, $78,203,204)$.

The type of helmet promotion activities that were implemented in Motala during the study period were related to the predisposing, reinforcing, and enabling factors of the PRECEDE-PROCEED model. However, the majority of the activities consisted of providing different types of information and was hence related to predisposing factors (paper II). But the decision to adopt a municipal helmet law and the helmet contracts with school children and adults were related to reinforcing factors. There were also subsidized helmets for children and free helmets for adults, which could be categorized as enabling factors. It probably would have been better if more of the promotion activities that were implemented had been related to reinforcing factors, for example more rewards or incentive systems to promote helmet wearing. Also, the helmet contracts with school children did not turn out as planned: less than one percent of the contracts were signed, probably due to shortcomings in support from the schools (paper II). Other studies have found that helmet contracts can increase helmet wearing among adult cyclists (164), but such an approach might not be suitable for younger school children. 
Data from the questionnaires administered two years after the helmet law in Motala showed that there was no significant effects on the three factors in the PRECEDE-PROCEED model when considering the primary target group, school children 6-12 years of age (paper IV). Moreover, there were only a few positive effects on the children's parents and teachers. The overall findings of the questionnaire are disappointing, but they concur with the results of the observational study of helmet wearing among school children two and a half years after introduction of the law, which also demonstrate the lack of any long-term effect (paper III). However, the questionnaire study did show that most of the children and their parents and teachers were already very positive to the use of bicycle helmets before the helmet law was adopted in Motala. It would have been very difficult to improve the children's attitudes and beliefs about bicycle helmets when approximately $95 \%$ of those subjects already owned a helmet and were positive to use it. Furthermore, an average of $68 \%$ of younger school children in Motala was observed to use helmets during the entire study period (paper III). Even if this indicates that one third of the children did not wear a helmet, it would probably have been difficult to increase those rates very much simply through helmet promotion, especially since a definite majority of the subjects in the target group already had positive attitudes towards such practice. The pre-law wearing rate in Motala was also high compared with the rates achieved by successful helmet programs for children in other countries. Two examples of such programs are as follows: the Seattle Bike Helmet Campaign in the United States, which succeeded in increasing helmet use among children aged 5-15 years from about $5 \%$ to $60 \%$ over a tenyear period $(170,242)$; and the four-year helmet program for school children aged 5-12 in Montérégie, Quebec, Canada, which led to a rise in voluntary helmet wearing from about $1 \%$ to $33 \%$ (51).

Compared to the control group, the questionnaire respondents in Motala had overall more favorable attitudes and beliefs about helmet use and they also perceived stronger social norms for helmet wearing (paper IV). Because there were no differences in demographic variables between Motala and the control area, the overall differences in attitudes and beliefs can probably be explained by helmet promotion activities conducted in Motala before the pretest. It would have been valuable to have performed more than one pretest in the questionnaire study, since that would have made it possible to detect pre-law trends in attitudes and beliefs among bicyclists in Motala. However, that was not possible due to limited resources. Furthermore, the pretest in the questionnaire study was carried out only about one month before the helmet law 
was introduced, which might have been too late, because the political decision to adopt the law had already been made, and some preliminary information activities had been conducted (paper II). It is possible that these preliminary activities did have significant positive effects on the attitudes and beliefs of school children in Motala, but that the effects were concealed in the evaluation due to the late pretest. Still, that explanation does not seem plausible, since most of the helmet promotion activities and publicity occurred after the pretest, and also a majority of the school children in the control group were positive to bicycle helmet wearing at the time of the pretest.

The questionnaire study showed one obvious effect of the Motala helmet law: a markedly increased proportion of school children in the municipality said that they would ride bicycles more often if a real helmet law was introduced (paper IV). That finding is encouraging, because it contradicts the potential risk of reduced cycling among younger school children. However, the size of the effect is surprising, although it probably depended on the publicity and discussions concerning bicycle helmet laws that occurred in the media during the study period (paper II). Notably, the same, albeit weaker, tendencies were seen for school children in the control group (paper IV).

There have never been stated any explicit objectives about the wearing rates that should be achieved by adopting a helmet law in Motala, although the general aim has been to accomplish increased and sustained helmet wearing among all bicyclists. Unfortunately, that goal has not yet been achieved. Two years after introduction of the law, about $90 \%$ of people riding bicycles on bike paths in Motala did not use a helmet (paper III). Notwithstanding, the helmet law initiative has been dogged by several problems, mainly during the initiation phase, and many of them have led to poor rooting of the law in the schools and shortcomings in regard to clarification of the roles and responsibilities of the municipal actors. The law would almost certainly have a potential to reach a more substantial and more sustainable effects on helmet use, if some of the problems could have been avoided. That would have enabled better coordination of the helmet promotion program with the political follow-up activities and the post-law media publicity. Nevertheless, it is reasonable to assume that a non-compulsory helmet law like the one in Motala, which can not impose penalties, will not be able to increase average helmet wearing enough to be an effective alternative to a mandatory helmet law. 
Even if local, non-mandatory legislation is not a realistic alternative to a national bicycle helmet law, there are a number of positive experiences made from the Motala initiative that are worth mentioning (paper II). Many people, associations, and organizations were involved in the work on the law, including individuals from outside Motala. Furthermore, numerous helmetpromoting activities were carried out, which probably would not have been the case if the helmet law had not been adopted. Many of the actors involved in the initiative felt that it had boosted the interest in traffic safety issues in the municipality, and that it had also led to increased cooperation between individuals that otherwise might not have occurred.

\subsection{Is there a need for a national helmet law that applies to all bicyclists in Sweden?}

The present traffic safety situation for people riding bicycles in Sweden is not compatible with vision zero. In addition to a number of fatalities every year, there are too many head injuries, which often occur without the involvement of motor vehicles (22). Previous research has shown that increased helmet use among cyclists can save lives and reduce head injuries. Furthermore, it has been found that wearing rates can be more effectively increased by helmet promotion combined with a compulsory helmet law for all bicyclists than by helmet promotion alone. Helmet laws that have been introduced in Australia, New Zealand, and some parts of Canada indicate that it is possible to achieve wearing rates of about $80 \%$. The research underlying this thesis revealed that most bike riders in Sweden do not use a helmet (paper I), and, despite a trend towards increased wearing during the 1990s, the present rate is far below the goal of an average wearing rate of $80 \%$ that was declared in the mid 1990s (224). This thesis also suggests that local non-compulsory helmet laws can not be effective alternatives to a national compulsory helmet law for all categories of bicyclists (papers II-IV).

What level of helmet use can be reached by voluntary means in Sweden? If the historical trend in voluntary bicycle helmet wearing during the period 19882002 continues over the coming years, about $30 \%$ of all cyclists will probably use helmets by the year 2010 (paper I). However, if the wearing trend seen in the last five years continues, the average rate in the future will be even lower. Although predictions based on historical data should be interpreted with caution, it can be said that rather large deviations from the previous general trend will have to occur if helmet wearing in Sweden is to come anywhere near a 
level of $80 \%$ in the near future. Experience gained in Victoria, Australia, has shown that it should be possible to achieve average voluntary use of about $30 \%$. In support of that assumption, studies of the impact of the seat belt law for drivers and front seat passengers passed in Sweden in 1975, have found that the voluntary wearing rate was about $35 \%$ before the law, and it rose to $85 \%$ soon after the law took effect and has even increased somewhat since then $(269,270)$.

From the discussion above, it can be concluded that a national helmet law is needed for all categories of bicyclists in Sweden-but when should such a law be introduced? Should we wait until voluntary helmet use has reached a certain level, for instance about $30 \%$ ? In most countries that have introduced bicycle helmet laws applying to all bicyclists, the average pre-law rates of voluntary wearing were indeed $30-40 \%$, but that does not necessarily mean that it is inappropriate to introduce helmet laws when voluntary wearing rates are lower. For example, a law was passed in New South Wales, Australia, when the average wearing rate was only about $20 \%$, and the level rose to about $80 \%$ two years after the law took effect (112-115). Furthermore, a study of the influence of the mandatory helmet law for moped riders that was introduced in Sweden in 1978 has shown that even though the pre-law wearing rate was as low as $10-20 \%$, about $95 \%$ of these road users wore helmets directly after the law came into effect (271). Another example is the Swedish safety belt law applying to adult passengers in the backseat of cars, which was introduced in 1986; at that time, the voluntary use of back-seat belts by adults was $10-20 \%$, whereas the wearing rate today is about $75 \%$ (269).

Another aspect of delaying the passing of a bicycle helmet law until a certain level of voluntary helmet use is reached is that a number of bicyclists will be killed or sustain head injuries during the "waiting period." Based on the assumption that a helmet law for all bicyclists will increase the average wearing rate to about $80 \%$, it is possible to estimate the effects on the numbers of fatalities and injuries. This has been done in a study of Swedish data from the mid 1990s (18). If the estimates from the previous study are updated according to observed helmet wearing and numbers of bicyclists hospitalized with head injuries in 1999-2001, the results indicate that an average helmet use of about $80 \%$ will annually result in 10-15 fewer deaths and about 500 fewer hospitalized cyclists with head injuries. 
As mentioned, Sweden has decided to make bicycle helmet use mandatory for children (aged 0-14 years) from January 1, 2005 (89). The decision to introduce the helmet law met a certain amount of criticism, because it applies only to children, which might be a message to teenagers and adults that they do not need to use bicycle helmets (272). However, it seems that it is probably better to have a bicycle helmet law solely for children than to have no helmet law at all, at least if the initiative can be regarded as a first step towards a national law that applies to all bicyclists. In any case, there is reason to believe that the coming helmet legislation for children will have only a small positive influence on traffic safety. There will probably not be any system of sanctions making it possible to impose fines on non-wearers, because children younger than 15 are not legally responsible for paying such penalties in Sweden. Despite that, the wearing rate among younger children will hopefully increase somewhat, at least if the pending law is coordinated with extensive helmet promotion. However, if a helmet law should have a substantial impact on traffic safety, it definitely must include bicyclists of all ages. After all, a clear majority of bicycle-related fatalities and head injuries in Sweden occur in adults, and the rate of helmet wearing is also much lower in that age category than among children.

But what about the possibility that a helmet law will have negative side effects on bicycling? International findings indicate that there is a risk of reduced cycling among teenagers, but not among younger children and adults. The results of the questionnaire study of the Motala helmet law also suggest that younger school children will not reduce their bicycling (paper IV). On the other hand, it is also plausible that bicycling will increase after a helmet law is passed, as has been seen among adults in Australia and children in Canada. Regrettably, it is impossible to know in advance whether or not a national helmet law will affect cycling exposure. Nevertheless, being aware that a helmet law can lead to reduced bicycling makes it easier to avoid that potential problem. There is also a lack of knowledge as to whether a national helmet law can have negative long-term effects on public health. Even if cycling exposure were to be reduced, it should not automatically result in decreased levels of physical activity in general, since a prerequisite for such an effect is that a reduction in bicycling is not counterbalanced by some other form of physical activity $(273,274)$. Hence, there are several unanswered questions about the risks associated with introduction of a general bicycle helmet law. These uncertainties seem less pronounced when it comes to possibilities with a helmet law. We know that such legislation will increase the rate of helmet wearing, 
which will reduce the number of bicycle-related head injuries and in turn improve public health (Figure 21). According to Evans (275), the question of whether to introduce a bicycle helmet can not be answered by scientific studies alone, because it is ultimately a political decision.

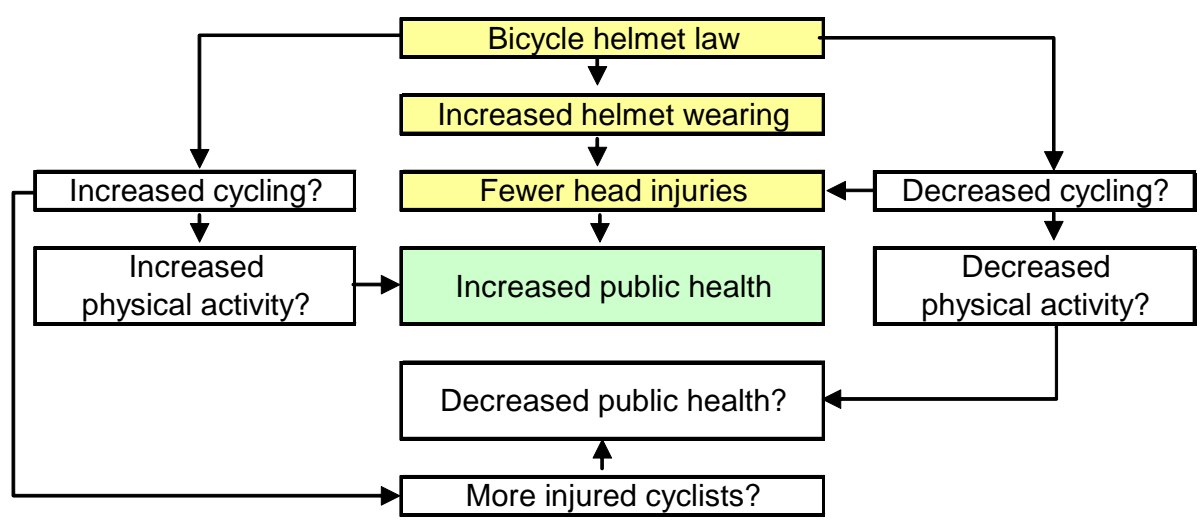

Figure 21. Tentative description of the plausible effects of a bicycle helmet law on public health.

\subsection{Future research}

Even though much research has already been done related to bicycle helmet wearing, many questions have not yet been answered. Examples of some of the areas that need future research are given below.

- Theoretical analysis of factors that promote the use of bicycle helmets. Considerable information has been accumulated about the different explanations that bicyclists give for why they do or do not use a helmet. However, there is a lack of knowledge about how those reasons are interrelated, and what explanations are most strongly correlated with helmet wearing. For example, we do not know what beliefs about helmet use can have the greatest influence on voluntary helmet wearing. Even if helmet wearing should be made mandatory for all bicyclists, compliance would not be $100 \%$, thus it is important to determine what factors can help make compliance as extensive as possible. To address issues such as these, it will be necessary to test different theoretical models on bicycle helmet use, for instance the previously discussed PRECEDE-PROCEED or the theory of planned behaviour. In particular, there is a scarcity of theoretical models applied to adult bicyclists. 
None of the models mentioned above in any way describe how different factors influencing a behavior can change over time. Considering the wearing of bicycle helmets, there are probably different phases in the process, which vary from never having reflected over using a helmet, to deciding to wear a helmet every time you ride a bicycle. Application of theoretical models focused on processes of behavioral changes are needed to identify different phases of helmet use and to ascertain what factors influence the transfer from one stage to another. One example of such a model is the "stages of change model" $(276,277)$, which, among other things, describes six phases in the process of behavior change (precontemplation, contemplation, preparation, action, maintenance, and termination). Another example is the "diffusion of innovations" (278), which, for example, explains how different groups of people adopt new ideas or behaviors. This model identifies five ideal types of individuals, based on how fast they accept a particular innovation (e.g., use of bicycle helmets): innovators, early adopters, early majority, late majority, and laggards. According to the model, innovators and early adopters account for about $15-20 \%$ of the population, which corresponds very well with the average bicycle helmet wearing in Sweden (paper I). The category called early majority supposedly comprises about one third of the population, and it would be interesting to know what group of bicyclists could be assigned to that category, since many of them would be potential helmet wearers.

- What impact would a helmet law for all bicyclists have on public health? There is a lack of knowledge about what effects a general bicycle helmet law would have on cycling exposure. What measures can be taken to effectively counteract any possibly negative effects of a helmet law on bicycling? More information is needed to explain the causal relationship between changes in cycling exposure and altered physical activity, and along with that, changes in public health.

- Continued development of measures aimed at increasing the use of bicycle helmets. Whether or not a bicycle helmet law applying to all age categories is adopted, more information is needed about new ways of promoting helmet use. In this respect, it would probably be beneficial to use different incentives or rewards to give people secondary motives (in addition to safety reasons) for wearing a helmet. It would probably also help to improve the design and usability of helmets so that they can be perceived as "cool" and 
trendy. Perhaps bicycle helmets could even be integrated with modern IT technology to add functions that are not solely intended to increase safety.

- Improved quality in helmet wearing. Earlier research has indicated that the quality of helmet wearing among bicyclist is sometimes inadequate from a safety perspective, particularly among children and teenagers (100, 279). Examples that have been observed are loose or open chin straps, and incorrect placement of the helmet on the head, which leads to reduced protection if an accident occurs. Problems such as these probably also prevail in Sweden, but little is known about the scope of the situation or how it might be counteracted.

- The relationship between socioeconomic status and helmet use. Studies have shown that a low rate of bicycle helmet wearing is associated with low socioeconomic status (26), but this relationship has not been elucidated in Sweden. However, Swedish researchers have shown that the risk of injury among bicyclists is higher among children to parents with low socioeconomic status (280), and there is a similar association for children with a low level of education or income among their parents (281). Therefore, it is reasonable to assume that a relationship between bicycle helmet wearing and socioeconomic status does exists in Sweden, as well as in some other countries. 


\section{GENERAL CONCLUSIONS}

The findings discussed in this thesis indicate that there is a need to increase bicycle helmet wearing in Sweden. The current average rate of helmet use is $15-20 \%$, which is far from the goal of $80 \%$ that was proposed by official document several years ago. If the observed trend in helmet wearing during the period 1988-2002 continues in the near future, it is estimated that average voluntary helmet use will be about $30 \%$ by the year 2010 . To achieve substantial and sustained bicycle helmet use in a country will require helmet promotion in combination with a national law that makes helmet wearing mandatory for all bicyclists.

Considering the effects of local non-compulsory helmet laws like the one in Motala, the present studies revealed an initial increase in helmet wearing among younger school children, but there was no major long-term influence on helmet wearing among bicyclists in general. Accordingly, it can be concluded that this type of initiative is not a sufficiently powerful alternative to a mandatory national helmet law. Nevertheless, the following lessons were learned from the initiation and implementation of the local non-compulsory helmet law in Motala:

- Committed individuals are important to initiate and promote a local helmet law, but the work must not become dependent on a single person.

- All issues concerning bicycle helmets in the municipality should be coordinated with the law.

- An official project manager should be appointed and the different roles and responsibilities of the actors should be clarified.

- A local helmet law must receive sufficient support from relevant target groups.

- The municipal government must be involved at all stages and must have a strategy for control and follow-up of the law.

- Referring to a municipal initiative such as the one in Motala as a "bicycle helmet law" can presumably have a significant impact on the amount of publicity in the media. 


\section{ACKNOWLEDGEMENTS}

I would like to express my gratitude to the following organizations, which have given financial support to the research underlying this thesis: both the head office and the south-eastern office of the Swedish Road Administration (SRA), the National Institute of Public Health, and the Swedish Road and Transport Research Institute (VTI).

I am also sincerely grateful to many people who have, in various ways, supported me or contributed to my work over the years-unfortunately, it is not possible to mention all of their names. I owe particular gratitude to my supervisor and coauthor, Kent Lindqvist at Linköping University, for his experience, guidance, and never-ending support and encouragement, and also for introducing me to the local bicycle helmet law in Motala.

I thank my colleague and co-author of one of the papers, Robert Ekman at the Swedish Rescue Services Agency, for many years of enthusiastic discussions about bicycle helmet issues. I would also like to express my appreciation to Toomas Timpka at Linköping University and my research colleagues Nils Petter Gregersen and Anders Nyberg at VTI for valuable comments on this thesis; Mats Fredriksson at Linköping University for statistical guidance; Mats Wiklund and Åsa Forsman at VTI for answering my statistical questions; Jörgen Larsson at VTI for keeping me updated on head injury statistics among bicyclists; and the people at the VTI library for helping me find relevant literature. Many thanks also to Christina Ruthger for letting me reproduce her painting on the cover of this thesis; to Lewis Gruber for translating Swedish text to English in some of the papers; and to Patricia Ödman for fast and excellent revision of my English text, I especially appreciate that you often suggest alternatives.

I am grateful to Jan Ifver, Thomas Lekander, Per Gunnar Land, and Torsten Martinsson at the head office of SRA, and Birgitta Sjöberg and Hans Sävenhed at the southeastern office of SRA, and Lothar Schelp at the National Institute of Public Health. You have all been my official contacts with the financing organizations and have also encouraged me in my work. Special thanks to Thomas Lekander, for patiently waiting for the research results and for never failing to answer my questions about traffic safety statistics. I am also obliged to Hans Erik Pettersson and Sonja Forward at VTI for their social and financial support of my postgraduate studies, and I owe many thanks to Marianne Almgren at SRA for helping me in the process of finding financial support to finishing this thesis.

I am indebted to all the people who have carried out observations of bicycle helmet wearing in Sweden over the years and in that way supplied me with data for my re- 
search. Special thanks to my contacts who have helped me coordinate the helmet observations: I can not mention all your names, but I offer my appreciation to the Swedish Central Federation of Women's Motor Transport Corps (SKBR), in which most of you are members. I am also grateful to my contacts who are not members of SKBR. Furthermore, I warmly acknowledge many present and former colleagues at VTI who have helped me over the years to collect observational data on bicycle helmet use in Linköping, including Inger Engström, Helena Hellsten, Anders Nyberg, Gunilla Sjöberg, Mohammad Reza Yahya, Maria Berlin, Hans-Yngve Berg, Göran K. Ahrusell, Christina Aldrin, Mona Grund, and Ann-Sofie Senneberg. I am particularly obliged to Helena Hellsten for administrative help with the observational studies and Ann-Sofie Senneberg and Gunilla Sjöberg for various administrative help in the thesis.

Many thanks are also due to the following municipal officials and politicians who were members of the coordinating committee of the bicycle helmet law in Motala: Bertil Thorén, Annika Dahlström, Pirjo Kovalainen, Magnus Larsson, Gunilla Ragnarsson, Viola Borg, and Anita Alexandersson. Special recognition to Gunilla and Anita for social support and for assisting with the observational studies in Motala, and to Pirjo for help with coordinating the data collection in Motala and for giving me access to information and documents concerning activities related to the helmet law. Moreover, I am thankful to Ann-Marie Hanson in Hässleholm, Inga-Lill Karlsson and Gunnar Mårtensson in Västervik, and Monica Hull and Ulla Kvarnström in Katrineholm, for helping me coordinate the observational and questionnaire studies in the control areas.

I have also received much social support during my years with this thesis, and for that I would like to express my great appreciation to the following people: Members of the Swedish Bicycle Helmet Group for stimulating, instructive, and friendly meetings. Special thanks to the chairmen's of the group, Leif Svanström and Ulf Björnstig, and to the former secretariat, consisting of Robert Ekman and Glenn Welander. I am also very grateful for social support from my colleagues at VTI, specially Anders Nyberg, Inger Engström, Satu Heikkinen, and Torbjörn Falkmer and Hans-Yngve Berg (both former colleagues at VTI) for encouraging discussions about conducting work on a thesis parallel to other ordinary VTI-projects. Many thanks are also due to the people at the Division of Social Medicine and Public Health at Linköpings University, for inviting me to both formal and social activities. I will specially remember the "Ghost-walking-tour". A special thanks to Kjell Johansson for encouraging discussions and for letting me work in his room on my visits to Linköpings University.

Finally I am immensely grateful to my wife Catarina and my children Hampus and Linnea for love and patience, despite my many late hours working on the thesis. 


\section{REFERENCES}

1. Janlert U. A dictionary of public health science (in Swedish). Borås, Sweden: Natur och Kultur; 2000.

2. Krug E, editor. Injury. A leading cause of the global burden of disease. Geneva, Switzerland: World Health Organization, Violence and Injury Prevention; 1999.

3. WHO. A 5-year WHO Strategy for Road Traffic Injury Prevention. Geneva, Switzerland: Horld Health Organization; 2001.

4. Peden M, Scurfield R, Sleet D, Mohan D, Hyder A, Jarawan E, et al., editors. World report on road traffic injury prevention. Geneva: World Health Organization; 2004.

5. SIKA/SCB. Road Traffic Injuries 2002. Official Statistics of Sweden. Stockholm: Swedish Institute for Transport and Communications Analysis. Statistics Sweden; 2003.

6. Government Bill. Vision zero and road traffic safety in society (in Swedish). Prop 1996/97:137. Stockholm; 1997.

7. SRA. Government assignment. A presentation of the work on traffic safety (in Swedish). Report. Borlänge: Swedish Road Administration; 2004.

8. Koornstra M, Lynam D, Nilsson G, Noordzij P, Petterson H-E, Wegman F, et al. SUNflower: a comparative study of the development of road safety in Sweden, the United Kingdom, and the Netherlands. Leidschendam: SWOV Institute for Road Safety Research; 2002.

9. Australian Transport Safety Bureau. Road Fatalities Australia: 2002 Statistical summary. ACT, Australia: Australian Transport Safety Bureau; 2003.

10. NHTSA. Traffic Safety Facts 2000 - Overview. Washington: National Highway Traffic Safety Administration, U.S. Department of Transportation; 2001.

11. IRTAD: Brief Overview. International Road Traffic and Accident Data. Internet IRTAD International Road Traffic and Accident Data.

http://www.bast.de/htdocs/fachthemen/irtad/english/englisch.html. 2003.

12. U.S. Census Bureau: IDB Summary Demographic Data. Internet U.S. Census Bureau, Population Division, International Programs Center. http://www.census.gov/ipc/www/idbsum.html. 2003.

13. SCB. Road traffic injuries. Known by the police and the hospitals 1992-1993 (in Swedish). Stockholm: Official Statistics of Sweden; 1996.

14. SOU. From child accidents to children's rights to safety and development (in Swedish). Stockholm: the Ministry of Health and Social Affairs; 2003.

15. Larsson J. Analysis of inpatient statistics 1988-2001 according to traffic injuries (in Swedish). VTI Notat. Linköping: Swedish National Road and Transport Research Intstitute; 2004. Report No.: 8-2004.

16. Fredlund P. Traffic injuries. Blekinge 1988-1995 (in Swedish). Rapport. Karlskrona: Register of traffic injuries. Blekinge hospital, County council of Blekinge; 1996.

17. Björnstig U, Näslund K. Pedal Cycling Accidents - Mechanisms and Consequences. A study from Northern Sweden. Acta Chir Scand 1984(150):353-359.

18. Nolén S. Traffic safety potential of increased bicycle helmet use in Sweden (in Swedish). VTI Notat. Linköping: Swedish National Road and Transport Research Institute; 1998. Report No.: 34 .

19. SRA. Traffic safety report 1998 (in Swedish). Publication 1999. Borlänge: Swedish Road Administration; 1999. Report No.: 35.

20. Öström M, Björnstig U, Näslund K, Eriksson A. Pedal cycling fatalities in northern Sweden. Int J Epidemiol 1993;22(3):483-8.

21. SCB. Road traffic injuries 1996. Stockholm: Official Statistics of Sweden; 1997. 
22. Björnstig U, Öström M, Eriksson A, Sonntag-Öström E. Head and face injuries in bicyclists--with special reference to possible effects of helmet use. Journal of Trauma 1992;33(6):887-93.

23. Henderson M. The Effectiveness of Bicycle Helmets - A Review. Report. Sidney, NSW: Motor Accidents Authority; 1995. Report No.: MAARE-010995.

24. Danielsson K. Increase the safety. Mapping the accident pattern in Sweden (in Swedish). Report. Vällingby: National Board for Consumer Policies; 1987. Report No.: 1986/87:11.

25. Sacks JJ, Holmgreen P, Smith SM, Sosin DM. Bicycle-associated head injuries and deaths in the United States from 1984 through 1988. How many are preventable? Jama 1991;266(21):3016-8.

26. Towner E, Dowswell T, Burkes M, Dickinson H, Towner J, Hayes M. Bicycle Helmets A review of their effectiveness: A critical review of the literature. London: Department for Transport; 2002.

27. O'Hare M, Langford J, Johnston I, Vulcan P. Bicycle Helmet Use and Effectiveness. Report. Clayton: Monash University Accident Research Centre; 2003 January, 2003.

28. Larsson J. Personal Communication. In. Linköping: Statens väg- och transportforskningsinstitut; 2004.

29. the National Board of Health and Welfare. Classification of diseases and health problems 1997. A systematic catalogue (in Swedish). Report. Stockholm: the National Board of Health and Welfare; 1998.

30. Larsson J. Number of injured cyclist 1998-2001. Divided on main diagnosis and age. Personal communication (in Swedish). In. Linköping: Swedish Road and Transport Research Institute; 2004.

31. SCB: Population statistics. Internet SCB, Statistics Sweden. http://www.ssd.scb.se/databaser/makro/Produkt.asp?produktid=BE0101. 2004.

32. Ekman R, Welander G, Svanstrom L, Schelp L, Santesson P. Bicycle-related injuries among the elderly - a new epidemic? Public Health 2001(115):38-43.

33. Emanuelson I. Epidemiology and management of traumatic brain injury in children. Helsinki: University of Helsinki; 1999.

34. Attewell RG, Glase K, McFadden M. Bicycle helmet efficacy: a meta-analysis. Accident Analysis \& Prevention 2001(33):345-352.

35. Thompson D, Rivara F, Thompson R. Helmets for preventing head and facial injuries in bicyclists (Cochrane Review). The Cochrane Library 2003(1):1-27.

36. Kolb B, Whishaw I. Fundamentals of human neuropsychology. Third ed. ed. New York: W.H Freeman and Company; 1990.

37. O'Rourke NA, Costello F, Yelland JD, Stuart GG. Head injuries to children riding bicycles. Med J Aust 1987;146(12):619-21.

38. Andersson AL, Bunketorp O, Allebeck P. High rates of psychosocial complications after road traffic injuries. Injury 1997;28(8):539-543.

39. Emanuelson I, Von Went L, Beckung E, I H. Late outcome after severe traumatic brain injury in children and adolescents. Pediatric Rehabilitation 1998;2(2):65-70.

40. Dorsch MM, Woodward AJ, Somers RL. Do bicycle safety helmets reduce severity of head injury in real crashes? Accident, Analysis \& Prevention 1987;19(3):183-90.

41. Rivara FP, Thompson DC, Patterson MQ, Thompson RS. Prevention of bicycle-related injuries: helmets, education, and legislation. Annu Rev Public Health 1998;19:293-318.

42. Thompson DC, Rivara FP, Thompson RS. Effectiveness of bicycle safety helmets in preventing head injuries. A case-control study Jama 1996;276(24):1968-73.

43. Thompson RS, Rivara FP, Thompson DC. A case-control study of the effectiveness of bicycle safety helmets. N Engl J Med 1989;320(21):1361-7. 
44. Thompson DC, Nunn ME, Thompson RS, Rivara FP. Effectiveness of bicycle safety helmets in preventing serious facial injury. Jama 1996;276(24):1974-5.

45. TTM Consulting. Bicycle Helmet Usage Rates in Victoria: March 1994. General Report. Abbotsford: TTM Consulting Pty. Ltd.,; 1994. Report No.: GR 94-6.

46. Healy M, Maisey G. The impact of helmet wearing legislation and promotion on bicyclists in Western Australia. Report. Perth: Western Australia Police Department. Research and Statistics Unit; 1992 August 1992. Report No.: TB92-6.

47. MacKay M, Klassen T, Cushman R. Trends in bicycle helmet use in Ottawa-Carleton, 1988-1997. Impact of bicycle helmet legislation? In. Ottawa, Ontario: Plan-it Safe. Child \& Youth Injury Prevention Center. Children's Hospital of Eastern Ontario; 1998.

48. Järvinen M. The bicycle helmet law (in Swedish). Oral presentation in Stockholm 3 october 2003. In: Liikenneturva, Finland; 2003.

49. Miller PA, Binns HJ, Christoffel KK. Children's bicycle helmet attitudes and use. Association with parental rules. The Pediatric Practice Research Group. Arch Pediatr Adolesc Med 1996;150(12):1259-64.

50. DiGuiseppi CG, Rivara FP, Koepsell TD. Attitudes toward bicycle helmet ownership and use by school-age children. American journal of diseases of children 1990;144(1):83-86.

51. Farley C, Haddad S, Brown B. The effects of a 4-year program promoting bicycle helmet use among children in Quebec. American Journal of Public Health 1996;86(1):46-51.

52. Farley C, Laflamme L, Vaez M. Bicycle helmet campaign and head injuries among children. Does poverty matter? J Epidemiol Community Health 2003;57:668-672.

53. Parkin PC, Spence LJ, Hu X, Kranz KE, Shortt LG, Wesson DE. Evaluation of a promotional strategy to increase bicycle helmet use by children. Pediatrics 1993;91(4):772-7.

54. Nakayama DK, Pasieka KB, Gardner MJ. How bicycle-related injuries change bicycling practices in children. American journal of diseases of children 1990;144:928-929.

55. Fullerton L, Becker T. Moving targets: Bicycle-related injuries and helmet use among university students. Journal of American college health 1991;39(5):213-217.

56. Lajunen T, Rasanen M. Why Teenagers Owning a Bicycle Helmet Do Not Use Their Helmets. Journal of Safety Research 2001;32(3):323-332.

57. DiGuiseppi CG, Rivara FP, Koepsell TD, Polissar L. Bicycle helmet use by children. Evaluation of a community-wide helmet campaign Jama 1989;262(16):2256-61.

58. Dannenberg AL, Cote TR, Kresnow MJ, Sacks JJ, Lipsitz CM, Schmidt ER. Bicycle helmet use by adults: the impact of companionship. Public Health Rep 1993;108(2):2127.

59. Parkin PC, Morris B, Chipman M, Miller C, Hu X, Wesson D. Peer and parental factors associated with bicycle helmet use in children. Report (Manuscript). Toronto: Department of Pediatrics, Div of general pediatrics, Hospital for sick children.; 1991.

60. Nolén S. What do cyclists think about using helmets - a literature study (in Swedish). Linköping: Swedish National Road and Transport Research Institute; 1999. Report No.: VTI report 429.

61. Finch CF. Teenagers' attitudes towards bicycle helmets three years after the introduction of mandatory wearing. Inj Prev 1996;2(2):126-30.

62. Heinonen M. Reasons for wearing a cycling helmet. Report. Helsinki: The central organization for traffic safety; 1994. Report No.: 70.

63. Rodgers GB. Bicycle helmet use patterns in the United States. A description and analysis of national survey data. Accident Analysis \& Prevention. 1995;27(1):43-56.

64. Andersen JA. The 1994 Ontario Bicycle Survey. Report. Ontario: Safety Research Office. Safety Police Branch; 1994. Report No.: FYI-94-106.

65. Fosser A. Bicycle helmets. Attitudes to their use among bicyclists. TOI-notat. Oslo: Institute of Transport Economics, TOI; 1991. Report No.: 0946/1991. 
66. Berg P, Westerling R. Bicycle helmet use among schoolchildren-the influence of parental involvement and children's attitudes. Inj Prev 2001;7(3):218-22.

67. Kundskaparna. Presentation of opinions about the use of bicycle helmets among children in secondary schools (in Swedish). Report. Stockholm: Kundskaparna; 1994.

68. Taylor SB, Halliday ME. Cycle helmet wearing in Great Britain. TRL Report. Crowthorne: Transport Research Laboratory; 1996. Report No.: 156.

69. Leviatan N, Levy B. Results from a qualitative study concerning attitudes to bicycle helmets (in Sweden). Report. Stockholm: Kommunicera Marknadskonsultation AB; 1995.

70. Sipinen L. Why don't cyclists wear helmets? Interview study to find out the reasons for not wearing the helmet. Report (in Finish). Helsinki: The central organization for traffic safety in Finland; 1993.

71. Royles M. International literature review of cycle helmets. Project Report. Crowthorne, Berkshire: Transport Research Laboratory; 1994. Report No.: 76.

72. Stevenson T, Lennie J. Empowering school students in developing strategies to increase bicycle helmet wearing. Health Educ Res 1992;7(4):555-66.

73. Garpenlind A, Löffler C. The use of bicycle helmets among male teenagers. Future ideas for campaigns (in Swedish). University paper 41-60 p. Lund: Lunds University; 1993.

74. Elliott \& Shanahan Research. An exploratory study of high school students' reaction to bicycle helmets. Report. Sydney: Elliot \& Shanahan Research; 1986. Report No.: GR/86/10.

75. Howland J, Sargent J, Weitzman M. Barriers to Bicycle Helmet Use Among Children. Results of Focus Groups With Fourth, Fifth, and Sixth Graders. American journal of diseases of children 1989;143(6):741-744.

76. Unwin N. Cycling behaviour and cycle helmet use: a survey of university students. Health education journal 1992;51(4):184-187.

77. Colyer MM, Hallam JCF, Hui K, Lewis GDW, Morfey CL, Thorpe JE. User acceptability and economic benefits of hard-shell bicycle helmets - Results of a UK survey. In: 1986 international IRCOBI conference on the biomechanics of impacts; 1986 2-3-4 September; Zurich, Switzerland: International Research Council on Biokenetiscs of Impacts; 1986.

78. Nolén S. Could helmet use among adult bicycles be predicted from the "theory of planned behaviour"? A pilot study (in Swedish). VTI Notat. Linköping: Swedish Road and Transport Research Institute; 1998. Report No.: 2.

79. Carlsson A, Isaksson C, Lind U, Persson I, Strand M, Teryd H, et al. Bicycle helmet. Why not?! A study of attitudes (in Swedish). Uppsats 10 p. Linköping: Faculty of health science, Linköping university and County of Östergötland, Birgittaskolan; 1992.

80. Persson H. The bicycle helmet in the society (in Swedish). University paper. Göteborg: Department of Ethnology, Göteborgs University; 1994.

81. Otis J, Lesage D, Godin G, Brown B, Farley C, Lambert J. Predicting and reinforcing children's intentions to wear protective helmets while bicycling. Public Health Reports 1992;107(3):283-289.

82. Carlson Gielen A, Joffe A, Dannenberg AL, Wilson ME, Beilenson PL, DeBoer M. Psychosocial factors associated with the use of bicycle helmets among children in counties with and without helmet use laws. J Pediatr 1994;124(2):204-10.

83. Spolander K. The comfort and usability of bicycle helmets (in Swedish). VTI Rapport. Linköping: Swedish Road and Traffic Institute; 1982. Report No.: 242.

84. Swedish Consumer Agency. Helmets for all. Nice looking helmets reduce head injuries. Report. Vällingby: Swedish Consumer Agency; 1993. Report No.: Report 1992/93:18. 
85. Nolén S, Lindqvist K. Effects of measures for increased bicycle helmet use. Review of research (in Swedish). VTI Rapport 487. Linköping: Swedish National Road and Transport Research Institute; 2003.

86. BHSI: Helmet Laws for Bicycle Riders. Internet Bicycle Helmet Safety Institute, BHSI. http://www.helmets.org/mandator.htm. 2004.

87. Olafsson O. Helmet use in Iceland. J. Traffic Med 1999;27(1-2):5.

88. U.S Department of Health and Human Service. Healthy People 2010. Volume II. Objectives for Improving Health. Part B: Focus Areas 15-28. Report. Washington, DC: U.S Department of Health and Human Service; 2000 November.

89. Government office of Sweden. The government make use of bicycle helmets mandatory for children up to the age of 15 (in Swedish). In: Government office of Sweden, Press release, 2004 may 10; 2004.

90. Tarvainen A-L. Personal communication. In. Helsingfors: The ministry of communication in Finland; 2002.

91. Liikenneturva: Monitoring of Traffic Behaviour in Finland year 2002. Internet Liikenneturva. The Central Organization for Traffic Safety in Finland.

http://www.liikenneturva.fi/suomi/tutkimus/Reports/kayttaytymisenseuranta2003.pdf. 2002.

92. Scuffham PA, Langley JD. Trends in cycle injury in New Zealand under voluntary helmet use. Accident Analysis \& Prevention 1997;29(1):1-9.

93. Leicester P, Nassau F, Wise A. The Introduction of Compulsory Bicycle Helmet Wearing in Victoria. General Report. Hawthorn: Vicroads road Safety Division; 1991 February 1991. Report No.: GR/91-4.

94. Wood T, Milne P. Head injuries to pedal cyclists and the promotion of helmet use in Victoria, Australia. Accident Analysis \& Prevention 1988;20(3):177-85.

95. Transafe. Bicycle Helmet Safety. Final Report on the Motorcycle and Bicycle Helmet Safety Inquiry. Report of the House Representatives Standing Committee on Transport Safety. Canberra: The Parliament of the Commonwealth of Australia; 1985 November 1985.

96. NRSP. Road Safety Update. In: Fall in cycle helmet wearing rates. Christchurch: National Road Safety Plan; 1993.

97. NISU. Bicycle Helmets. Injury Issues Monitor, National Injury Surveillance Unit 1992(1):1-8.

98. Scott IKR. Report on Australian bicycle helmet requirements and education programs by state and territory. Melbourne: Child Accident Prevention Foundation of Australia. National Injury Surveillance Unit; 1992.

99. Scuffham P. Helmet Mandatory in New Zealand. Headlines 1994;3 (Spring, 1994)(2):8.

100. Foss RD, Beirness DJ. Bicycle Helmet Use in British Columbia: Effects of the Helmet Use Law. In: University of North Carolina, Chapel Hill, Highway Safety Research Center, Chapel Hill, NC, USA; 2000.

101. Leblanc JC, Beattie TL, Culligan C. Effect of legislation on the use of bicycle helmets. Cmaj 2002;166(5):592-5.

102. Vulcan P. Establishing Compulsory Bicycle Helmet Wearing - the Experience in Victoria, Australia. In: Rogmans W, editor. Helmets for all. European conference on how to promote helmet wearing for leisure and sport, 26-28 April 1993, Stockholm, Sweden. Amsterdam, The Netherlands: European consumer safety association (ECOSA); 1993. p. 70-9.

103. Safe Kids: Safe Kids Canada supports bicycle helmet legislation. Internet Safe Kids Canada. 
http://www.safekidscanada.ca/ENGLISH/IP_PROFESSIONALS/SafeKidsWeek2002/Bi keHelmetLegislation.html. 2004.

104. BHSI: Model Helmet Law. Internet Bicycle Helmet Safety Institute, BHSI. http://www.bhsi.org/modlaw.htm. 2004.

105. Wise A. Bicycle Helmet Usage Rates in Victoria 1983-1989. General Report. Hawthorn: Vic Roads Road Safety Division; 1989 July 1989. Report No.: GR 89-1.

106. Morgan M, Peberdy J, Rogerson P. Bicycle Helmet Usage Rates in Victoria -1990 - 1991 and Other Bicycle Safety Factors. Report. Hawthorn, Victoria: Vic Roads. Road Safety Division; 1991 1991/07. Report No.: GR 91-9.

107. Finch CF, Newstead SV, Cameron MH, Vulcan AP. Head Injury Reductions in Victoria Two Years After Introduction of Mandatory Bicycle Helmet Use. General Report. Clayton, Victoria: Monash University Accident Research Centre; 1993 July 1993. Report No.: 51.

108. Marshall J, White M. Evaluation of the Compulsory Helmet Wearing Legislation for Bicyclists in south Australia. Report. Walkerville: South Australian Department of Transport, Office of Road Safety; 1994 November 1994. Report No.: 8/94.

109. Rungie C, Trembath R. Observational study of bicycle helmet wearing among south Australian schoolchildren. Report 14/88. Adelaide: South Australian Department of Transport, Road Safety Division; 1987. Report No.: 8/94.

110. Williams MA. Evaluation of the NSW introduction of compulsory bicycle helmet legislation. Research Note. Sydney: Roads and Traffic Authority of New South Wales, Road Safety and Traffic Management; 1995. Report No.: RN 17/94.

111. King M, Fraine G. Bicycle helmet legislation and enforcement in Queensland 1991 to 1993: Effects on helmet wearing and crashes. In: Andreassen D, Rose G, editors. 1994 Australian pedestrian and bicyclist safety and travel workshop, Melbourne, Australia. Proceedings; 1994; Melbourne: ARRB Transport Research Vermont South; 1994.

112. Walker MB. Law compliance and helmet use among cyclists in New South Wales. Consultant Report. Rosebery: Roads and Traffic Authority. Road Safety Bureau; 1990. Report No.: CR 6/90.

113. Walker MB. Law compliance and helmet use among cyclists in New South Wales, April 1991. Consultant Report. Rosebery: Roads and Traffic Authority. Road Safety Bureau; 1991 July 1991. Report No.: CR 1/91.

114. Walker MB. Law compliance among cyclists in New South Wales, April 1992. A third survey. Report. Rosebery: Roads and Traffic Authority. Network Efficiency Branch; 1992 July 1992.

115. Smith NC, Milthorpe FW. An observational survey of law compliance and helmet wearing by bicyclists in New South Wales - 1993. Report. Sydney: Roads and Traffic Authority. Network Efficiency Branch; 1993.

116. Scuffham P, Alsop J, Cryer C, Langley JD. Head injuries to bicyclists and the New Zealand bicycle helmet law. Accident Analysis \& Prevention 2000;32(4):565-73.

117. LTSA: Cycle helmets. Internet Land Transport Safety Authority, LTSA. http://www.ltsa.govt.nz/research/helmets.html. 2002.

118. Povey LJ, Frith WJ, Graham PG. Cycle helmet effectiveness in New Zealand. Accident Analysis \& Prevention 1999;31(6):763-770.

119. Schieber RA, Kresnow MJ, Sacks JJ, Pledger EE, O'Neil JM, Toomey KE. Effect of a state law on reported bicycle helmet ownership and use. Arch Pediatr Adolesc Med 1996;150(7):707-12.

120. Ni H, Sacks JJ, Curtis L, Cieslak PR, Hedberg K. Evaluation of a statewide bicycle helmet law via multiple measures of helmet use. Arch Pediatr Adolesc Med 1997;151(1):5965 . 
121. Kanny D, Schieber RA, Pryor V, Kresnow MJ. Effectiveness of a state law mandating use of bicycle helmets among children: an observational evaluation. Am J Epidemiol 2001;1;154(11):1072-6.

122. Liller K, Mearns J, Cabrera M, Joly B, Noland V, McDermott R. Children's bicycle helmet use and injuries in Hillsborough County, Florida before and after helmet legislation. Injury Prevention 2003(9):177-179.

123. Rodgers GB. Effects of state helmet laws on bicycle helmet use by children and adolescents. Inj Prev 2002;8(1):42-6.

124. Cote TR, Sacks JJ, Lambert-Huber DA, Dannenberg AL, Kresnow MJ, Lipsitz CM, et al. Bicycle helmet use among Maryland children: effect of legislation and education. Pediatrics 1992;89(6 Pt 2):1216-20.

125. Abularrage JJ, DeLuca AJ, Abularrage CJ. Effect of education and legislation on bicycle helmet use in a multiracial population. Arch Pediatr Adolesc Med 1997;151(1):41-4.

126. Macknin ML, Medendorp SV. Association between bicycle helmet legislation, bicycle safety education, and use of bicycle helmets in children. Arch Pediatr Adolesc Med 1994;148(3):255-9.

127. Gilchrist J, Schieber RA, Leadbetter S, Davidson SC. Police enforcement as part of a comprehensive bicycle helmet program. Pediatrics 2000;106(1 Pt 1):6-9.

128. Dannenberg AL, Gielen AC, Beilenson PL, Wilson MH, Joffe A. Bicycle helmet laws and educational campaigns: an evaluation of strategies to increase children's helmet use. Am J Public Health 1993;83(5):667-74.

129. Puder DR, Visintainer P, Spitzer D, Casal D. A comparison of the effect of different bicycle helmet laws in 3 New York City suburbs. Am J Public Health 1999;89(11):1736-8.

130. Ainsworth RA. Report on compulsory helmet wearing for bicyclists, and other bicycling issues. Report. Perth: Select Committee on Road Safety; 199412 May 1994.

131. Cameron M, Newstead S, Vulcan P. Analysis of Reductions in Victorian Road Casualties, 1989 to 1992. In: 17th ARRB Conference, Gold Coast, Queensland, 14-19 August 1994; Proceedings; 1994; Gold Coast, Queensland: Australian Road Research Bord Ltd, Vermont South; 1994. p. 165-82.

132. Cameron MH, Vulcan AP, Finch CF, Newstead SV. Mandatory bicycle helmet use following a decade of helmet promotion in Victoria, Australia - An evaluation. Accident Analysis \& Prevention 1994;26(3):325-337.

133. McDermott FT. Bicyclist head injury prevention by helmets and mandatory wearing legislation in Victoria, Australia. Ann R Coll Surg Engl 1995;77(1):38-44.

134. Vulcan AP, Cameron MH, Heiman L. Evaluation of Mandatory Bicycle Helmet Use in Victoria, Australia. In: Association for the Advancement of Automotive Medicine. 36th annual conference, Portland, Oregon, October 5-7, 1992. Proceedings.; 1992; Des Plaines, IL.: Association for the Advancement of Automotive Medicine, AAAM; 1992.

135. Carr D, Skalova M, Cameron MH. Evaluation of the Bicycle Helmet Wearing Law in Victoria During Its First Four Years. Report. Clayton, Victoria: Monash University Accident Research Centre; 1995. Report No.: 76.

136. Macpherson AK, To TM, Macarthur C, Chipman ML, Wrigth JG, Parkin PC. Impact of Mandatory Helmet Legislation on Bicycle-Related Head Injuries in Children: A Population-Based Study. Pediatrics 2002;110(5):1-5.

137. Borglund ST, Hayes JS, Eckes JM. Florida's bicycle helmet law and a bicycle safety educational program: did they help? J Emerg Nurs 1999;25(6):496-500.

138. Shafi S, Gilbert JC, Loghmanee F, Allen JE, Caty MG, Glick PL, et al. Impact of bicycle helmet safety legislation on children admitted to a regional pediatric trauma center. J Pediatr Surg 1998;33(2):317-21. 
139. Finch CF, Heiman L, Neiger D. Bicycle use and helmet wearing rates in Melbourne, 1987 to 1992: the influence of the helmet wearing law. General Report. Clayton, Victoria: Monash University Accident Research Centre; 1993 July 1993. Report No.: 45.

140. Heathcote B, Maisey G. Bicycle use and attitudes to the helmet wearing law. Report TB94-1. Perth: Traffic Board of Western Australia.; 1994.

141. Macpherson AK, Parkin PC, To TM. Mandatory helmet legislation and children's exposure to cycling. Inj Prev 2001;7(3):228-30.

142. Haglund BJA, Svanström LO. Evidence based injury prevention. About effects and efficiency in injury prevention and safety promotion (in Swedish). Stockholm: Karolinska Institutet. Department of Public Health Sciences. Division of Social Medicine. The National Institute of Public Health. National injury program; 1999. Report No.: 1999:22.

143. Ruch-Ross HS, O'Connor KG. Bicycle helmet counseling by pediatricians: A random national survey. American Journal of Public Health 1993;83(5):728-730.

144. Cushman R, Down J, MacMillan N, Waclawik H. Helmet promotion in the emergency room following a bicycle injury: a randomized trial. Pediatrics 1991;88(1):43-7.

145. Cushman R, James W, Waclawik H. Physicians promoting bicycle helmets for children: a randomized trial. Am J Public Health 1991;81(8):1044-6.

146. Stevens MM, Olson AL, Gaffney CA, Tosteson TD, Mott LA, Starr P. A pediatric, practice-based, randomized trial of drinking and smoking prevention and bicycle helmet, gun, and seatbelt safety promotion. Pediatrics 2002;109(3):490-7.

147. Johnston BD, Rivara FP, Droesch RM, Dunn C, Copass MK. Behavior change counseling in the emergency department to reduce injury risk: a randomized, controlled trial. Pediatrics 2002;110(2 Pt 1):267-74.

148. Kim AN, Rivara FP, Koepsell TD. Does sharing the cost of a bicycle helmet help promote helmet use? Inj Prev 1997;3(1):38-42.

149. Smith PK. Increasing Bicycle Helmet Use in Michigan: A School-Based Intervention Pilot Program. Evaluation Report. Report. Michigan: Michigan Bicycle Helmet Advisory Committee; 1991.

150. Watts D, O'Shea N, Flynn E, Trask A, Kelleher D. Effect of a bicycle safety program and free bicycle helmet distribution on the use of bicycle helmets by elementary school children. J Emerg Nurs 1997;23(5):417-9.

151. Britt J, Silver I, Rivara FP. Bicycle helmet promotion among low income preschool children. Inj Prev 1998;4(4):280-3.

152. Floerchinger-Franks G, Machala M, Goodale K, Gerberding S. Evaluation of a pilot program in rural schools to increase bicycle and motor vehicle safety. J Community Health 2000;25(2):113-24.

153. Logan P, Leadbetter S, Gibson RE, Schieber R, Branche C, Bender P, et al. Evaluation of a bicycle helmet giveaway program--Texas, 1995. Pediatrics 1998;101(4 Pt 1):578-82.

154. Ljungblom B-Å. A program aimed at increasing the ownership and wearing of bicycle helmets among children and young people in Ronneby municipality. A study of how children, young people and their parents perceive the road traffic environment (in Swedish). Report. Karlskrona: the County council of Blekinge; 1989.

155. Svernfors T. Bicycle helmet project at the West school in Falun. How information confront prejudices among children in secondary schools and make them use helmets (in Swedish). Memo. Göteborg; 1993 1993-06-29.

156. Hendrickson SG, Becker H. Reducing one source of pediatric head injuries. Pediatr Nurs 2000;26(2):159-62.

157. Berglund A. Evaluation of a bicycle helmet project during 1989-1991 (in Swedish). Östersund: The county council of Jämtland. Division of planning. The group of Societal medicine; 1992. 
158. Winn GL, Jones DF, Bonk CJ. Taking it to the streets. Helmet use and bicycle safety as components of inner-city youth development. Clin Pediatr 1992;31(11):672-7.

159. Liller KD, et al. Promoting Use of Bicycle Helmets among Children: A School and Community-Based Effort. Journal of Health Education; v26 n3 p173-77 May-Jun 1995; 1995.

160. Morris BA, Trimble NE. Promotion of bicycle helmet use among schoolchildren: a randomized clinical trial. Can J Public Health 1991;82(2):92-4.

161. Moore DW, Adair V. Effects of a school-based education program on safety helmet usage by 11- to 13-year-old cyclists. Educational Psychology 1990;10(1):73-78.

162. Parkin PC, Hu X, Spence LJ, Kranz KE, Shortt LG, Wesson DE. Evaluation of a subsidy program to increase bicycle helmet use by children of low-income families. Pediatrics 1995;96(2):283-7.

163. Quine L, Rutter DR, Arnold L. Persuading school-age cyclists to use safety helmets: Effectiveness of an intervention based on the Theory of Planned Behaviour. British Journal of Health Psychology, Vol 6(4), 327 345, Nov 2001.

164. Nolén S. "Helmet Contract" - A method of increasing bicycle helmet usage among those cycling to and from work. In: Book of Abstracts of papers presented at "Third International Conference on Injury Prevention and Control in Melbourne" 18-22 February, 1996. Bedford Park, South Australia: NISU. Australian Institute of Health and Welfare; 1996.

165. Nolén S. Progress report on the project "methods for increased bicycle helmet use among adult commuters" (in Swedish). In. Linköping: Swedish Road and Transport Research Institute.; 1999.

166. Björnstig U, Andersson P. Is a Bicycle helmet law an effective intervention to reduce injuries? An analysis of attitudes among teenagers and adults (in Swedish). Läkartidningen 1995;92(7):662-5.

167. Björnstig U, Andersson P. A bicycle helmet campaign targeting teenagers and adults: Attitudes and results (in Swedish). Umeå: The university hospital of Norrland. The group of accident analysis; 1993. Report No.: 43.

168. Lee AJ, Mann NP, Takriti R. A hospital led promotion campaign aimed to increase bicycle helmet wearing among children aged 11-15 living in West Berkshire 1992-98. Inj Prev 2000;6(2):151-3.

169. Bergman AB, Rivara FP, Richards DD, Rogers LW. The Seattle children's bicycle helmet campaign. Am J Dis Child 1990;144(6):727-31.

170. Rivara FP, Thompson DC, Thompson RS, Rogers LW, Alexander B, Felix D, et al. The Seattle Children's Bicycle Helmet Campaign: Changes in Helmet Use and Head Injury Admissions. Pediatrics 1994;93(4):567-569.

171. Mock CN, Maier RV, Boyle E, Pilcher S, Rivara FP. Injury prevention strategies to promote helmet use decrease severe head injuries at a level I trauma center. J Trauma 1995;39(1):29-33; discussion 34-5.

172. Wesson D, Spence L, Hu X, Parkin P. Trends in bicycling-related head injuries in children after implementation of a community-based bike helmet campaign. J Pediatr Surg 2000;35(5):688-9.

173. Ekman R, Schelp L, Welander G, Svanström L. Can a combination of local, regional and national information substantially increase bicycle-helmet wearing and reduce injuries? Experiences from Sweden. Accident Analysis \& Prevention 1997;29(3):321-8.

174. Berchem SP. A community campaign that increased helmet use among bicyclists: Summary report. City of Madison, WI: Department of Transportation, City of Madison, Wisconsin. Traffic Engineering Devision.; 1987.

175. Rouzier P, Alto WA. Evolution of a successful community bicycle helmet campaign. J Am Board Fam Pract 1995;8(4):283-7. 
176. Morris BA, Trimble NE, Fendley SJ. Increasing bicycle helmet use in the community. Measuring response to a wide-scale, 2-year effort. Can Fam Physician 1994;40:1126-31.

177. Green L, Kreuter M. Health Promotion Planning. An Educational and Environmental Approach. Second ed. Mountain View: Mayfield Publishing Company; 1991.

178. Farley C. The Promotion of Safe Behaviours at the Community Level. Evaluation of a Bicycle Helmet-Wearing Campaign among 5- to 12- Year-Old Children. Stockholm: Karolinska Institutet; 2003.

179. Nolén S. Bicycle Helmet Use in Blekinge during five years with the promotion campaign "Säkereken". Results from observational studies 1996-2000. (in Swedish). VTI Notat. Linköping: Swedish National Road and Transport Research Institute; 2001. Report No.: 31-2001.

180. Jacobson B. Personal Communication (in Swedish). In: Borås municipality; 2002.

181. Widarsdotter K. Personal Communication (in Swedish). In: Borås municipality; 2000.

182. Nolén S. Bicycle helmet use in Sweden 1988-2002. Results from VTI:s observational study 2002. (in Swedish). Linköping: Swedish National Road and Transport Research Institute; 2003. Report No.: VTI notat 37-2003.

183. Ståhlspets Å. Bicycle project 1997 (in Swedish). Gävle: Technical office, Gävle municipality; 1998 1998-02-02.

184. Frank C. The NTF Skånes moulders of public opinion for increased bicycle helmet wearing (in Swedish). Report. Malmö: NTF-Skåne; 1994. Report No.: Bicycle helmet 1:94.

185. SRA. The project company helmet 1995-1997 for increased bicycle helmet wearing in region Skåne (in Swedish). Report. Borlänge: Swedish Road Administration; 1997. Report No.: Publ 97:142.

186. Ressler WH, Toledo E. Kasdah B'Rosh Tov: a description and evaluation of the Israeli bicycle helmet campaign. Health Educ Behav 1998;25(3):354-70.

187. B J Elliott \& Associates. Bicycle helmet research. Report. Melbourne: B J Elliott \& Associates; 1983.

188. SRA. "God anticipated everything, except gravel on asphalt". Evaluation of the bicycle week 1995 (in Swedish). Publ. 1995;. Borlänge: Swedish Road Administration. Division of market analysis; 1995. Report No.: 43.

189. SRA. Analysis of the press, radio and TV. Bicycle week 1995 and 1996 (in Swedish). Publ. 1996;. Borlänge: Swedish Road Administration. Division of market analysis; 1996. Report No.: 54.

190. SRA. Evaluation of the campaign BICYCLE WEEK 1998. Publ. 1998;. Borlänge: Swedish Road Administration; 1998. Report No.: 81.

191. Friberg I. A commission from Swedish Road Administration: An evaluation of the campaign "Bicycle week" (in Swedish). Rapport. Stockholm: IFS Ingrig Friberg Samhällsinformation AB; 1997. Report No.: Pnr:664.

192. Connor M, Norman P. The Role of Social Cognition in Health Behaviours. In: Connor M, Norman P, editors. Predicting Health Behaviour. Buckingham: Open University Press; 1995.

193. Thompson B, Kinnel S. Social Change Theory. In: Bracht N, editor. Health promotion at the community level. New advances. 2nd ed. Thousand Oaks, California: Sage Publications; 1999.

194. Thompson NJ, Sleet D, Sacks JJ. Increasing the use of bicycle helmets: lessons from behavioral science. Patient Educ Couns 2002;46(3):191-7.

195. Ajzen I. From intentions to actions: A theory of planned behavior. In: Kuhl J, Beckmann J, editors. Action Control. From Cognition to Behavior. Heidelberg: Springer; 1985.

196. Ajzen I. Attitudes, Personality and Behavior. Milton Keynes, UK: Open University Press; 1988. 
197. Ajzen I. The theory of planned behavior. Organizational behaviour and human decision processes. 1991;50:179-211.

198. Fischbein M, Ajzen I. Belief, attitude, intention and behavior: An introduction to theory and research. Reading, MA: Addison-Wesley; 1975.

199. Quine L, Rutter DR, Arnold L. Comparing the Theory of Planned Behaviour and the Health Belief Model: The example of safety helmet use among schoolboy cyclists. In: Norman P, Abraham C, Conner M, editors. Understanding and changing health behaviour. From health beliefs to self-regulation. Amsterdam: Harwood academic publishers; 2000.

200. Forward SE. What is the value in attitude studies? In: the International Conference on Road Safety in Europe 9-11 September 1996; 1996; Birmingham, UK; 1996.

201. Ajzen I, Fischbein M. Understanding attitudes and predicting social behaviour. Englewood Cliffs, New Jersey: Prentice Hall; 1980.

202. Connor M, Sparks P. The Theory of Planned Behaviour and Health Behaviours. In: Connor M, Norman P, editors. Predicting Health Behaviour. Buckingham: Open University Press; 1995.

203. Quine L, Rutter DR, Arnold L. Predicting and understanding safety helmet use among schoolboy cyclists: A comparison of the theory of planned behaviour and the health belief model. Psychology and Health 1998;13:251-269.

204. Lajunen T, Rasanen M. Can social psychological models be used to promote bicycle helmet use among teenagers? A comparison of the Health Belief Model, Theory of Planned Behavior and the Locus of Control. Journal of Safety Research 2004;35:115123.

205. Thulin H, Kronberg H. Different age groups of pedestrians and cyclists in different traffic environments - exposure and risks (in Swedish). VTI-Meddelande. Linköping: Swedish National Road and Transport Research Institute; 2000. Report No.: 886.

206. Statistics Sweden: Population in Swedish municipalities 1950 - 2000 (in Swedish). Internet Statistics Sweden.

http://www.scb.se/befovalfard/befolkning/befstor/befarlig/befarligkommun.asp. 2001.

207. Motala municipality: A pearl on the edge of the lake Vättern. Internet http://www.motala.se/. 2001.

208. World Health Organization. Manifesto for Safe Communities Adopted at the First World Conference on Accident and Injury Prevention 1989. Stockholm: Karolinska Institute; 1989.

209. Karolinska Institutet: WHO Collaborating Centre on Community Safety Promotion. Karolinska Institutet. http://www.phs.ki.se/csp/. 2003.

210. Bracht N, Kingsbury L, Rissel C. A Five-Stage Community Organization Model for Helath Promotion: Empowerment and Partnership Strategies. In: Bracht N, editor. Health promotion at the community level. New advances. 2nd ed. Thousand Oaks, California: Sage Publications; 1999.

211. Lindqvist K, Timpka T, Schelp L. Ten years of experience from a participatory community-based injury prevention program in Motala, Sweden. Public Health 1996;110:339346.

212. Motala Municipality. Minutes, Municipal council 19 June 1995. KF \$ 114. (in Swedish). In: Motala Municipality; 1995.

213. Patton MW. Qualitative evaluation and research methods. Second edition ed. Newbury Park: SAGE Publications; 1990.

214. Marton F. Phenomenography: A Research Approach to Investigating Different Understandings of Reality. In: Scherman RR, Webb RB, editors. Qualitative Research in Education: Focus and Methods. London: The Falmer Press; 1988. 
215. Streiner D, Norman G. Health measurement scales. A practical guide to their development and use. second ed. New York: Oxford university press; 1995.

216. Cohen J. Statistical power analysis for the behavioral sciences. Second Edition ed. Hillsdale NJ: Lawrence Erlbaum Associates; 1988.

217. Svanström L, Welander G, Ekman R, Schelp L. Development of a Swedish bicycle helmet promotion program-one decade of experiences. Health Promotion International 2002;17(2):161-9.

218. Nolén S, Lindqvist K. Local "bicycle helmet law" in Motala - A process study (in Swedish). VTI report. Linköping: Swedish National Road and Transport Research Institute; 2001. Report No.: 459.

219. SRA. Deep studies of fatal accidents in South of Sweden during 1997-2002 (in Swedish). Publication 2003:136: Swedish Road Administration, South, South-Eastern and Western offices; 2003.

220. Gustafsson S, Thulin H. Pedestrian and cyclists - exposure and injury risks in different traffic environments for different age groups. Results from TSU92- the years of 1998 to 2000. (In Swedish). VTI meddelande. Linköping: Swedish Road and Transport Research Institute, VTI; 2003. Report No.: 928.

221. Nilsson G, Thulin H. An evaluation of the governments 11-points program 1999 (in Swedish). In. Linköping: Swedish Road and Transport Research Institute. Memo, dated 2003-11-14; 2003.

222. Ministry of Industry Employment and Communications. 11-point program for improving road traffic safety. In: the Government Offices; 1999.

223. SRA: 11-point program for improving road traffic safety (in Swedish). Internet Swedish Road Administration. http://www.vv.se/traf_sak/punkt_korthet/punkter_i_korthet.htm. 2000.

224. SRA, National Swedish Police Board, Swedish Association of Local Authorities. Swedish National Traffic Safety Program 1995-2000 (in Swedish): Swedish Road Administration, National Swedish Police Board, Swedish Association of Local Authorities; 1994.

225. Lindahl E. Bicycle Helmet Usage in Urban Areas August-September 1999 (in Swedish). Borlänge: Swedish National Road Administration; 1999. Report No.: VV 1999:136.

226. Tiippana L. Bicycle counts 2002 (in Sweden). Memo. Stockholm: Department of highways and real estates. Division for strategic traffic planning; 2003. Report No.: 2/2003.

227. Svensson HE. Bicycle helmet observations in Göteborg. Personal communication. (in Swedish). In. Göteborg: Department of road traffic, Göteborg; 2003.

228. Mallard C. Personal communication (in Swedish). In. Malmö: NTF-Skåne; 1997.

229. SRA. Traffic safety. Results from the traffic safety survey 2002 (in Swedish). Publication 2003:46. Borlänge: Swedish Road Administration; 2003.

230. Gustafsson S, Thulin H. Transports in Sweden. Results from TSU92- during 1995-2001. (In Swedish). VTI notat. Linköping: Swedish Road and Transport Research Institute, VTI; 2002. Report No.: 46-2002.

231. NHTSA. Traffic Safety Facts 2000 - Pedal cyclists. Washington: National Highway Traffic Safety Administration, U.S. Department of Transportation. NCSA, National Center for Statistics and Analysis; 2002. Report No.: DOT HS 809613.

232. Rosenkranz K, Sheridan R. Trauma to adult bicyclists: a growing problem in the urban environment. Injury, International journal of the care of the injured 2003;34:825-829.

233. Allebeck P, Diderichsen F, Theorell T. Social medicine and psychosocial medicine (in Swedish). andra upplagan ed. Lund: Studentlitteratur; 1998.

234. Rosenberg ML, Sleet DA. Injury Control Recommendations for Bicycle Helmets. Journal of School Health 1995;65(4):133-139. 
235. Trippe H. Bicycle Helmet Initiatives -Where Have We Got To? Journal of Traffic Medicine 1994;22(3):113-7.

236. Berg P, Westerling R. Far too few schoolchildren use protective helmets when bicycling. Review of the literature and questionnaires as basis for promotion of increased use of the helmets (in Swedish). Lakartidningen 1999;96(19):2383-6.

237. Graitcer PL, Kellermann AL, Christoffel T. A review of educational and legislative strategies to promote bicycle helmets. Injury Prevention 1995;1(2):122-9.

238. Dowswell T, Towner EM, Simpson G, Jarvis SN. Preventing childhood unintentional injuries--what works? A literature review. Inj Prev 1996;2(2):140-9.

239. Hedin A, Källestål C. Knowledge Based Public Health Work, Part 1. Handbook for Reviews of Published Reviews on Interventions in the Field of Public Health. Report. Stockholm: National Institute of Public Health; 2002. Report No.: 2002:38.

240. The Cochrane Collaboration: Cochrane Reviewers' Handbook 4.1.6. Updated January 2003. The Cochrane Collaboration. http:/www.cochrane.de/cochrane/hbook.htm. 2003.

241. Schieber RA, Gilchrist J, Sleet DA. Legislative and regulatory strategies to reduce childhood unintentional injuries. Future Child 2000;10(1):111-36.

242. Klassen TP, MacKay JM, Moher D, Walker A, Jones AL. Community-based injury prevention interventions. Future Child 2000;10(1):83-110.

243. DiGuiseppi C, Roberts IG. Individual-level injury prevention strategies in the clinical setting. Future Child 2000;10(1):53-82.

244. Coffman S. Bicycle Injuries and Safety Helmets in Children. Review of Research. Orthopedic Nursing 2003;22(1):9-15.

245. The National Institute of Public Health. 1st national conference on bicycle helmets 26-27 October 1995, the conference \& health resort in Lundsbrunn, Götene. Positive health effects thru collaboration. It is it is worth while preventing accidents! Conference report. Stockholm: The National Institute of Public Health; 1996. Report No.: 1996:93.

246. The National Institute of Public Health. 2nd national conference on bicycle helmets $27-$ 28 November 1997, the conference \& health resort in Lundsbrunn, Götene. A bicycle helmet is a vaccine against head injuries. It reduce suffering and costs. Vaccinate! Conference report (in Swedish). Stockholm: The National Institute of Public Health; 1998. Report No.: 1998:25.

247. Evans L. Traffic safety and the driver. New York: Van Nostrand Reinhold; 1991.

248. Krag T. Cycle Helmets. In: To the participants in the "Helmets For All" Conference 2628 April, 1993, Stockholm. Copenhagen: European Cyclists Federation. ECF policy office. Dansk Cyklist Forbund; 1993.

249. Bayliss J. Do bicycle helmets protect, and should they be mandatory? (Letter comment). Jama 1997;277(11):883.

250. Davis A. Increasing the number of cyclists is more important. BMJ 1997;314(4 January):69.

251. Hillman M. Health benefits of cycling greatly outweigh loss of life years from deaths. BMJ 1997;314(4 January):70.

252. Godefrooij T. Debate is counterproductive. BMJ 2001;322(28 April):69.

253. Robinson DL. Changes in head injury with the New Zealand bicycle helmet law. Accid Anal Prev 2001;33(5):687-91.

254. Robinson DL. Head injuries and bicycle helmet laws. Accid Anal Prev 1996;28(4):46375.

255. Adams J, Hillman M. The risk compensation theory and bicycle helmets. Inj Prev 2001;7(4):343.

256. Davis R. Death on the Streets. Cars and the mythology of road safety. North Yorkshire: Leading Edge Press and Publishing Ltd; 1992/93. 
257. Hillman M. Cycle Helmets. The Case for and Against. Psi Report 752. 1993. 32p 1993.

258. Wardlaw MJ. Three lessons for a better cycling future. BRITISH MEDICAL JOURNAL 2000(321):1582-5.

259. OECD. Behavioral adaptations to changes in the road transport system. Road Transport Research. Paris: Organization for Economic Co-operation and Development; 1990.

260. Hedlund J. Risky business: safety regulations, risk compensation, and individual behavior. Injury Prevention 2000;2000(6):82-90.

261. Lardelli-Claret P, Dios Luna-del-Castillo J, Jiménez-Moleón J, Garcia-Martin M, BuenoCavanillas A, Gálvez-Vargas R. Risk compensation theory and voluntary helmet use by cyclists in Spain. Injury Prevention 2003(9):128-132.

262. Thompson DC, Thompson RS, Rivara FP: Risk compensation theory should be subject to systematic reviews of the scientific evidence. Internet Inj Prev 2002; 8: 1e. http://ip.bmjjournals.com/cgi/eletters/8/2/e1. 2002.

263. Nationalencyklopedin: National encyclopedia CD-ROM for PC (in Swedish). Bra Böcker AB, Höganäs. 1998.

264. Premfors R. Policy analysis (in Swedish). Lund: Studentlitteratur; 1989.

265. Tillgren P, Haglund B. Memo about the concept Policy, dated 22 Oct. 2002 (in Swedish). In; 2002.

266. Walt G. Health Policy. An introduction to process and power. London, Johannesburg and New Jersey: Witwatersrand University Press and Zed Books; 1994.

267. Vedung E. Public policy and program evaluation. New Brunswick and London: Transactions Publishers; 1997.

268. Nolén S. Bicycle helmet use in Sweden 1988-1996. Results from the observational study 1996 (in Swedish). VTI-Meddelande. Linköping: Swedish Road and Transport Research Institute; 1997. Report No.: 820.

269. Cedersund H-Å. Use of seat belts in Sweden 2003 (in Swedish). VTI notat. Linköping: Swedish Road and Transport Research Institute; 2004. Report No.: 11.

270. Edvardsson K, Rydgren H. Use of seat belts in Sweden 1971-1975. Effects of campaigns and legislation (in Swedish). TSV Info grp Memo no. 105. Borlänge: the National Road Safety Office; 1975.

271. Tingvall C. Effects of mandatory use of moped helmets (in Sweden). TSV Stat grp Memo no. 31. Borlänge: the National Road Safety Office; 1981.

272. Government office of Sweden. A bicycle helmet law for children - comments on a proposal circulated for consideration (in Swedish). In: Government office of Sweden, Memo, 2003 October 24; 2003.

273. Macpherson AK, Macarthur C. Bicycle Helmet Legislation: Evidence for Effectiveness. Pediatr Res 2002;52(4):472.

274. Pless IB. Venting spleen: helmet legislation. Inj Prev 2000;6(1):3.

275. Evans L. Cycle helmets and the law. Bmj 1994;308(6943):1521-2.

276. Prochaska J, DiClemente C, Norcross J. In search of how people change. American Psychologist 1992;47(9):1102-1114.

277. Prochaska J, Johnson S, Lee P. The Transtheoretical Model of Behavior Change. In: Shumaker S, Schron E, Ockene J, McBee W, editors. The Handbook of Health Behavior Change. Second ed. New York: Springer Publishing Company; 1998.

278. Rogers E. Diffision of innovations. fourth ed ed. New York: The free press; 1995.

279. Forjuoh SN, Fiesinger T, Schuchmann JA, Mason S. Helmet use: a survey of 4 common childhood leisure activities. Arch Pediatr Adolesc Med 2002;156(7):656-61.

280. Laflamme L, Engström K, Hasselberg M. Socioeconomic differences in injury risks. A report on the socioeconomic distribution of injuries among children and youths in Swe- 
den (in Swedish). SOU. Stockholm: The Child Safety Commission; 2002. Report No.: SOU 2002:68.

281. Hasselberg M, Laflamme L. Children at risk in traffic: improvement potentials in the Swedish context. Acta Paediatrics 2004(93):113-119. 


\section{Papers}

The articles associated with this thesis have been removed for copyright reasons. For more details about these see:

http://urn.kb.se/resolve? urn:nbn:se:liu:diva--22196 